\title{
THE STRAWBERRY IN NORTH AMERICA FLETCHER
}




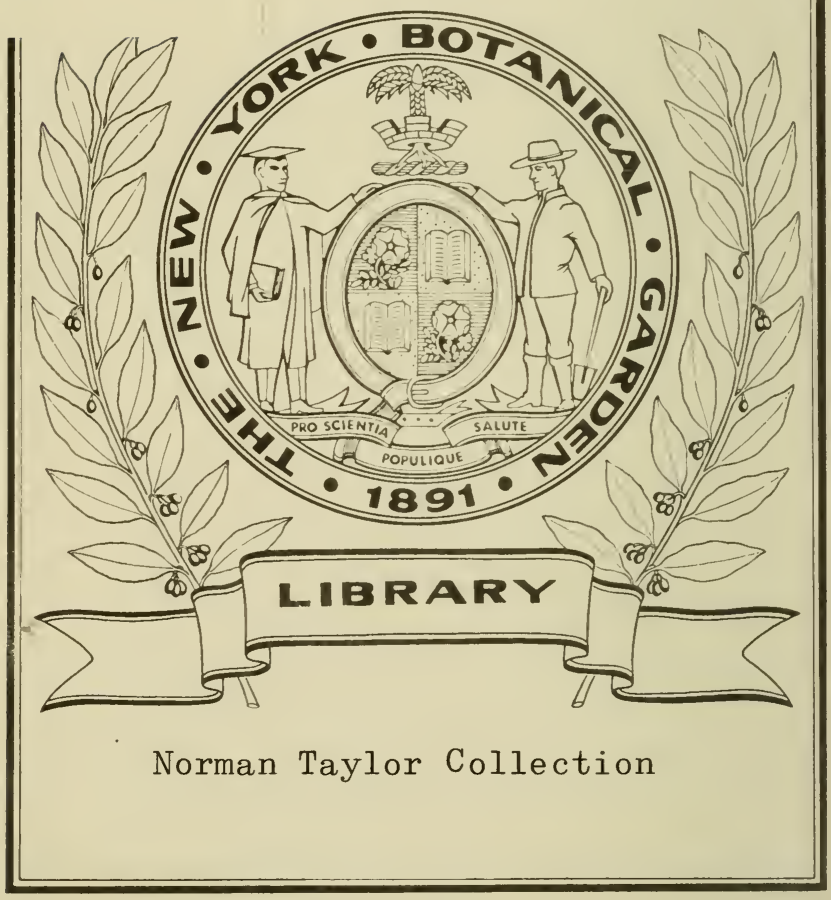






\section{THE STRAWBERRY IN NORTH AMERICA}




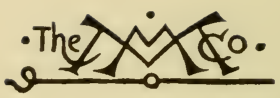

THE MACMILLAN COMPANY

NEW YORK - BOSTON - CHICAGO - DALLAS ATLANTA - SAN FRANCISCO

MACMILLAN \& CO., LiMITED

LONDON - BOMBAY - CALCUTTA

MELBOURNE

THE MACMILLAN CO. OF CANADA, LTD.

TORONTO 


\section{THE STRA WBERRY IN NORTH AMERICA}

\section{HISTORY, ORIGIN, BOTANY, AND BREEDING}

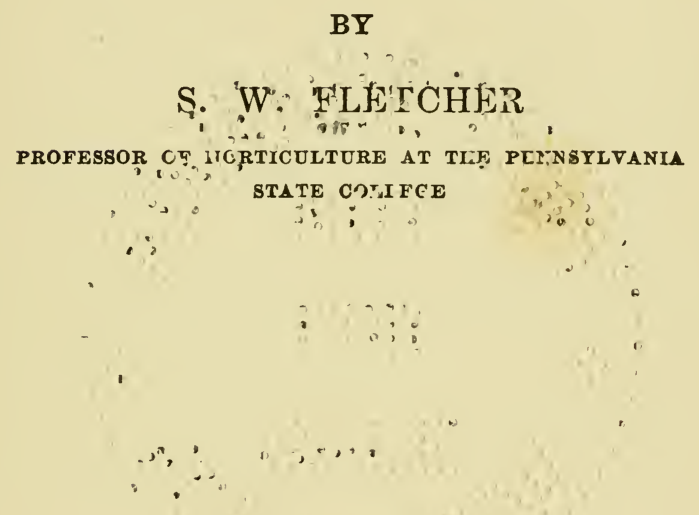

Now 1 gork

THE MACMILLAN COMPANY

1917

All rights reserved 
CDPTR:aET, 1917,

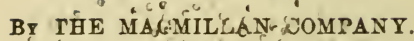

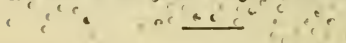

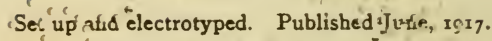

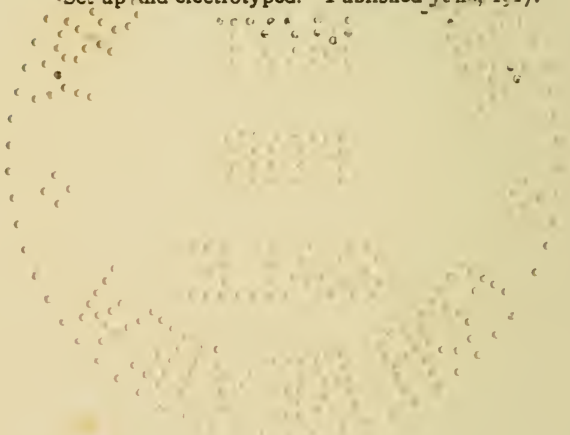

Normood 㨡resg

J. S. Cushing Co. - Berwick \& Smith Co.

Norwood, Mass., U.S.A. 


\section{PREFACE}

THIs book completes a survey of the strawberry as grown in North America. Modern cultural methods are presented in a companion volume, "StrawberryGrowing," and all of the more than 1800 North American varieties are described in Technical Bulletin 11, Virginia Agricultural Experiment Station, Blacksburg, Virginia, "North American Varieties of the Strawberry." The present volume deals mainly with the origin and history of the North American type- one of the most interesting chapters in our pomology.

The assistance of many pomologists and cultivators is gratefully acknowledged, more especially of Matthew Crawford, Cuyahoga Falls, Ohio. A number of the illustrations are borrowed, for which acknowledgment is made in the List of Illustrations.

State College, Pennsyluania,

S. W. FLETCHER. May 3, 1917. 



\section{CONTENTS}

\section{CHAPTER I}

EARLy History.

Strawberries in colonial days . . . . . . . $1-6$

Wild strawberries of Virginia . • . . . 1-2

Wild strawberries of New England . . . . 2-3

Wild strawberries of the West . . . . . 3-4

First steps in the domestication of the wild strawberry . . . . . . 4-6

The beginning of garden culture . . . . . 6-12

Varieties listed in early trade catalogs . . 6-7

Cultural directions in early books . . . . 7-12

"New England Farmer" . . . . . .

"American Gardener" . . . . . 10-11

"American Gardeners' Calendar" . . 11-12

The beginning of commercial culture . . . 12-21

Near Boston . . . . . . . 13-14

Near New York . . . . . . 14-17

Yields and prices $\quad . \quad$. $\quad . \quad$. $\quad . \quad$. $17-18$

The mystery of strawberry-growing . 18-19

Varieties increase . . . . . . . 19-21

Introduction of the Hovey . . . . . . 21-27

Origin of the Hovey $\quad$. $\quad$. $\quad$ •

The first novelty . . . . . . . 23-25

Unsatisfactory results with the Hovey . . 25

A new interest in plant breeding . . . 26-27

Extension of commercial culture, 1838-1854 • . 27-30

Near Cincinnati . . . . . . 27-28

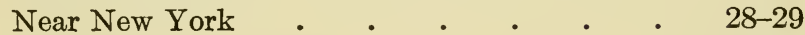

In the South . . . . . . . 29-30

Condition of strawberry culture before the introduction of the Wilson . . . . . 30-34

Yields and prices . $\quad . \quad$. $\quad . \quad$. $30-31$ 
Varieties

Stimulating effect of the pollination discussion .

CHAPTER II

The Rise of Commercial Strawberry-Growing .

The sway of the Wilson . . . . . . 35-43

Origin . . . . . . . . . $\quad$. 34-36

Immediate popularity $\quad$. $\quad$. $\quad$. $\quad$. $\quad$ - $36-39$

Good points and objectionable features . . 39-40

Competitors - Crescent and Sharpless . . 40-41

Boom days . . . . . . . 42-43

Contrasting methods of culture . . . . $43-50$

Field culture at Cincinnati . . . . 4 43-45

Market garden culture at Pittsburgh . . 45-48

Yields and prices about 1865 . . . . 4 48-49

Special cultural methods . . . . . $49-50$

Forcing in hot-beds and cold-frames . . $\quad 49-50$

Strawberry mounds . . . . . 50

Improvement in transportation facilities . . . $\quad$ 50-60

Extension of railroads . . . . . . 50-52

Competition from the South . . . . 52-54

Ventilator cars and fruit-growers' express 54-55

Introduction of refrigerator cars . . . . 55-60

Early experiments of Parker Earle . . 55-58

The first pre-cooling plant . . . . . 58

Beginning of the modern re-icing system . $\quad 58-60$

Early history of certain of the older strawberry districts $\quad 60-75$

New Jersey . . . • . . . 60-62

Delaware-Maryland peninsula . . . . $\quad$. 62-63

Oswego County, New York • . . . 63-64

Michigan . . . . . . . . 64-65

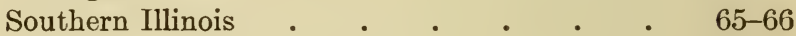

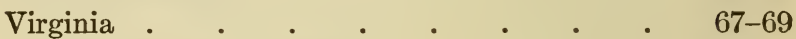

Charleston, South Carolina . . . . $\quad$. 69-70

Florida . . . . . . . . $70-72$

North Carolina $\quad . \quad$. $\quad . \quad$. $72-73$

Gulf States and lower Mississippi Valley . 73-74

Pacific Coast . . . . . . . 74-75

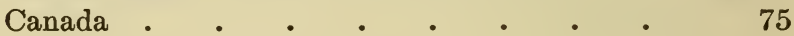


History of Strawberry Packages, Methods of

Training, and Pollination • • . 76-108

Early packages . . . . . . • 76-81

Pottle . . . . . . . . .

Punnet . . . . . . . .

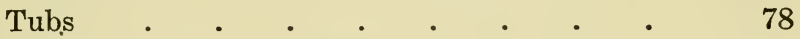

Cincinnati stand of drawers . . . . $\quad$ 78-81

Evolution of the box and crate package . . . 81-86

Early types of boxes and crates . . . $81-82$

Introduction of the return crate and box $\quad$ 82-83

Origin of the "Hallock" . . . . . 83

The first gift packages . $\quad$. $\quad$. $\quad$. $\quad$. 84

Slow adoption of gift packages in the East . 84-86

History of methods of training . . . . 87-94

Hill training before the Wilson . . $\quad$ - $\quad 87$

The era of broadcast training . . . . $\quad$ - 88-89

Evolution of the matted row . . . . 90-92

Early methods of renewing the bed . . . 92-94

History of the pollination discussion . . . 94-109

Experiments of Duchesne and Keens 94-96

Early pollination troubles in North America . 96-98

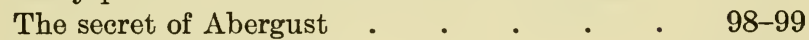

The "Strawberry War" . . . . . . 99-102

Influence of culture on sex . . . . 102-104

Report of the Cincinnati Horticultural Society 105-107

Final vindication of "Longworth's Theory" . 107-109

\section{CHAPTER IV}

Origin and Botany. . . . . . . 109-156

Early history in Europe . . . . . . 109-113

References in early writings . . . . 109-111

Origin of the English name . . . . 111-113

Origin of the garden strawberry of Europe . . 113-125

Experience with the Wood and Hautbois . $\quad 113$

Introduction of the Scarlet . . . . 113-114

Introduction of the Chilean . . . . 114-116 
Possible origin of the Pine

116-123

As a pure seedling of $F$. chiloensis . 117-118

As a hybrid of $F$. virginiana and $F$. chiloensis $118-123$

Keens' Seedling

Origin of the garden strawberry of North America 123-125

Record of $F$. virginiana under cultivation

125-138

Historical evidence.

125-128

Origin of Hovey .

128-132

Origin of Crescent and Sharpless

128-130

Origin of Downer's Prolific .

130-131

Botanical evidence

131-132

Reversion of seedlings

132-138

Anatomical characters

132-134

Hardiness

134-135

Record of $F$. chiloensis under cultivation .

135-136

Origin of the everbearers

136-138

The Alpines

European everbearers

Early failures in North America

138-147

138-141

141-142

The Pan-American and its descendants

142-144

144-147

Botany of the strawberry .

$147-156$

Diffusion of wild strawberries . . . . 147-148

$F$. virginiana . . . . . . . 148-150

F. chiloensis . . . . . . . 150-153

F. vesca . . . . . . . . 153-154

F. elatior . . . . . . . . . 154-156

CHAPTER V

Desirable Characters in a Variety . • 157-187

Desirable characters in the plant . . . . 157-162

Health, vigor and productiveness . . . 157-158

Hardiness . . . . . . . 158-159

Foliage . . . . . . . . 159-160

Runners . . . . . . . . 160-161

Fruit stalks and blossoms . . . . 161-162

Desirable characters in the fruit . . . . 162-175

Season of ripening . $\quad . \quad$. . . 162-163

Size . . . . . . . . . . 163-164

Records of "mammoth" berries . . . 164-167 
Shape, calyx, color . . . . . . 167-171

Seeds, shipping value $\quad . \quad$. . . . 171-172

Flavor, quality $\quad$. $\quad$. . . . . 172-175

Describing and scoring varieties . . . . . 175-181

Form for describing varieties . . . . 176-178

Score cards . . . . . . . . 178-181

Food value . . . . . . . . . . . .

Chemical analyses . $\quad . \quad$. $\quad . \quad$ 181-183

Are wild strawberries sweeter than cultivated sorts . . . . . . . 183-184

Supposed medicinal value $\quad$. $\quad$. $\quad$ 184-187

CHAPTER VI

Breeding • . . . . . . . . 188-227

The four stem-varieties . . . . . . 189-192

Descendants of Hovey $\quad$. $\quad$. $\quad$. $\quad$. 189-190

Descendants of Wilson . $\quad$. $\quad$. $\quad$. $\quad$ • 190

Descendants of Sharpless . . . 190-191

Descendants of Crescent . . . . . . 191-192

Breeding for a specific purpose . . . . 192-201

Changing ideals $. \quad . \quad . \quad . \quad . \quad .192-193$

Breeding for one thing at a time . . . 193-195

Selecting the parents . . . . . 195-196

Botanical relationships and morphology . 196-198

When fruit buds are formed . . . . 198-200

Abnormal structural forms . . . . 200-201

Breeding methods . . . . . . . 201-210

Methods of the early breeders . . . . 201-203

Hand-crossing . . . . . . . 203-207

Sowing the seed $\quad$ • $\quad$. $\quad$. . 207-208

Fruiting the seedlings . . . . . 208-210

Bud variation . . . . . . . 210-215

Variation caused by environment . . . 210-211

Reported instances of bud variation . . 211-212

"Pedigree" plants . . . . . . . 212-214

Strawberry breeders . $\quad$. $\quad$. $\quad$. $\quad$ 215-220

Achievements of Boyden, Downer, Durand 215-216

List of breeders, 1854-1900 . . . . 216-217

Breeders since 1900 . $\quad$ • . . . . 217-218 
The rewards of strawberry breeding . $\quad \begin{gathered}\text { PAOES } \\ 218-219\end{gathered}$

Methods of introducing varieties . . . 219-220

Naming and testing new varieties . . . . . 220-227

Form of name . . . . . . . 220-221

Synonyms . . . . . . . . . 222

What is a distinct variety . . . . 223-224

Value of variety tests . . . . . 224-225

Why varieties run out . . . . . . 225-227 


\section{LIST OF ILLUSTRATIONS}

FIGURE

PAGE

1. Crimson Cone; grown near New York about 1820 . 16

2. C. M. Hovey, originator of the Hovey strawberry $\quad 22$

3. The Hovey strawberry, the first variety of any fruit originated in North America by definite plant breeding. (From Mag. Hort., 1840, p. 286)

4. Parker Earle, who developed the refrigerator car for strawberry transportation . . . . 60

5. Type of punnet used for the New York City market, 1815-1850 . . . . . . . .

6. The Cincinnati stand of drawers, used in the Mississippi Valley, 1850-1890. (From The Cult. and Count. Gent., 1866, p. 222).

7. A "male and female blossom of the Hudson," as drawn by Nicholas Longworth, in 1842. (From Mag. Hort., 1842, p. 258)

8. Nicholas Longworth, who directed attention to the pollination problem

9. Drawing of the strawberry in Parkinson's "Paradisus Terrestris," published in 1629] . . . 110

10. Old Pine, or Pineapple, the progenitor of the garden strawberry. (From British Fruits, I, No. 47) .

11. Keens' Seedling, the first improved variety; introduced in 1821. (From Trans. Royal Hort. Soc., V, p. 261)

12. Large Early Scarlet, a form of $F$. virginiana and the dominant variety in North America, 1830-1860. (From Rept. U. S. Dept. Agr., 1853) . .

13. Pan-American, the first North American everbearer.

(From L. R. Johnson, Cape Girardeau, Mo.)

14. F. virginiana. (From "Evolution of Our Native Fruits" by L. H. Bailey, p. 428) . . . 149

15. F. chiloensis

16. The Alpine form of $F$. vesca 
FIGURE

PAGE

17. A "mammoth" berry; it weighed $4 \frac{3}{4}$ ounces. (From catalog of A. T. Goldsborough, Washington, D.C.) .

18. Banana, introduced in 1870 . $\quad$ • . $\quad . \quad 168$

19. The long root stalk of a very old plant $\quad$. 197

20. Proliferous strawberry. (From Meehan's Monthly, 1894, p. 37) . • • • $\cdot$ (From Rept. Cuba

21. An abnormal structural form. (From Rept. Cuba Exp. Station, 1905-1909, p. 145) . . . . 200

22. A freak strawberry, with the exposed seed carpels covered with pulp, like a blackberry. (From Meehan's Monthly, 1902, p. 12) - · · $\cdot$. 201

23. A staminate blossom, showing the numerous yellow the cone of green pistils

24. Anthers clipped off and exposed to the sun, to secure pollen . . . . . . $\cdot$.

25. Pollinating with a camel's-hair brush. (From L. H. Bailey, Ithaca, New York) . • • • • 199 202 204 205

26. Matthew Crawford, for nearly fifty years the foremost North American propagator of the strawberry . 


\section{THE STRAWBERRY IN NORTH AMERICA}





\section{THE \\ STRA WBERRY IN NORTH AMERICA}

\section{CHAPTER I}

\section{EARLY HISTORY}

From the settlement at Jamestown to the introduction of the Wilson

The strawberry is distinctly Pan-American. Both of the species from which most of the garden varieties of today have descended-Fragaria virginiana and $F$. chiloensis - were secured by the Old World from the New. The largest acreage of cultivated strawberries is on this continent. The value of all the strawberries produced and marketed in North America each year, exclusive of the large quantity grown for home use, exceeds $\$ 20,000,000$; this represents more than half of the commercial strawberry production of the world. The rise of commercial strawberry culture in the United States and Canada, which has taken place within the memory of men now living, is one of the most interesting chapters in North American horticulture.

\section{Strawberries in Colonial Days}

From the beginning of its Caucasian history, and probably for centuries previous, North America has 
been a land of wild strawberries. The first settlers at Jamestown, in 1607, found them in abundance. Captain John Smith mentioned, among other fruits found in the new Eldorado, "strawberries which ripen in April." One of the early colonists reported to his friends in England that when he went into the woods he came upon great areas of land overgrown with these plants, and the berries were "four times larger and much more exquisitely flavored" than the wild strawberries of England. ${ }^{1}$ In fact, so abundant were the berries, another man declares, that in walking through the woods around Jamestown "it was impossible to direct the foot without dyeing it in the blood of this fruit." ${ }^{2}$ Some may consider this statement colored by the vivid experiences of the explorer; but certainly not the report of conservative Ralph Hamor that there were "great fields and woods abounding with strawberries, much fairer and more sweete than ours."

As fast as the Virginia settlers cut down the forests, strawberries sprang up in the clearings. When the fields had been cropped to exhaustion with corn, wheat, and tobacco, they were abandoned and new ground cleared, as was the custom in the prodigal husbandry of that period. These old fields soon abounded with wild strawberries. For a century or more after the settlement of Virginia, wild strawberries were so plentiful that "very few persons take care to transplant them, but can find enough to fill their baskets, when they have a mind, in the deserted old fields."

The wild strawberries of New England. - Meanwhile the Pilgrims, the Massachusetts Bay colony, and other

${ }^{1}$ Percy's Discourse, p. xliii.

${ }^{2}$ Force's Historical Tracts, Vol. III. 
northern settlers, were having similar delightful experiences. Young's "Chronicles of the Pilgrims" records expeditions from Plymouth into the surrounding country, on which they found "strawberries innumerable." New England was forest clad at that time (1620); it was the custom of the Indians to burn over certain areas each year, in order to secure ground in which to plant corn. Strawberries thrived in these burnt-over districts. Morton, who was at Plymouth in 1622, says, in his "New England Canaan," "Wild strawberries grew in plenty in the meadow and champaign lands."

In 1629 William Wood visited New England; he returned to England in 1633 and there published the following year his "New England's Prospect," which is a record of his experiences and observations in the New World. Of the Massachusetts Plantations he says, "There is likewise Strawberries in abundance, verie large ones, some being two inches about; one may gather halfe a bushell in a forenoone." In 1643 Roger Williams wrote, "This berrie is the wonder of all the fruits growing naturally in these parts. In some parts where the natives have planted" (that is, planted corn), "I have many times seen as many as would fill a good ship within a few miles compass. The Indians bruise them in a mortar and mix them with meale and make Strawberry bread." Strawberry bread was commonly used by the Indians in other parts of the continent, as well as along the Atlantic coast.

The colonists of New York, Pennsylvania, Maryland, the Carolinas, and other parts of the Atlantic seaboard found wild strawberries no less abundant than in Virginia and New England. In 1683 William Penn mentioned with appreciation the abundance of wild 
strawberries in Pennsylvania. As the pioneers pushed westward, in parallel lines, occupying successively western New York, Michigan and Illinois, Kentucky, Ohio and the great Mississippi Valley, the wild strawberry everywhere greeted them with an abundance of fresh fruit - a most welcome addition to frontier fare. It was so in lost Arcadia, and in old Quebec. The wild strawberry refreshed the "forty-niners" of California, and those who followed the Lewis and Clark trail. In our own time, it has brought cheer to the settlers on the last frontiers, in Manitoba and Alaska. Always the wild strawberry has been intimately and gratefully associated with pioneer life. We can hardly blame those who have enjoyed its bounty under these circumstances if they refuse to admit that any cultivated variety is half as sweet.

First steps in the domestication of the wild strawberry.For many years after the colonies were established, there was little, if any, garden culture of the strawberry. Wild berries were so plentiful that this was unnecessary. The abundant supply of native berries was appreciated all the more because of the limited supply of most other fruits. It was extremely difficult to secure improved varieties of apples, pears and other tree fruits. There were no nurseries here then; trees or cions had to be brought from Europe. The journey was long and trying, occupying fully a month, and the recourse to seedling orchards gave but a small proportion of useful sorts.

The first step in the domestication of the strawberry naturally would be to transfer to the garden some of the most superior plants found in the fields. Since the native berry was so decidedly superior to the best European sorts of that time, there was no object in importing varieties from Europe, as was the case with most other fruits. It is 
possible that this amelioration may have been begun, in a very limited way, by the first settlers, since it is recorded by English horticulturists that the Large Early Scarlet, a large-fruited form of $F$. virginiana, was introduced into England about 1624. It is not likely, however, that garden culture began much before 1700. Any superior wilding that was found was more likely to be sent to Europe, where the possibilities of the "American Scarlet" as a garden fruit were instantly appreciated and enthusiastically exploited, than to be kept in America, where every hillside and meadow yielded an abundant harvest to all who might seek it.

Small towns soon sprang up, and the cultivated area surrounding them gradually widened. As the land became more fully subdued in tilled crops, it was no longer the habitat of the wild strawberry. It became necessary for the housewife to go farther and farther afield to gather the annual supply for preserves and jam. There came a time when this trip became long and irksome; then wild plants were transplanted to the garden. This was the beginning of strawberry culture. It now became desirable to scrutinize the wild plants more closely, so as to find those of superior productiveness, size or flavor, in order that the garden space might be most fruitful. This was the beginning of strawberry breeding.

Until about 1750, there was no garden culture of the strawberry except of these transplanted wildings, and even these were grown only in a very few gardens. Nearly everybody, even in the larger towns, still depended upon the supply of wild berries. Long before the Revolution, wild strawberries became an article of barter and sale in Boston, New York, Philadelphia and Baltimore. Their streets resounded then, as now, with the long drawn out 
and not unmusical vendor's cry, "Strawber-r-ries, ripe strawber-r-ries!" At that time the strawberry season was limited to the period of ripening of the nearby wild berries, which was not over four weeks; now it is extended over six months, and berries may be had the year around.

\section{The Beginning of Garden Culture}

Garden culture of the strawberry began to receive more serious attention about 1750 , especially from a few well-todo amateurs who could afford to employ private gardeners. The hautbois, wood and Chilean strawberries were introduced from Europe then, together with some of the improved varieties of $F$. virginiana that had been developed by English horticulturists.

Varieties listed in early trade catalogs. - Much of this interest was stimulated by the establishment, about the middle of the century, of the first North American nursery, by William Prince, at Flushing, on Long Island, New York. For many years, Prince's Linnæan Garden was the chief center for the dissemination of horticultural plants. William Prince died in 1802, leaving the business to his son, William Prince, who, in turn, handed it down to his son, William Robert Prince; so that the firm had an unbroken history of over a century. It exerted a profound influence during the formative period of North American horticulture. The first North American trade catalogs of horticultural plants were issued by Prince. In one of the earliest, sent out in 1771, three kinds of strawberries are offered for sale: "Large Hautboys, the Chili, the Redwood."

He sold these for "one shilling per dozen roots." The Hautboys was $F$. elatior, the hautbois of Europe; 
the Chili was $F$. chiloensis, the wild strawberry of the Pacific coast of North and South America, which had been introduced into Europe about 1735; the Redwood was $F$. vesca, the common wild strawberry of England. The native Scarlet or Virginian strawberry, $F$. virginiana, was generally considered so superior in flavor to the hautbois and Chilean, as well as more prolific, that these were grown only in a few gardens; the Red Wood, and its companion the White Wood, were cultivated quite commonly, especially in the vicinity of Boston.

Perhaps Prince did not list any variety of $F$. virginiana in 1771 because his stock was mostly imported from Europe; but it is more likely that no variety had yet appeared sufficiently superior to the wild berry to warrant propagation. Large Early Scarlet, which became a standard variety later, had been sent to England more than a century before, but it does not seem to have been grown here until after 1800 . In his 1791 catalog Prince added to his list "Hudson (very large, fine flavor, and great bearers); $2 \mathrm{~s}$ per dozen." Later this was called Early Hudson; it was the first named variety listed in North America, and was a form of the Scarlet.

Cultural directions in early books. - In 1790 appeared the first North American book containing much information on horticulture, Samuel Dean's "New England Farmer." This is a cyclopedic work, patterned somewhat after Philip Miller's "Dictionary of Gardening," a standard English book, much quoted in America at that time. It gives an interesting picture of the status of strawberry culture in North America at the close of the eighteenth century. "There are four sorts," says Dean, "the wood strawberry, the Virginia or Scarlet strawberry, the haut- 
boy strawberry and the Strawberry of Chili." He advises that the Virginian be grown: "It is most common and perhaps most worthy of cultivation." The relative importance of hay and strawberries is clearly defined by Dean: "Our grass fields often produce these strawberries in plenty, but it is better to have a spot of ground devoted to the culture of them, as they will be much larger and better flavored, and the trampling of the grass in the mowing may be thus in some measure prevented." His cultural directions, mostly quoted from Miller, are interesting not only as a record of the approved methods of that time, but also as evidence of the slavish copying of English methods which characterized the early years of North American horticulture:

"Lay the ground out into beds of four feet broad, with paths two feet or two feet and a half between them, these paths being for the convenience of gathering the strawberries and for weeding and dressing the beds. The plants should be in the quincunx order, and fifteen inches apart, so there will be but three rows in each bed. The plants should never be taken from old, neglected beds, where the plants have been suffered to run into a multitude of suckers, or from any plants which are not fruitful; and those offsets that stand nearest to the old plants should always be preferred to those which are produced from the trailing stalks at a greater distance.

"During the summer the plants should be kept clear from weeds, and all the runners should be pulled off as fast as they are produced. If this is constantly practiced the plants will become very strong. Wherever the suckers are suffered to remain they rob the fruitful plants of their nourishment in proportion to their number. I have known, where the old plants have been constantly kept 
clear of suckers, they have continued very fruitful three years without being transplanted."

With slight modification, these directions, written 125 years ago, might stand for the "Kevitt System," and other so-called modern methods of culture. Probably he had the Scarlet strawberry most in mind when he advised, "But little dung should be applied to the soil, as a large quantity will cause them to run much and to be less fruitful." The English practice of growing strawberries in raised "beds" seems to have fastened that name permanently upon the planting of small areas. Not until 1850 was there a strawberry "field." One important departure from English methods is noted: "The time to remove the plants is said by the above mentioned author, (Miller), to be September or the beginning of October, but they are known to do well in this country when removed in early spring."

There is nothing in "The New England Farmer," or contemporaneous publications, which would indicate that strawberries were grown commercially at that time. The only strawberries marketed were the wild ones that were peddled about the streets. Strawberry culture was confined to the home gardens of gentlemen of means who employed private gardeners. These gardeners were mostly from England, where they had been trained in the apprentice school of rule-of-thumb gardening. It was inevitable that they should persist in attempting to grow strawberries here exactly as they had been taught to grow them in England. The results were hardly less disastrous than was the case with grapes. For years the general public considered strawberry-growing an exceedingly difficult and uncertain matter, that only the initiated might undertake with prospect of success. Here 
and there wild plants were transferred to gardens, but most people depended upon the meadows and hillsides for a supply. This was the situation at the close of the eighteenth century.

In 1804 appeared the first indigenous book devoted wholly to horticulture, "The American Gardener," by John Gardiner and David Hepburn. The first edition gives but scant consideration to the strawberry: "Wild strawberries may be planted in shady situations, but the others do best in open situations. Pineapples, Chili, scarlet and hautboy are also very good strawberries." This is the first record of the cultivation in North America of the "Pine" strawberry, from which most of the varieties of today have sprung; but it may have been imported some years previous, as it was quite widely disseminated in Europe by 1759.

There was added to the second edition of "The American Gardener" a valuable "Treatise on Gardening," which had been "written many years ago by a learned and eminent Virginian, who printed it for the use of his friends," and who resided at Williamsburg. Probably it was written before 1790. This anonymous but eminent citizen of Virginia - possibly John Taylor of Caroline, author of "Arator" - gives the following clear-cut directions on strawberry culture; it is evident that his experience had been extended and his observation keen:

"There are three sorts chiefly propagated; the wood, the scarlet or Virginia and the hautboy. There is a green sort which some call drayton and others pine apple, from its participating of the flavor of that delicious fruit, but none has ever been brought into this country, and it is but rarely to be met with, even in England.

"September is the best month for transplanting, 
though it is often done in February. But I have myself transplanted with success when in full bloom. The soil this plant delights in ought to be a fresh loamy sort. If too rich the vines grow rampant, and do not produce the fruit so good as in ground less enriched. All strawberries should be at least a foot distant, but I recommend two feet, to have them in great perfection. They ought to be planted with alleys two feet wide, for the convenience of going between to cleanse them of weeds, very prejudicial to them. In the spring, when your vines are in flower, if it is dry, water them, otherwise their blossoms will drop off.

"In September you should pull off all the strings, or runners, and every weak plant; dig up between the beds and strew some fine mould or wood-pile earth between the plants, observing not to cover them with it; this will greatly strengthen them and your fruit will be much larger. They do not last above three years, so that to keep constantly supplied you should make a new plantation a year before the old ones are destroyed. The Scarlet strawberry will come a fortnight sooner than any other sort. The Chili strawberry will grow to the size of a hen's egg. The best dung (if any) for strawberries is that of cows, sheep and pigeons. In order to have them later in season and to afford a succession, cut off the tops of some before they blossom, which will retard their ripening until the forward ones are gone. Many people keep them constantly strung, but I should imagine that wounds them, but in the proper season."

The "American Gardeners' Calendar," by Bernard McMahon, a nursery-man and seedsman of Philadelphia, was published in 1806. McMahon recognized six kinds: the Scarlet, Hautbois, Chilean, Monthly Alpine, Wood, and " $F$. Anassa, the Pineapple, together with many others 
arising from these, differing principally in the color of their fruit." He recommended the Scarlet and the Pineapple for general cultivation, and advised planting in beds four feet wide, with plants fifteen to eighteen inches apart each way. This, likewise, was the advice of Grant Thorburn in his "Gentleman's and Gardener's Kalender," showing that English methods still dominated American practice. A trade catalog issued in 1810 by William Booth, of Baltimore, offered, in addition to the several species listed by McMahon, two named varieties of the Scarlet - Large Early Scarlet and Hudson's Bay. These two varieties soon became the dominant sorts, and held this position for fifty years, until the introduction of the Wilson. Booth also listed "a new strawberry raised from seed"; this is the first record of a seedling strawberry in North America.

\section{The Beginning of Commercial Culture}

The cultivation of strawberries for market began soon after 1800. Until then, only wild or "common" fruit had been marketed. Perhaps the surplus product of some home gardens had been sold or bartered among neighbors, but only in a very limited way. About this time the nurseries began to propagate and disseminate several improved varieties of $F$. virginiana, notably Early Hudson, Hudson's Bay, and Large Early Scarlet. These were so superior to the wild berries offered for sale, especially in size, that soon there was a demand for them that could no longer be met by neighborly exchange of the product of home gardens. In response to this demand, commercial strawberry culture, as distinct from garden or amateur culture, began. 
Near Boston. - The first commercial strawberry growing began about 1812 in the vicinity of the four largest towns of that period - Boston, New York, Philadelphia and Baltimore. At that time none of these cities had a population of over 50,000, except New York. In his "Travels in New England," written before 1817 but not published until 1821, Dr. Timothy Dwight notes that five kinds of strawberries were cultivated in New England: "Red Meadow, White Meadow, Field, Hudson and Hautboy." Red Meadow was the common wild strawberry; White Meadow was a white-fruited form of that species, then, as now, quite plentiful in the Berkshire hills. He considered Red Meadow the best of the five kinds, and said he had "cultivated it for more than twenty years, and during that time it has increased to twice its original size, being four and a half inches in circumference." Soon after this, certainly no later than 1820, commercial culture in New England began, and the Red Wood and "Early Virginia," which is Large Early Scarlet, emerged as the standard commercial sorts of that section. A reminiscence of this period was given by James F. C. Hyde in $1869:^{1}$

"Those of us who are now actively engaged in strawberry culture can remember when there were only two varieties of this fruit in cultivation in the best gardens of Massachusetts, and when it was grown in very limited quantities for market. We well remember when some of our neighbors picked daily fifty to one hundred boxes, and that was all that could be disposed of at fair prices. The varieties then cultivated were the Wood and Early Virginia, the former an imported variety, the latter an American sort. In time, some more foreign sorts were ${ }^{1}$ Amer. Jour. Hort., V, p. 2 (Jan., 1869). 
introduced, but they were not hardy enough to withstand the scorching suns of summer and blasting cold of winter, and they were not successfully or extensively cultivated. Then not a mile of railroad was built in this country; all the fruit (which was not much) was carried to market in wagons. Then the warm soils of New Jersey, that now produce strawberries by the tens of thousands of bushels, were covered with pines. Then the vast prairies of the west were an unbroken solitude."

The Red Wood was the most important commercial variety in New England until 1840, when the Hovey replaced it. White Wood, a white-fruited form of the same species, was grown to a more limited extent, as all white sorts must be. Red Wood was grown somewhat in other sections, especially in New York, until 1830. It is noteworthy as the only European sort that attained prominence commercially in the early years of North American strawberry growing. The Hautbois, Alpine, Pineapple, Chilean and other sorts imported from Europe were valued by amateurs, who could afford to woo their fickle fancies in home gardens, but were utter failures commercially. According to C. M. Hovey, the Red Wood was a heavy bearer under neglect, "producing a good crop for three successive years on beds running into mats." It was rather inferior in flavor, as compared with the Old Scarlet, but had the advantage of a longer season of ripening, so that it complemented the short season of that variety. Until the introduction of the Hovey, these two sorts supplied the Boston market.

The rapid growth of the city of New York soon created a demand for strawberries that made the available supply of wild berries inadequate. For many years these wild berries had been hawked about the streets, coming mainly 
from the near county of Bergen, New Jersey. Commercial strawberry culture for the New York market began about 1820 in the vicinity of Hackensack, Bergen County, New Jersey. Andrew M. Hopper, of Pascock, New Jersey, thus recalls the circumstances: "When I was a boy of ten years, I can well remember picking strawberries with my father. At that time (about 1824) we had no crates, but packed the baskets in larger baskets called hampers. In those days there were no commission merchants in New York that dealt in berries, so each farmer was compelled to go with and sell his own fruit. There were no railroads then; all the berries were carted to New York in wagons, crossing the Hudson at Hoboken, or went by boat." The market was very limited ; in the words of F. H. Hexamer, " A few wagon-loads of Hackensack berries, brought across the river in sailing sloops as often as twice a week, when wind and tide permitted, constituted the entire supply of New York; and a period of three weeks comprised the limits of the strawberry season."

The methods of growing strawberries for the New York market at that time were very crude. Near Boston the industry began by enlarging the home garden; the plants still were grown in beds, carefully trenched and dunged and all runners removed, in accordance with the most approved English practice. It was not field culture of the strawberry, as we know it today, but merely an extension of the home garden, culminating later in the intensive market gardens of Belmont and Arlington. The New York supply, on the other hand, which came mostly from the sandy soils of Bergen and Monmouth counties, was grown in open fields and on rough hill-sides. The plants were simply set out and allowed to take care of themselves ;

${ }^{1}$ Rept. N. J. Hort. Soc., 1881, p. 27. 
little if any cultivation was given. They soon took possession of the land and shifted for themselves during the five or more years that the field was left in berries, except that the weeds were mowed occasionally.

The variety used in this unique and easy-going scheme was the Crimson Cone, a form of the Scarlet. It also was called Scotch Runner, Scotch Runaway, and Dutchberry; in New York these berries were called "Hackensacks", because most of them came from the New Jersey town of that name. The Crimson Cone was fairly prolific of medium sized berries with very long necks, which made

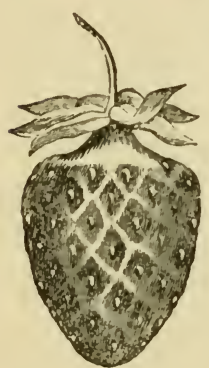

FIg. 1. - Crimson Cone ; grown near New York about 1820 . them easy to pick so as to leave the hulls on the vines. This was considered an advantage since strawberries usually were sold after being "capped." The fruit was marketed in the small, splint baskets formerly used for wild berries, but now holding about half a pint. These baskets were nested one on top of another, in hampers. They sold in New York for three to eight cents a basket. The average net returns from an acre were thirty to forty dollars, which was considered a good profit, and was larger than that from most other crops grown at that time.

This free and easy method of strawberry growing supplied most of the berries marketed in New York until about 1840; then it was crowded out by more intensive methods. There must have been other centers of production tributary to New York, however, since IVilliam Prince stated in 1827, "The bulk of the fruit sold in the New York market is Early Hudson."

At a few other points besides the vicinity of Boston 
and New York there was considerable progress in commercial strawberry culture some years before the introduction of the Hovey. Philadelphia then was a center of horticultural interest, with a large body of enthusiastic amateurs who did much to encourage the culture of the strawberry. As early as 1815, perhaps sooner, Anne Arundel County, Maryland, began to grow strawberries for the Baltimore and Philadelphia markets, laying the foundation of the industry which now gives Maryland preeminence in strawberry acreage. About 1830 the Horticultural Society of Charleston, South Carolina, was a center of amateur interest in strawberry culture, and several interesting papers on this subject appear in its proceedings. Cincinnati, then in the "far west," had barely made a beginning in the industry, the magnitude of which, a few years later roused the wonder and admiration of the East.

Yields and prices. - Save in the neighborhood of Boston, the methods were quite crude, and the results meager. A correspondent of the American Farmer, in 1823, advanced the opinion that strawberries should be left to grow up in grass, since that is the way they grow in nature. The same year a Maryland correspondent of this paper reported his success in growing "two squares of strawberries, each forty-five feet square, using the native strawberry from the woods." The yield was so great that "a single acre would produce the enormous quantity of 80 bushels." Feeling that this statement "might be considered by some as bordering upon the marvellous," he called in "several gentlemen of high respectability" to vouch for the truth of his assertions. ${ }^{1}$

The prices received in those days are likely to rouse the 1 American Farmer, Dec. 26, 1823. 
covetousness of the modern grower. The Genesee Farmer for 1833 reports: "A few strawberries were in the Fulton Street market, New York, on May 21, and were selling at the rate of 12 shillings a quart." 1 In June, 1837, strawberries were quoted on the Fulton Street market at " $12 \frac{1}{2}$ cents per basket, containing about a pint." As a matter of fact, these baskets hardly averaged one third of a quart. On the same date Faneuil Hall Market, Boston, quoted :

“Strawberries, per quart: Wood, 25 to $37 \frac{1}{2}$ cents.

Keens' Seedling, 50 to 75 cents. Common, $37 \frac{1}{2}$ to 50 cents."

The lower price of strawberries on the New York market was doubtless because all the supply was "common," having been grown under conditions but little removed from the wild.

Strawberries could not have been over-abundant in the home town of the Genesee Farmer (Rochester, New York), or it would not have been moved to report, in 1833, "A pint of strawberries of large size and delicious flavor were picked from the garden of H. N. Langworthy, of this village." 2 Nor would it appear that the standard of size was high, if we are to believe the Poughkeepsie (New York) Journal, which, in 1836, was " presented with several mammoth strawberries from the garden of N. G. Carnes of this city, the largest of which measures three and three quarters inches in circumference." Nowadays "mammoth" berries are over twelve inches in circumference.

The mystery of strawberry growing. - Numerous experiences like the following tended to discourage the exten${ }_{1}^{1}$ Genesee Farmer, 1833, p. 166.

${ }^{2}$ Ibid., 1833, p. 175. 
sion of planting at this time: "My strawberry vines are thick and luxuriant; they blossom well and then blight. How can the blight be prevented?" 1 This wholesale "blighting" of blossoms was due to lack of pollination; these were pistillate plants. Although the facts concerning the sex relations of the cultivated strawberry had been clearly pointed out by Duchesne, and by Michael Keens, in England, these facts were not generally known or accepted in North America or, for that matter, still less so in England. The inevitable result was that many luxuriant beds of strawberries, on which every attention but one had been lavished, were wholly "barren," or indifferently fruitful. These experiences gave the strawberry a reputation for fickleness, which was not removed until the controversy between Longworth and Hovey, about 1845 , directed attention to this hitherto unsuspected essential to success.

Varieties increase. - Although the improvement in cultural methods between 1800 and 1838, when the Hovey was introduced, was not marked, there was considerable progress in the development of improved varieties. In 1800 the Red Wood, Early Hudson and Old Scarlet comprised the list of sorts that were really worthy of general cultivation; the Chili, Hautbois, Alpine and Pineapple deserved attention only from amateurs who could afford to pet them. By 1836 the list had grown to over fifty; the most valuable of the new sorts were Large Early Scarlet, Hudson's Bay, Methven Scarlet, and Mulberry. Hudson's Bay first appears in the 1823 catalog of William Prince, as "Large Hudson." It had been introduced into England from North America about 1785, but, like Large Early Scarlet, apparently was not appreciated here until 1 American Farmer, May, 1823, p. 46. 
after it had won recognition abroad. Large Early Scarlet was catalogd here in 1824 .

Following the production of Keens' Seedling in 1819, by Michael Keens, of Isleworth, England, quite a number of "Pines," mostly descendants of this variety, were introduced here, as well as a number of English varieties of the Scarlet. Keens' Seedling was listed by Prince in 1824. In 1827 William Prince cultivated thirty varieties in his Linnæan Garden, of which he valued Old Scarlet, Early Hudson, and Hudson's Bay most highly. Few of the imported Pine varieties were sufficiently successful here to warrant their cultivation except in home gardens, and even there they required a great deal of coddling. A notable exception was the Mulberry, which C. M. Hovey reported in 1835 as "extensively cultivated around Boston for the market," and which he used in making the crosses that produced the Hovey.

One European variety of the Scarlet, introduced about 1825, gained a strong foothold here. In 1832 the Genesee Farmer, of Rochester, New York, acknowledged: "The distribution of the Methven Scarlet through this western country, by Messrs. Buel and Prince, has given an entirely new impetus to the cultivation of the strawberry." This variety, a seedling of Hudson's Bay, was quite widely grown until about 1845 . In 1838 it was quoted on the Boston market at fifty to seventy-five cents a box, which was higher than Keens' Seedling. In 1835 William Prince, who had the best horticultural collection in the country, offered for sale fifty varieties, of which Hudson's Bay, Large Early Scarlet, Early Hudson and Morrisania Scarlet were the only sorts of North American origin. He adds, "Many other kinds have been imported." 
At the close of this period - with the introduction of the Hovey, in 1838 - the strawberry was still a fruit of the open fields and home gardens. In the vicinity of Boston, New York, Philadelphia, Baltimore and Cincinnati, and perhaps near a few other towns, a little progress had been made in commercial culture. The great uncertainty that attended its cultivation, due to ignorance of pollination requirements as well as to lack of suitable varieties, prevented most people from growing it, even in the home garden. Wealthy gentlemen, who employed private gardeners, were able to serve the improved English varieties to their guests, as a luxury; most people still depended upon the supply of wild fruit.

\section{The Introduction of the Hovey}

The origination of the Hovey strawberry, in 1834, marked a turning point in North American horticulture. Although the United States had cut herself loose from England politically, she was still tied to the apron strings of the mother country horticulturally. English varieties and English methods still dominated. Probably this was more true of the strawberry than of any other fruit. Of the fifty or more varieties that had been grown previous to this time, all were imported from England, with the exception of Old Scarlet, which was merely the type of $F$. virginiana. Even Large Early Scarlet, Hudson's Bay, Early Hudson, and Morrisania Scarlet, which had originated here, first had been submitted to English gardeners for the stamp of their approval, before being grown in North America. In home gardens, and in the commercial plantations near Boston, strawberries were planted in trenched beds, and grown in hills, regardless of the radical 
difference in climatic conditions. American horticulturists still were copying Old World methods.

Origin of the Hovey. - The first named variety of any fruit produced in North America by definite plant breeding was the Hovey strawberry, originated by C. M. Hovey of Boston, in 1834. It was natural that this important

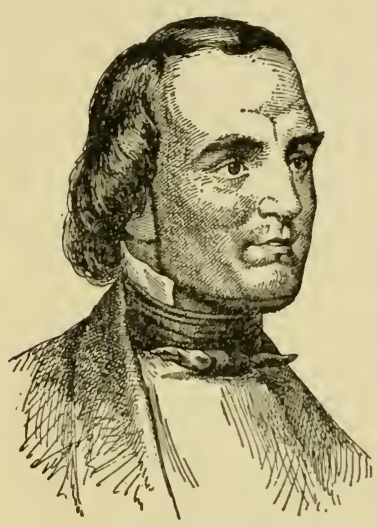

FiG. 2.- C. M. Hovey, originator of the Hovey strawberry.

pioneer work should have been done at that point and at that time. Boston was the center of progressive horticulture in North America. In 1829 a group of enthusiastic and wellposted amateurs had organized there the Massachusetts Horticultural Society, which now has an unbroken and notable history of nearly a century. The organization of this society definitely marked the separation of horticulture from general agriculture on this continent. This pioneer society (the one organized at New York in 1818 had but a brief existence), together with the strong society organized at Philadelphia a little later, made possible the organization of the American Pomological Society, in 1849. It also made possible the publication of the Magazine of Horticulture, edited by C. M. Hovey for forty years, our most valuable single repository of horticulture.

Hovey was led to undertake his work in strawberry breeding by the obvious lack of suitable varieties for culture in North America. Large Early Scarlet, Hudson's Bay, Early Hudson, Crimson Cone, and Methven Scarlet, 
together with Red Wood in the vicinity of Boston, comprised the list of commercial sorts. All were deficient in productiveness, size and quality; all, with the exception of Red Wood, had a very short fruiting season. A number of the improved varieties of the Pine, which then were being received with great acclaim in Europe, had been introduced and given a fair trial. In size and quality they were distinctly superior, but none, with the possible exception of Mulberry, gave promise of becoming valuable for general cultivation. They did not possess sufficient stamina to endure the rigors of our climate.

In 1834 Hovey made six hand crosses in his garden, clipping the anthers from the unopened flowers, and transferring the pollen to the receptive pistils with a camel's hair brush, in the most approved fashion of today. Like many another plant breeder, Hovey was so unfortunate as to lose his labels, so that he never knew positively which cross produced his famous seedling. The loss of labels was a far greater misfortune than Hovey could have imagined. If the real parentage of the Hovey were known, it would do much to clear up present doubts concerning the botanical origin of the North American strawberry. This is discussed more fully in Chapter III. Boston Pine, the only other variety introduced by Hovey, was produced in the same lot of seedlings, and was supposed by him to be Grove End Scarlet $\times$ Keens' Seedling. It was grown to some extent near Boston for pollinating the Hovey, but did not become prominent.

The first novelty. - Hovey first exhibited his seedling before the Massachusetts Horticultural Society in 1838. It created a furore. The fruit was much larger and more attractive than any variety known, while the productiveness of the plants, as grown in the garden of the originator, 
was said to be phenomenal. It was acclaimed the "perfect" strawberry, for which America long had been waiting. Hovey was editor of the only horticultural journal on the continent and an acknowledged authority on the subject; he was also a practical nurseryman. Hence he was in a better position to profit by his seedling than most originators

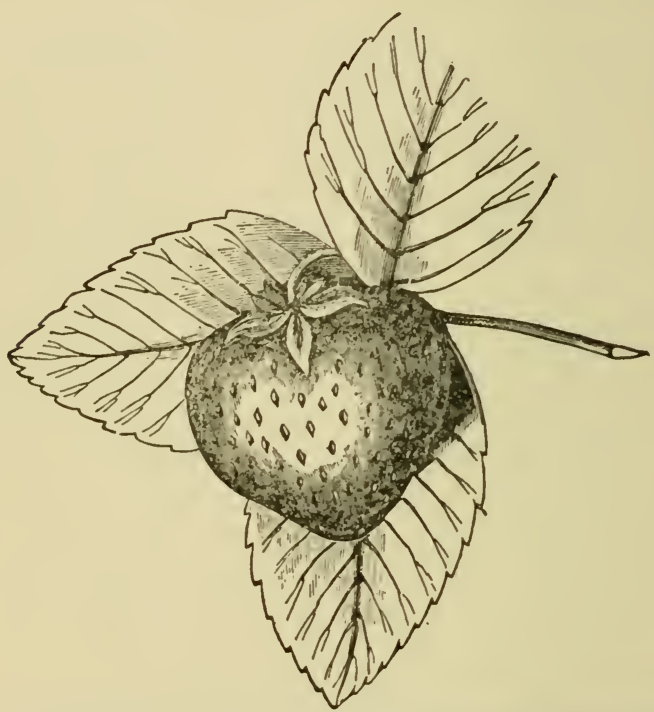

FIG. 3. - The Hovey strawberry, the first variety of any fruit originated in North America by definite plant breeding.

of valuable varieties have been since then. In 1840, and for several years thereafter, plants of the Hovey sold for $\$ 5.00$ a dozen. It quickly was disseminated to all parts of the continent where strawberries were grown. It was quoted on the Boston market in 1841 at fifty cents a quart, which was twice the price received for any other sort.

The Hovey was received with enthusiasm. Coming 
from such an eminent source, accompanied by the unqualified endorsement of the Massachusetts Horticultural Society, - the center of authority in horticultural matters at that time, - it was natural that much should be expected of the new variety. This was the first experience of the American public with the modest claims of an originator; its first baptism with the fervid oratory that heralds the introduction of a novelty.

Unsatisfactory results with the Hovey. - These great expectations were realized only in part. The Hovey was a failure as a commercial variety except in the vicinity of Boston, where it was a prominent market sort until 1860 , and in a few other places. Like most of the other varieties of that period with pine blood, it required high culture and was tender, and it did not make enough plants. Part of the unsatisfactory results with the Hovey, during the first few years after its introduction, were due to the fact that it was pistillate variety. After the necessity for planting it with a pollen-bearing variety became generally known, about 1846, it gained somewhat in favor, but it did not displace Large Early Scarlet, Hudson's Bay, Early Hudson and Crimson Cone in any large market except Boston. After 1848 it was rarely quoted on the market of any other city.

Although the Hovey was a great disappointment as a market variety, it quickly became the most popular sort for the home garden, on account of its superiority in size, attractiveness and quality. It was distinctly an amateur variety. For years it captured most of the prizes at the strawberry exhibitions, then so popular. Apparently the Hovey passed out of cultivation about 1890 , but possibly it may be found still in some of the gardens near Boston. 
A new interest in plant breeding. - Our debt to the originator of the Hovey is not so much for the merit of the variety itself as for the stimulus that it gave to the breeding of new varieties of strawberries and other fruits. It was the first important North American variety. Until then we had been content to depend upon Europe for varieties, and most of these had failed. The financial reward that Hovey received from the sale of his seedling, no less than the excellence of the variety itself, fired the imagination and stirred the efforts of fruit growers everywhere. All over the country men began to make crosses and to grow seedlings. Alexander Ross, of Hudson, New York, originated the Ross' Phœnix, which became a popular commercial variety in the East. John Burr, of Columbus, Ohio, produced Burr's New Pine, a notable variety in its time. Nicholas Longworth, of Cincinnati, Ohio, made it possible for his tenant to produce the McAvoy's Superior and the Longworth; the latter still is a standard market sort in California. Dr. Brinkle, of Philadelphia, is reported to have raised and described seventy varieties, but only two of these are on record. Robert Buist, of Philadelphia, and many others, took a share in what was then the great lottery of nature. In 1846 a committee of the Cincinnati Horticultural Society listed forty varieties as worthy of cultivation; eighteen of these were of North American origin.

It was inevitable that in this first rush of enthusiasm many worthless and wholly untried seedlings should be named and introduced. William Robert Prince, who introduced over fifty varieties, all worthless, was the most conspicuous offender. We are still trying to live down the habit acquired then of introducing seedlings without first ascertaining whether they are distinct from existing 
sorts, and whether they will give satisfaction anywhere except on the grounds of the originator. The introduction of the Hovey marked the emancipation of our horticulture from that of the Old World, and the beginning of North American plant breeding.

\section{Extension of Commercial Culture, 1838-1854}

In the sixteen years between the introduction of the Hovey and the introduction of the Wilson, there was a considerable extension of the strawberry industry, especially in the territory tributary to Cincinnati, New York and Baltimore. The greatest progress was made at Cincinnati; between 1845 and 1849 it was the leading strawberry market of the country. In 1848 Charles Cist recorded the quantity marketed in Cincinnati at that time :

\section{"In 1846, 4200 bushels. \\ In 1847, 4576 bushels. \\ In 1848, 4965 bushels.}

"To this should be added large quantities sent off by railroads. I should put down the entire product of the strawberry in 1847 at 6500 bushels, and in 1848 at 7000 bushels." 1 He informs us that these berries were raised on "not over 250 acres," which would make the average yield 896 quarts an acre; and that "the biggest individual acreage was 60 acres, in three fields, owned by a Mr. Culbertson." The Horticulturist records that this "Strawberry King sent to the market of Cincinnati, in a single day, four thousand quarts of strawberries. He employs sixty hands in gathering them." 2 The berries

${ }^{1}$ U. S. Patent Office Report, 1848, pp. 609-17.

2 The Horticulturist, 1847, p. 95. 
were hulled before they were marketed, and were sold loose, by the quart, peck or bushel, as needed.

This was an almost unbelievable quantity of strawberries, and should have made the "King" rich. But the law of supply and demand seems to have been working as smoothly then, as now, for A. J. Downing reports, "The price received by the Cincinnati growers in 1847 was an average of six cents a quart - the largest and cheapest supply known in any city of the world." 1 In 1848, according to Cist, "Prices opened at 20-25 cents for a day or two, soon fell to 10-15 cents, and then to 3-4 cents. The season's sales will not average higher than 7 cents unless the season itself has proved unfavorable. I know of no year in which strawberries have averaged as high as 10 cents per quart." This has a familiar ring to the berry growers of today. About one half of the strawberries raised near Cincinnati at that time were Early Hudson; most of the remainder were Old Scarlet, Necked Pine and Hovey.

Near New York. - Notwithstanding the greater publicity given to strawberry production near Cincinnati, New York, then a city of over 300,000 , rapidly was becoming the greatest strawberry market in the world, as it is today. It no longer was obliged to depend upon the meager supply of "Hackensacks," brought twice a week in sailing sloops, wind and tide permitting, or ferried across the river at Hoboken. The era of railroad transportation had begun. Strawberries now were coming from points in New Jersey and New York which had been wholly inaccessible a few years previous. On June 20, 1847, one train on the Erie Railroad carried 26,667 quarts of strawberries into New York. By 1849, "In 26 days, 4572 bushels of strawberries

${ }^{1}$ The Horticulturist, 1848, p. 25. 
were sold in New York. Over 80,000 baskets, equal to 833 bushels, were brought to the city in one day by the Erie Railroad alone. The average value was 3 cents per basket." ${ }^{1}$ As the baskets held but a third of a quart, the price received was about nine cents a quart. This is about the average price received now, but nine cents then represented more profit than now.

In 1849 , S. B. Parsons stated that the strawberry crop was "very profitable, particularly where irrigation can be obtained. Nearly 5000 bushels are every season sold in the city of New York, and to the cultivator the profit is enormous." 2

In the South. - Important centers of strawberry production were beginning to develop in the South, creeping farther and farther down the Atlantic coast, in response to the demand for earlier and still earlier berries. The reverse operation - shipping northern berries to the South - was reported as feasible by Nicholas Longworth, in 1852. He said, "The plan of shipping them to New Orleans, packed in ice, has just commenced, and may eventually become an important branch of the business, as they can be carried down in a week by our regular packets." Very little came of this enterprise, however; even now the current of trade is almost wholly from South to North.

Anne Arundel County, Maryland, which supplied the Baltimore and Philadelphia markets, then was the most important strawberry district in the South; it had over 250 acres about 1850. These were mostly Large Early Scarlet, Hart and Stewart, all varieties of $F$. virginiana. By 1857 this county had "some 600 acres of land planted to straw-

1 The Horticulturist, 1849, p. 102.

2 Trans. New Haven County Hort. Soc., 1849, p. 13. 
berries within a neighborhood of a few square miles, and producing scarcely less than twenty thousand bushels," says the astounded Horticulturist." The "Strawberry King" of that section was Rezen Hammond, who had about 100 acres of this fruit. Anne Arundel berries went as far north as Philadelphia, but not to New York. In 1859 Thomas Meehan reported, "The freight train from Baltimore to Philadelphia on the night of the 7th of June brought upwards of 60,000 boxes." 1

\section{Condition of Strawberry Culture Before the INTRODUCTION OF THE WILSON}

The introduction of the Hovey had done much to raise the standard of size, quality and appearance for amateur varieties, but the standard for market berries remained practically unchanged until the introduction of the Wilson. A "great yield of strawberries" was noted by the New England Farmer, in 1840, "eight bushels and three pecks being picked from ten square rods of Methven Scarlet, which sold for \$77.00.” In 1844 Thomas Bridgeman related that Jesse Buell, of Albany, New York, bragged extensively because he had "picked a pailful that morning of Methven Scarlet strawberries which had an average circumference of three inches each; and sixty-three of them, divested of the calyx, weighed a pound." In 1847 the average yield to the acre near Cincinnati was 896 quarts and the average price six cents a quart. This does not look particularly attractive now. Before the introduction of the Wilson the average yield was about forty bushels an acre, which is 500 quarts an acre

1 The Horticulturist, 1857, p. 388.

1 Gardeners' Monthly, 1859, p. 106. 
below the average at the present time. In $1849 \mathrm{~A}$. J. Downing asserted "One hundred bushels per acre frequently are grown here by market gardeners." Ten years later, the Secretary of the Cincinnati Horticultural Society reported, "The best yield of the Hovey upon our best virgin forest soil is from forty to fifty bushels per acre. The profits of the Hovey under the best circumstances are from $\$ 100$ to $\$ 120$ an acre, clear of all expenses." 1

Another view of strawberry economics at that period is afforded in a report by John C. Youtcy of Cincinnati, in 1855. He says : "I had two acres of Early Washington which produced 60 bushels and sold for $\$ 425$; five acres of Hovey which produced 178 bushels and sold for $\$ 1260$; three acres of Hudson which produced 102 bushels and sold for $\$ 530$. The gross receipts from ten acres were $\$ 2210$. The expense of picking including boarding of hands was $\$ 225$ and the expense of marketing was $\$ 75$. The probable cost of cultivation per annum was $\$ 15$ an acre." Although the average price in the New York market was about nine cents a quart, fancy fruit brought a premium. "Fruit of high flavor," says Pardee, "measuring from three to four inches in circumference, will command fifty cents per quart in New York or any other market."

- Varieties. - Practically all the berries marketed, except in Boston, were varieties of $F$. virginiana, which accounts for the small size. Here and there the larger and more fastidious Hovey and English varieties of the Pine were grown for a select trade by the initiated, but in a very limited way. About 1853, William Cammack, an English gardener near Washington, D. C., achieved more than a local reputation growing British Queen and Victoria

${ }^{1}$ The Horticulturist, 1859, p. 385. ${ }^{2}$ Ibid., 1855, p. 366. 
Ovata. His best berries sold in Washington and Baltimore for seventy-five cents a quart when common stock brought ten or twelve cents a quart. ${ }^{1}$ Pine varieties, however, including the Hovey, formed but a very small part of the strawberries brought to market. Excluding the wild berries, it is likely that over ninety per cent of the strawberries marketed before 1858, when the Wilson came rushing to the front, were pure varieties of $F$. virginiana, chiefly Large Early Scarlet, Hudson's Bay, Early Hudson, Crimson Cone and Methven Scarlet. Stimulating effect of the pollination discussion. - The leadership in strawberry production attained by Cincinnati, about 1845 , was due largely to the earlier acceptance by the growers of that neighborhood of the proposition that pistillate varieties must be inter-planted with staminate sorts in order to be most productive. Until the introduction of the Hovey, no attention had been given to the subject of pollination by North American growers, although the necessity for mixed planting had been pointed out years before. The subject was first brought prominently before the public by Nicholas Longworth, of Cincinnati, Ohio. The controversy over "Longworth's Theory," from 1842 to $1848^{2}$ had a most stimulating effect on strawberry culture, wholly aside from the greater certainty that resulted in the cultivation of pistillate varieties. It set people to thinking and investigating for themselves, instead of blindly accepting the opinions of authorities. Hundreds of voluntary observations and experiments on cross-pollination were reported in the horticultural press while "the strawberry question," as it was called, was before the public. There

1 Rept. Ind. Hort. Soc., 1898, p. 70.

2 See Chapter III for a full discussion of this subject. 
was a general questioning of methods, and a searching for cause and effect, which prepared the way for the remarkable extension of commercial planting that followed the introduction of the Wilson.

The close of this period, in 1854, found commercial strawberry culture well extablished in the vicinity of Boston, New York, Philadelphia, Baltimore and Cincinnati, with scattered plantings in a few outlying districts, notably in western New York. Only a meager beginning had been made; most people still knew only the wild berry. "Strawberries are quite commonly cultivated by private gentlemen," said Chauncey E. Goodrich of Utica, New York, in 1853, "and they make very fine displays of this fruit at our occasional city fairs. But the public supply is mostly from the fields, where they are gathered growing spontaneously." 1 "Only thirty years since," said Parker Earle of Cobden, Illinois, in 1887, "the growing of strawberries for market was confined to a few gardeners in the vicinity of half a dozen of our larger cities, and means of transportation consisted mostly of the market wagon. A few hundred wealthy gentlemen, who had had some country places and kept professional gardeners, grew this luxurious berry for their own tables; and a few market gardeners for market. Outside of this limited culture most of the people of the country knew nothing about the strawberry except what they had gleaned from the fragrant hillsides, where nature had planted them with the daisies and buttercups." 2

It is probable that the total quantity of cultivated strawberries marketed in 1854 did not exceed 40,000 bushels. If the average yield was thirty bushels to the

${ }^{1}$ U. S. Patent Office Rept., 1853, p. 314.

${ }^{2}$ Rural New Yorker, 1887, p. 128. 
acre, which was considered good at that time, the total area under commercial cultivation was less than 1400 acres, which is one fourth of the present acreage in Sussex county, Delaware. The cultivated strawberry was still a fruit for the wealthy amateur; it had not yet become a fruit for the millions. 


\section{CHAPTER II}

\section{THE RISE OF COMMERCIAL STRAWBERRY- GROWING}

The variety which was to transform the commercial culture of the strawberry in North America from an insignificant industry, occupying less than 1500 acres, to an industry requiring 150,000 acres, and wonderfully popularize its culture in the home garden, was born near Albany, New York, in 1851. In that year James Wilson, a Scotch gardener who had a small nursery business near Albany, sowed seeds of the Hovey, Black Prince and Ross' Phœnix, all popular garden varieties at that time. Both Black Prince and Ross' Phœnix were Pines, the former a seedling of Keens' Imperial, and a direct descendant of the original Pineapple strawberry ; the latter a seedling of Keens' Seedling. The seeds were the result of natural pollination; no hand crossing was done. The parentage of the Wilson, therefore, is a matter of speculation. James Wilson was confident that his famous seedling was Hovey $\times$ Black Prince, and this opinion was shared by A. S. Fuller.

Only one of the seedlings showed promise. At a meeting of the Albany and Rensselaer Horticultural Society, held at Albany on June 22, 1853, "James Wilson exhibited a new seedling strawberry." 1 Apparently it did not at${ }^{1}$ Mag. Hort., 1853, p. 419. 
tract attention, as there was no further comment on it that year. The following summer James Wilson showed a number of potted plants of his seedling, each laden with fruit. There was no lack of appreciation then. In the words of a current publication, "Such was the size and number of the berries upon each plant that people were astonished, curiosity was excited, and public attention was aroused to an examination of the claims of this new strawberry." It was then named Wilson's Albany.

James Wilson was a nurseryman, so he must have realized the value of his seedling and the profit that might be derived by keeping it himself for exclusive propagation and sale; yet he generously divided his stock of plants with his neighbors. Two years later, when demands for plants began to pour in, he had fewer plants to sell than some of his neighbors, and realized very little profit. He died in 1855 , leaving the nursery to his son, John Wilson, who continued to propagate the Wilson strawberry for several years. James Wilson was an unassuming man, who unselfishly declined to take advantage of an opportunity for private gain. Granville Cowing has declared, "The fruit growers and fruit consumers of this country owe him a debt far greater than many that have been paid in costly monuments of bronze and marble."

\section{The Sway of the Wilson}

Save in the vicinity of Boston, the stronghold of the Hovey, the Wilson was hailed everywhere as the greatest of market varieties. The rapidity with which it supplanted other varieties was remarkable, especially since no effort was made to bring it to public notice. It was not exploited by the originator or introducer, as was the 
Hovey, but won recognition on its merits. At that time the leading commercial varieties were Large Early Scarlet, Hudson's Bay, Early Hudson, Crimson Cone and Hovey. In 1852 the American Pomological Society, then composed largely of amateurs who were more insistent upon quality than commercial growers, recommended Boston Pine, Hovey, Jenny's Seedling and Large Early Scarlet as "worthy of general cultivation." Six years later, four years after the Wilson was introduced, it had so firmly established itself that the Fruit Growers' Association of Western New York (now the Western New York Horticultural Society), took a vote upon "the best market variety" with this result:

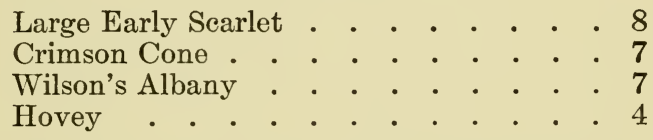

The same year the American Pomological Society added it to the list of varieties recommended for general cultivation. By 1861 it had largely superseded all other sorts for market purposes, although the Hovey and Large Early Scarlet persisted for some years, the former near Boston, the latter in western New York, where it vied with Wilson as late as 1864. The Wilson completely dominated the markets of the United States and Canada from 1860 to 1880. In 1872 W. C. Flagg estimated, "In the United States, the Wilson composes ninety per cent or more of the strawberries in cultivation." After 1880 the Wilson was gradually supplanted by a succession of varieties, beginning with Crescent and Sharpless, followed by Cumberland Triumph, Charles Downing, Miner's Prolific, Haverland and Bubach, down to the more numerous prominent varieties of today. It still is grown somewhat, 
particularly in Canada and the Pacific Northwest. The Wilson is unique among North American varieties in the complete ascendancy that it gained over all other sorts and held, practically undisputed, for a quarter of a century.

There was one section of the country, however, that persistently and consistently refused to see any virtue in the Wilson. This was the vicinity of Boston, most conservative of towns and the home of the Hovey. The originator of that notable variety appears to have considered it a personal affront that any other sort should be proposed for first honors. In 1860, after the Wilson already was firmly established in public favor, Hovey fervently declared, "Wilson's Albany has fruited with us this year in fine condition, and has come fully up to our expectations as one of the sourest, most dirty colored, and most disagreeable flavored of all recently introduced sorts - an excellent sort to make vinegar of. Besides, it is soft, watery, unfit for carriage, has a very large calyx, and is hollow at the core." 1 To this damning indictment his neighbors in the Massachusetts Horticultural Society loyally gave assent, voting unanimously, "The Wilson's Albany is unfit for general cultivation," and Marshall O. Wilder declared he "would as soon eat a turnip as a Wilson strawberry." This ought to have killed it. Fruit growers, however, were beginning to learn that the reputation of a variety cannot be made or marred by the pronouncement of any individual or Society, however high an authority, and kept on growing the Wilson. Boston never ceased to look upon the Wilson with a jaundiced eye. When her sons journeyed southward in 1861, and were forced by dire hunger to partake of the despised fruit, one of the survivors declared, "The Wilson strawberry killed more ${ }^{1}$ Mag. Hort., July, 1860, p. 307. 
Boston men during the war than Confederate bullets." From a safe perspective of years, this assertion appears to be a trifle exaggerated.

Good points and objectionable features of the Wilson. The immediate and long-continued popularity of the Wilson was due to the fact that it was dependable. It produced large crops of attractive fruit, even under indifferent care. Unlike the Hovey and the Pines, it did not require high culture, and it was much superior in productiveness, size and appearance to Large Early Scarlet, and other common varieties of the Scarlet. It was very firm, and could be shipped to distant markets under the trying conditions of transportation and marketing that prevailed then. It was bisexual, so that the troublesome problem of pollination was eliminated. In short, the Wilson simplified the cultivation of the strawberry. Not until then had it been possible for every one to grow strawberries, the poor as well as the rich. It did not require the services of a professional gardener. The strawberry now became, in fact, a fruit for the millions.

Even the best friends of the Wilson, however, had to admit that it was sour. Holding a brief for the consuming public, Henry Ward Beecher once spoke feelingly on this point: "I shall not feel easy in my mind till I have had my say about the Wilson's Albany. This vixenish berry is enough to turn a horticulturist's heart against his kind. It is the wickedest berry that was ever indulged with liberty. It is an invention by which the producers make money out of the consumer's misery. It has every quality of excellence except in the matter of eating. It bears prodigal crops of large-sized fruit, and is unfailingly sure. Now, is it not a thousand pities that such a berry should be of a nature so acid as to be a perfect virago among 
strawberries? It might live in a sugar bowl, and be acerb and crabbed still. It vexes me to pass by the fruit stands and see boxes and baskets of Wilson's Seedling outnumbering all others, and so large, plump, rich in color, and tempting that, with all my knowledge of its worthlessness, I am still tempted to buy. Let a man chew the rind of a shattuck, and imagine that it is an orange; let him eat cranberries, and call them sugar plums; and then let him eat Wilson's Seedling, and say, 'I have eaten strawberries.' I call upon the Society for the Prevention of Cruelty to Animals to unite with me, and with all rational beings, in suppressing the Wilson's Albany Seedling Strawberry." But the Wilson refused to be suppressed.

Competitors of the Wilson. - The Wilson held almost undisputed sway as a commercial variety for about twenty years. Many claimants for fame arose and were introduced with the customary and apparently inevitable sounding of trumpets; but none achieved more than local popularity. The various state horticultural societies had heated discussions on the question, "Is there a better strawberry than the Wilson," and invariably decided in the negative. About 1872 the Charles Downing, which had been introduced in 1867 at $\$ 1.00$ a plant, began to find favor in some quarters. It held high rank as a commercial variety until 1890. Four notable varieties, the Cresent, Sharpless, Cumberland Triumph and Miner's Prolific, were introduced between 1874 and 1877.

The only variety that really challenged the Wilson was the Crescent, which was introduced in 1876 . By that time the Wilson had begun to lose some of its pristine vigor and productiveness. There was widespread complaint that it had begun to "run out," although a few skillful growers, notably J. M. Smith of Green Bay, Wisconsin, cultivated 
it for many years thereafter with marked success. The time was ripe for the introduction of a new variety, equally cosmopolitan and tolerant of indifferent culture. The markets wanted a change from the Wilson. The Crescent met the situation. It was one of the most productive varieties grown up to that time. It was earlier than Wilson, which was more of an advantage then than now. Although smaller than Wilson, softer, more poorly colored, and even more inferior in quality, the markets took kindly to it for many years. The chief claim of the Crescent upon popular favor was that it thrived everywhere with a minimum of effort. It was frankly introduced as "the lazy man's berry," especially designed for members of the "No Sweat Club," and fully merited this enticing description.

The introduction of the Crescent gave a decided impetus to strawberry planting. As it was a pistillate, it was necessary to grow a staminate sort with it; Wilson, Cumberland Triumph, Sharpless and Miner's Prolific were commonly used. The Sharpless, introduced in 1877 , was the first of the very large-fruited varieties that could be produced without special difficulty by the commercial grower. Although not as productive as Crescent, it became a standard sort at once because of its size and beauty. When the markets began to tire of Crescent, about 1890, Haverland, Gandy and Bubach came to the front.

Three varieties never again can dominate the markets as did Wilson, Crescent and Sharpless between 1858 and 1895. These are the great triumvirate of North American varieties. Conclusive proof of this is furnished by the parentage records of North American varieties; two thirds of all the varieties produced since 1858 of which the parents are known have in them the blood of one or more of these three. 
Boom Days. - The introduction of the Wilson immediately was followed by a revival of interest among amateurs, and by a tremendous increase in commercial planting. Nearly every fruit grown in North American has had at least one great boom period, when, through some favoring circumstance, the market demand far exceeded the supply, and prices of both fruit and plantations went skyward. It has been so with the prune, orange, pomelo and apple; it was so with the strawberry. The "Strawberry Fever," as it was called, swept the country between 1858 and 1870 . It reached its climax about 1865; even the exhausting Civil War did not distract the strawberry enthusiasts of the North, where most of this planting occurred. Strawberries commonly sold for thirty to forty cents a quart, and profits of $\$ 1000$ an acre were not unusual. In 1861 Joseph Harris, editor of the Genesee

- Farmer, visited Bloomington, Illinois, and found Wilson strawberries selling at fifteen cents a quart, and corn at eight cents a bushel. ${ }^{1}$ People who had never before grown strawberries, or any other kind of fruit - merchants, grain and stock farmers, professional men - rushed into the strawberry business. The warning of Patrick Barry, and other cool heads, "This planting spirit has appeared to some as a sort of speculative mania, and the idea has suggested itself that the country soon will be overstocked," was disregarded. There were numerous discussions in the various state horticultural societies as to whether strawberry growing was not being "overdone," but these produced no appreciable diminution in the planting. Amateurs, as well as professionals, caught the craze. The annual "Strawberry Festival," first held at Belmont, Massachusetts, about 1858, spread over the country. ${ }^{1}$ The Cultivator, 1861, p. 288. 
Strawberry exhibitions, introduced by the Massachusetts Horticultural Society about 1848, were held everywhere.

The inevitable reaction came about 1870 . In the eastern cities, prices declined sharply to three or four cents a quart, which was below the cost of production. Hundreds of carloads were dumped into the Hudson River. Large fields, heavily loaded with fruit, were plowed under. The rapid extension of transportation facilities after the Civil War, which made it possible to market fruit from distant points, contributed largely to the decline in prices. Many lost heavily, especially those who had gone into the business merely as a speculation. In some places prices held up fairly well; but the years from 1870 to about 1885 are recalled by veteran growers as the "slump" period of North American strawberry-growing, during which the relations between supply and demand were re-adjusted, and methods of lowering the cost of production developed.

\section{Contrasting Methods of Culture, Yields and Prices}

The center of intensive strawberry culture long had been the vicinity of Boston. There strawberry growing had developed largely as an adjunct to market gardening. The plants were grown close together in narrow, raised beds and were heavily manured, highly tilled, and kept in hills. Varieties of high quality were grown, such as the Hovey, Mulberry and other Pines. These made but a moderate growth of runners and so were easily confined to hills. This system of culture had been introduced from Europe ; it was the common method throughout the East at the time of the introduction of the Wilson.

Field culture at Cincinnati. - Field culture of the 
strawberry, on an extensive rather than intensive scale, as we know it today, began about 1840, at Cincinnati. The varieties chiefly grown there, - Early Hudson, Necked Pine, and other varieties of the Scarlet, were exceedingly prolific of runners, and hence did not lend themselves as readily to intensive culture and hill training as the Pines. About 1850, there were 250 acres under field culture in Anne Arundel County, Maryland; Large Early Scarlet, Hart and Stewart, all varieties of the Scarlet, were grown. The planting of strawberries in rows far enough apart to be cultivated with a horse was first advocated about 1854, by Patrick Barry. This method was quickly adopted in western New York for Large Early Scarlet and Wilson.

The controversy between the exponents of intensive, or market garden culture, and the exponents of extensive, or field culture, was as vehement and as futile then as today. The two ideals are admirably portrayed in the reports of a committee of the Ohio Pomological Society, which met at Cincinnati in the spring of 1865 "to examine the great fields of that region, including the near-by hills of Kentucky, where the old fashioned method of cultivating this delicious fruit was exhibited." 1 Although admitting that this method "had furnished large results in the grand aggregate of production," the committee was not able to recommend it, and reported on it "only as a matter of historic interest." Following is the description of the Cincinnati method as reported by this committee: "A piece of rich land, so heavily timbered as to be free from grass, weeds and under-growth, was selected, cleared and broken up. In the spring it was planted with strawberries, in rows three or four feet apart; corn was fre${ }^{1}$ Rept. Ohio Pom. Soc., 1865, pp. 126-7. 
quently put into the same rows, and some cultivation given. In the fall the corn was harvested and any large weeds cut down. The next season a fair crop of very fine fruit was gathered and the runners were allowed to spread over the ground. In some cases a single cultivation was given in the spring. As the weeds made their appearance, they were cut down with a scythe and left upon the ground, and by the end of the summer the runners would have covered the surface completely, so the field was well stocked with plants.

"The next crop was a heavy one, except where the plants had become too thickly set. After this the increase of runners would soon make the patch too thick and some measures were necessary to reduce their numbers. A heavy harrow, dragged across the field when the ground was soft, was the means commonly used for thinning the crop, and this treatment was generally followed by another heavy yield of fruit. After this the crops were found to be lighter; the plants, being thus crowded together, could not be so productive, and by this time the natural growth of bluegrass and white clover was found to make rapid inroads upon the strawberries, and the fruit diminished in value, so that it was considered more profitable to break up the ground and apply it to other crops. Some would allow the strawberries to remain struggling for supremacy a few years longer, and would continue to gather light crops of fruit from among the grass, until it was no longer doubtful which was the legitimate occupant of the soil."

Market garden culture at Pittsburgh. - By way of contrast with this crude field culture, which was useful, no doubt under these conditions, compare the intensive culture practiced by others at that time, as reported by the same com- 
mittee, after a visit to the farm of John Knox, Pittsburgh, Pennsylvania. "The ground is deeply plowed and subsoiled twice in the autumn, and again deeply stirred in the spring before planting. The plants are set about a foot apart, in rows that are eighteen inches wide; three rows constitute a bed, when a space of two feet and a half is left between the beds. The beds are kept perfectly clear by hand culture, during the entire season, so as to encourage their utmost growth and the result in the autumn is a continuous mass of foliage. This is not merely the result of thorough preparation of the soil and clean culture during the season, but should also be attributed to the effect of constant summer pruning, or the removal of all runners, which constitute the wood growth of the strawberry plant and which exhaust the original stock if allowed to remain. On the contrary, if persistently cut back as soon as they appear the plants are rendered stocky and produce a number of points or fruit spurs, making what gardeners call a stool, having many crowns in each plant. This your committee consider one of the main causes of the wonderful fruiting they have witnessed upon these grounds." 1

Of the remarkable fruit produced by this intensive culture the committee reported: ${ }^{2}$ "On most of the plants there were ten to twelve ripe berries, sufficient to fill a quart measure. Mr. Knox informs us that he realizes sixty cents per quart after shipping the fruit 400 miles. Many suppose his success is owing to expensive culture and high manuring. Such is not the case. The plants while young receive timely and careful tillage. He covers lightly with straw in the winter and mulches heavily in summer."

${ }^{1}$ Rept. Ohio Pom. Soc., 1867, pp. 11-14.

${ }^{2}$ Ibid., 1869, p. 14. 
John Knox claimed an average yield of 300 bushels an acre. In 1860 he said, "Some varieties, the past season, yielded as high as 600 bushels per acre." 1 We might be inclined to doubt these assertions, were they not supported by unimpeachable authority. , Evidently Thomas Meehan, editor of the Gardeners' Monthly, and a most conservative horticulturist, was carried away by what he saw at the Knox Fruit Farm, for he wrote, "The size of these berries was the largest that anyone ever saw, and might easily be mistaken by a near-sighted observer for tomatoes. While I left strawberries selling in Philadelphia at ten cents per quart, and hardly salable at that, they were being shipped from here to all parts of the East for $\$ 1.00$ per quart for the first choice, and fifty cents for all that were left." Ten years later The Horticulturist reported: ${ }^{2}$ "Rev. John Knox of Pittsburgh succeeded in making his land devoted to the Jucunda strawberry pay from $\$ 1200$ to $\$ 1500$ an acre, and frequently sold fancy berries at the rate of one dollar per quart. These quart baskets often held but eighteen berries. From two and one half acres last year, he realized $\$ 3600$ net. He estimated his cost of production as about $\$ 200$ an acre."

Most of the Knox strawberries were an imported variety of which he had lost the label, so he called it "Knoxes 700." Being a nurseryman, as well as a strawberry grower and preacher, John Knox was not averse to turning a thrifty penny, as we learn from the aggrieved William Parry, - himself a nurseryman: "For several years he refused to sell any of his stock of Knoxes 700 until he had a very large quantity propagated. During

1 Country Gentleman, 1861, p. 126.

2 The Horticulturist, 1871, p. 210. 
this time of suspense we were treated to reports of its sales in New York at sixty cents a pint, of ten berries each. Finally he put on the market a large stock at $\$ 100$ per thousand. It then turned out to be Jucunda." This variety had been widely tested some years before and discarded as worthless. It has been a standard variety under high culture ever since.

John Knox was perhaps the most skilful strawberry cultivator this country has produced. He did more to demonstrate the possibilities of intensive or market garden culture of this fruit than any other man. For a number of years he held annual strawberry and grape exhibitions at his farm, which became the Mecca of horticulturists from all parts of the continent. The intensive methods now in vogue, and sometimes said to be of recent origin, do not differ materially from those practiced by him in 1865 . He died in 1872 .

Yields and prices. - Results almost as gratifying were secured by the skilful market gardeners near Boston. In 1867 Marshall P. Wilder told the incredulous fruit growers of Missouri that he "disliked to make large statements, but it is no uncommon thing to produce 4000 quarts per acre in the vicinity of Boston." A "wonderful yield" from a field of one and one half acres near Boston, planted with Lady of the Lake and Boston Pine, and trained in hills was reported in $1869:{ }^{1}$ "The yield was 8,500 quarts and the fruit sold either on the spot or in Boston for 30 to 35 cents a quart. The net proceeds exceeded $\$ 2500$. We venture to assert that no field of the same extent in any part of the country has produced like it or realized as much money." What probably is the record in net returns from a single acre was reported in

${ }^{1}$ The Southern Horticulturist, 1869, p. 187. 
1870: “ “A grower near Philadelphia marketed 90 quarts from an acre and realized $\$ 3600$ cash. We believe there is no instance on record of greater profits for a whole acre."

These were very exceptional yields and prices. The average commercial grower, then as now, had to be content with very moderate returns. Between 1865 and 1870 the West Jersey Fruit Growers' Association gathered data on yields and prices in its territory. The summary showed that the average yield was sixty bushels and the average selling price $\$ 3.50$ a bushel. ${ }^{2}$ This is not far from present conditions, either as to yield or price. "The premium crop in Burlington County, N. J. for 1870 was 253 bushels per acre which yielded over $\$ 1000.00$ profit." ${ }_{3}$ The yield of J. M. Smith, Green Bay, Wisconsin, in 1875, long stood as the record under field conditions. He said: "I measured off an exact quarter of an acre of Wilson, picked the fruit by itself, and kept a careful account of the different pickings. The result was 3,571 quarts, or at a rate of $446 \frac{1}{2}$ bushels (14,284 quarts) per acre." 4

Special cultural methods. - Before the extension of railroads and the introduction of refrigerator cars had made it possible to secure early berries from the South, various special methods were used by northern growers to ripen berries ahead of the normal season. In 1724 Steven Switzer wrote that strawberries had been forced in hotbeds by London gardeners for many years. This method was quite common among North American amateurs from 1820 to 1870 . Another popular method was to enclose strong field plants with cold frames in November or

1 The Horticulturist, 1870, p. 183.

2 Rept. Ind. Hort. Soc., 1870.

${ }^{3}$ Ibid., 1874, p. 135.

${ }^{4}$ Rept. Minn. Hort. Soc., 1887, p. 313. 
December and bank up the outside of the frame with soil, leaves or manure. After the plants were frozen they were mulched heavily and the frame covered with boards. In February or March the boards were replaced with hotbed sash and the mulch removed after it had thawed. During severe weather and at night the plants were protected with mats as well as sash; on warm days they were exposed to the air, especially when in blossom, so as to insure pollination. These plants ripened fruit ten to twenty days ahead of adjacent field plants.

The "strawberry mound" was an elaborate scheme for ripening strawberries out of doors a few days ahead of the normal season. As described in 1859 , it was round or oval, usually oval; in which case it was twelve feet wide at the base, and two and one half feet high. ${ }^{1} \quad$ The sides sloped at an angle of forty-five degrees, making the mound two feet wide and six feet long at the top. After it had been shaped the mound was paved, sides and top, with brick, leaving spaces four inches square between each two bricks. These were filled with rich soil and the plants set in them. The berries ripened a week or ten days earlier than on field plants. The strawberry mound may have been "ornamental for the garden," as The Cultivator says, but it certainly required a prodigious amount of labor for a few early berries. About 1860 southern berries began to reach northern markets in considerable quantity and these methods were no longer practicable.

\section{Improvement in Transportation Facilities}

The merit of the Wilson was not the only factor in the remarkable expansion of strawberry growing imme${ }^{1}$ The Cultivator, 1859, p. 304. 
diately following its introduction. The introduction of this variety happened to be coincident with the beginning of an era of unparalleled expansion in all directions, especially in transportation facilities. Railroads began to push across the country. They replaced the market wagon as well as the stage coach. Heretofore the cities had been almost wholly dependent upon the supply of strawberries that could be raised within driving distance. In a few seaboard markets, the local supply had been supplemented with strawberries brought by boat from more distant points. The advantages of water transportation had enabled the Atlantic cities, especially New York and Boston, to reach farther and farther down the coast for strawberries, beginning with New Jersey, passing on to the Chesapeake Bay region, and ending with Charleston and Savannah. Chicago had begun early to depend upon the Benton Harbor boat for a considerable supply. Most markets, however, had been restricted to home-grown berries.

The immediate effect of railroad building was to extend the radius of territory that was available for producing the strawberry supply of a city from several miles to several hundred miles. By 1862 New York City received strawberries from Cincinnati. About 1865 the construction of the Delaware Railroad made the fields of the Delaware-Maryland peninsula accessible to northern markets. The building of the Illinois Central Railroad into southern Illinois, and later to the Gulf States, opened new strawberry-producing territory. Such has been the compelling power of both the metropolis of the East and the metropolis of the West, that a large proportion of the strawberry-producing territory on the continent has developed along parallel lines, - one line extending south- 
ward from New York, down the Atlantic coast to Florida; the other extending southward from Chicago, down the Mississippi Valley to the Gulf. The introduction of the Morse telegraph, in 1835, also was an important factor in the extension of commercial planting; large quantities of fruit as quickly perishable as the strawberry cannot be marketed to advantage on blind consignment.

Competition from the South. - The extension of commercial planting in the South, following the introduction of the Wilson, was even greater than in the North. In the first edition of his "Fruits and Fruit Trees of America," published in 1845, A. J. Downing declared, "The strawberry belongs properly to cold climates, and though well known, is of comparatively little value in the south of Europe." He could not have anticipated the situation today, when nearly 10,000 of the 14,553 carloads marketed in 1914 in car lots came from southern states; and when some of our most productive and profitable plantations are found in the sub-tropical regions of southern Florida and southern California. The strawberry has proved to be the most tractable and adaptable of all fruits. Its low stature enables the northern horticulturist to protect it from extreme cold; while its short season of growth enables the southern horticulturist to grow it in the warmest sub-tropical regions of the continent, since it can complete its growth during the cool season.

Strawberries were grown successfully in the home gardens of the South from the earliest days of white occupation, especially in the vicinity of New Orleans, Charleston, and Augusta. There does not appear to have been any commercial culture of importance until about 1858, when Norfolk berries first reached northern markets in appreciable quantity. Chesapeake Bay and 
Charleston berries came in increasing quantity, and finally forced most northern growers to abandon the cultivation of early varieties and to depend upon midseason and late sorts. In 1869, William Parry of Cinnaminson, New Jersey, who then was reputed the largest strawberry grower in the country, voiced his regret at this situation: ${ }^{1}$ "We heretofore endeavored to get our berries to market as soon as possible, and the earliest varieties were preferred as most profitable; but now we find we must change our course and select the best varieties ripening at a later date, as we cannot compete with the South in early fruits, with which the markets are now well supplied before we commence to send. Our early strawberries the fore part of June scarcely averaged ten cents per quart, which, after paying for picking, freight and commission, leaves but little for the grower; while fine late strawberries were sold in the Philadelphia market on the 19th of June in large quantities at 35-50 cents per quart."

By 1880, when the railroads had begun to pour great quantities of southern berries into northern markets, in addition to those received by boat, many northern growers were ready to abandon the business. In 1881 the Massachusetts Horticultural Society held a special meeting to consider the problem, "How shall southern competition in the small fruit market be met?" Not being able to pass a law which would legislate their competitors out of business, the Society concluded to accept this counsel from Marshall P. Wilder: "Southern competition is not injurious but beneficial. We get strawberries from the South a month or six weeks before they are ripe here. It is an advantage to have these early fruits; they create an appetite for our own when they are ripe. The pro${ }^{1}$ Amer. Jour. Hort., VI (1869), p. 65. 
longing of the season is very desirable." It is doubtful, however, if he would be equally sanguine as to the beneficial effect of this competition now, when southern berries appear on the Boston market in considerable quantity as early as January, and are offered very freely in March and April, two months before local berries are ripe. Probably he would feel that the appetite now is created much too early in the season to last, in full vigor, until the arrival of local berries.

Ventilator cars and fruit-growers' express. - The rapid extension of railroads between 1860 and 1875 stimulated large plantings at great distances from the markets. Many fields were a thousand miles from their market. When shipped by express in open crates, and later in ventilator cars, the berries from these distant points frequently spoiled in transit. Responding to pressure from the shippers, and much against the wishes of express companies, the railroads first attached ventilator cars to certain passenger trains; later they put on special fast fruit trains, operating as nearly as possible on passenger schedule. In 1867 the Illinois Central Railroad put on the first fruit express train for strawberries, operating from Jonesboro and Cobden, in southern Illinois, to Chicago. The ventilator car was provided with springs and an air brake, like a passenger coach. It had many barred openings for ventilation, covered with wire netting to keep out cinders. If the crates were loaded in such a way as to secure a free circulation of air around them, the berries carried as well or better than by express, and the transportation charge was much less. Ventilator cars still are used for markets not over thirty-six hours distant.

One of the most discouraging features of the business at that time was the frequency with which the strawberry 
trains arrived in the market late. The success of the enterprise then, as now, depended upon getting the berries into market in time for the early morning trade. Berries shipped in ventilator cars which arrived late in the morning could not be held in good condition until the market of the following morning. The Horticulturist for 1871 reported: "An hour's difference in the arrival of a fruit train is sufficient to cause a decline in the price of 5 to 10 cents a quart upon all the fruit it carries. Upon one train which was carried over the Delaware Road this spring there were 256,000 quarts. The total loss to the growers by the arrival of this train one hour late was between $\$ 10,000$ and $\$ 20,000$." 1 "The most discouraging period in the history of the berry business that I can recall," says A. W. Slaymaker of Delaware, "was when the report came back regularly, on our biggest days, that the train got in too late for the market. I can only faintly depict the disappointment to hundreds of hard working growers who found their labors all in vain." 2 Between 1870 and 1880 the losses, from shipping long distances in ventilator cars, were very heavy. By 1880 there was a decided decrease in planting at points distant from the large markets, especially in the South; the risks were too great. At this juncture, the refrigerator car came into use, and gave greater security to the business. The railroad, telegraph and refrigerator car are a trio of facilities that have made commercial strawberry-growing continental instead of local.

The introduction of the refrigerator car. - The pioneer in strawberry refrigeration was Parker Earle, of Cobden, Illinois. In the face of the skepticism of growers and the

1 The Horticulturist, 1871, p. 226.

2 Rept. Peninsula Hort. Soc., 1905, p. 68. 
open hostility of railroads and express companies, he continued his experiments until they were successful, and paved the way for the great refrigerator interests of today. The story of these early struggles has been told by him ${ }^{1}$

"I think it was in 1868 that I built the first twelve refrigerator chests for shipping strawberries. I sent them to Chicago, Pittsburg, New York, Memphis and New Orleans, by express. When the express companies followed instructions and re-iced the berries they carried quite well. They held 200 quart baskets each and 100 pounds of ice. The express rates were so high and the neglect of re-icing so frequent that I had to give it up. Similar chests, only larger, were used from Charleston to New York by steamship lines at about the same time. It was later that the small pony refrigerator boxes began to be used from Florida. My boxes weighed 600 pounds when loaded; these pony boxes weighed about a hundred pounds.

"The first attempt at carrying carloads of strawberries under refrigeration was made by Mr. Davis, of Detroit, about 1868 . He came to Cobden with a car that was made for refrigerating beef and fish. It contained a vertical cylinder in each corner, about fifteen inches in diameter, and was iced from the top of the car, using salt with the ice. The consequence was the freezing of a part of the berries while the balance of the load was very unequally cooled. The result was a loss which did not invite a repetition of the venture.

"The experiment interested me greatly, and I thought I saw why it failed, - that the refrigeration was very unequal and, in parts, very excessive. The following year (1869) I got a car from the Michigan Central Railway that was being built to carry dairy products. It was loaded

${ }^{1}$ Yearbook, U. S. Dept. of Agriculture, 1900, pp. 444-5. 
with berries by an association of growers at Cobden. It held about a ton of ice in each end. I went ahead to Detroit to make sure of a market, and the car was loaded by the growers. With this half charge of ice it might have gone through in fair condition, but for the misfortune that some wise railroad man took out the plugs from the ice boxes in the roof to give the berries ' $a$ chance for a little air,' and left them out. Of course, the ice was melted in a day and the bulk of the cargo was ruined.

"This discouraged community efforts in this line at that time. I, however, began experimenting with our own berries by building a cooling box in our packing shed at Anna, Illinois, and holding the berries in it for twenty-four hours to cool off, and then sending them by express. It was found that those so cooled went into Chicago in better condition than those freshly picked from the field, although they were one day older. Repeated experiments seemed to establish this fact.

"This decided my plans. I went to Chicago and engaged the best refrigerator car then made - the old Tiffany patent, with a V-shaped ice box suspended from the roof and running the full length of the car. The utmost capacity of this ice pan was $1 \frac{1}{2}$ tons. I knew well that this quantity could not both cool off a load of berries and keep it cool for two or three days, so I built a cooling house at Anna large enough to hold ten tons of strawberries, and I cooled the load down for a day in that house, then transferred it to the Tiffany car. The berries went into the car at about fifty degrees $\mathrm{F}$. The result was a complete success from the start. No such solid, goodkeeping berries had ever been seen in Chicago. I enlarged this cooling house at Anna, built one at Villa Ridge, and another at Cobden. For several years we handled our 
own berries and other fruits, and much that we bought, with very good success. I think this first successful car was sent out in 1872 .

"But I was never satisfied with these cars built for the dairy product industry, which only carried about $1 \frac{1}{2}$ tons of ice. I wanted a car that could hold five tons in its boxes (a cooling house on wheels), in which the fruit could be placed as packed with the certainty that it would cool in transit and be safe for at least a three-day trip. After much canvassing among car builders, I finally secured a well-insulated car with this ice capacity. From this time forward the evolution in transportation methods was accomplished."

Railroads now began to build and operate refrigerator cars. These were used for several years with varying success, the chief difficulties being that the cars had a limited ice capacity and that there was no well-developed system for re-icing them en route. According to The American Garden, for 1885, "The experiment of shipping strawberries from Tennessee to New York in refrigerator cars, which was tried this year for the first time, did not prove a success. The transit required four days, and many of the berries were badly decayed." At this time the outlook was not encouraging. Refrigerator cars were satisfactory, if re-iced when necessary, but the shipper had no assurance that this would be done.

At this juncture F. A. Thomas, of Chicago, joined Parker Earle and proposed a plan that put the business on a substantial basis. As related by W. A. Taylor: ${ }^{1}$ "His plan was to provide a through service from shipping point to destination in special cars under one management, re-icing the cars in transit as found necessary. It was, in short,

${ }^{1}$ Yearbook, U. S. Dept. Agr., 1900, p. 445. 
the establishment of a private car line for fruit transportation, to be operated on a plan similar to that under which sleeping cars had long been run in the passenger service. He commenced operations with a few cars in western Tennessee in the spring of 1887, operating first on strawberries destined for the Chicago market. Owing to the distrust of shippers in regard to the effect of ice upon the fruit, he was compelled to buy fruit with which to fill the cars for shipment. A few tests demonstrated the practicability of the system, however, and the new service rapidly became popular. In the spring of $1888 \mathrm{Mr}$. Thomas shipped strawberries from Florida to New York successfully in refrigerator cars."

After this the development of refrigerator service was rapid. From a beginning of six cars in 1887, sixty were operated in 1888, 600 in 1891, and over 60,000 in 1901 . The business has been taken up by many private lines and railroads. The cars travel over the different railroads, as needed, being used first in Florida and Texas, then in Mississippi and Louisiana, and gradually working northward as the season advances. Icing stations are placed at intervals along the main routes of travel. Berries are shipped 1000 to 3000 miles and arrive in excellent condition.

More than half of the strawberries marketed in North America today are raised so far from the markets that they require refrigeration. Rapid transportation alone failed to carry this fruit to market in good condition. Without refrigerator cars the great strawberry industry of the southern states would be extremely hazardous, if not impossible. C. M. Hovey, who has been called the "father of American strawberry culture," won his claim to recognition by a lucky chance. We are under far greater obligation to 
Parker Earle, who worked on his plans for years, in spite of skepticism and under the discouragement of many

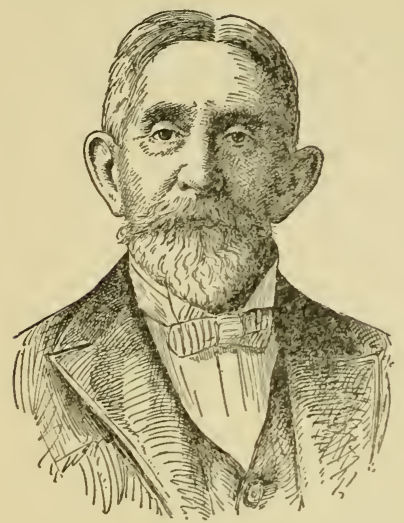

Fig. 4. - Parker Earle, who developed the refrigerator car for strawberry transportation. failures. $\mathrm{He}$ is one of the foremost of those whose skill and patience have made possible the strawberry industry of today. Parker Earle died at Los Angeles, California, February 12, 1917.

\section{Early History of Certain of the Older Straw- BERRY Districts}

The main factors in the rise of commercial strawberry growing have been considered in the foregoing paragraphs. It now remains to trace in greater detail the origin and growth of the industry in different parts of the United States and Canada, since the introduction of the Wilson. ${ }^{1}$ The districts are discussed somewhat in the order of their development.

New Jersey. - The largest extension of strawberry planting immediately after the introduction of the Wilson was in New Jersey and the Delaware-Maryland peninsula, to supply the New York market. For many years Bergen County, New Jersey, had been supplying the city with Crimson Cone berries, grown under neglectful culture, approaching the wild fruit. Northern New Jersey was the first section to feel the stimulus of the increasing demand.

${ }^{1}$ The present commercial importance of various strawberry districts is given in the Appendix of "Strawberry-Growing." 
The expansion of the industry in New Jersey between 1854 and 1865 was remarkable. In 1854 less than 50,000 bushels of strawberries were marketed in the entire country, and the supply of New York was less than 6000 bushels. By 1861 New York alone received 50,000 bushels. In that year the New York Times made this statement:

"The strawberry trade of New York is the largest of any one point in the world. It is estimated that 50,000 bushels are sold annually in New York, while about 12,000 bushels are sold in Philadelphia, 12,000 in Cincinnati, and 10,000 in Boston. During one week last season 400,000 baskets were received daily in New York. From one point in New Jersey, twenty-five miles distant from the city, there were received by steamboat in a single day 200,000 baskets. New York City received last year from all sources not less than $8,000,000$ baskets of strawberries. The value of these, at the wholesale price of two and a half cents the basket, was $\$ 200,000$, for which the consumers probably paid double that sum. About 1500 acres of choice land in the vicinity of New York are required to supply this market with strawberries. Some farmers cultivate 30 to 50 acres." These baskets, it should be remembered, held only about a third of a quart. The same year, Pardee estimated that the sales in these four cities amounted to 93,000 bushels.

During the next few years the strawberry area increased, but gradually moved to the southern part of the state. Between 1860 and 1868 Burlington County had a larger acreage than any other county in the country. "In the immediate vicinity of Moorestown, New Jersey, there were grown in 1862 more than 6000 bushels of strawberries, which at the moderate rate of $\$ 3.50$ per bushel, produced a return to the farmers of that vicinity of at 
least $\$ 20,000 . " 1$ The same year the West Jersey Fruit Growers' Association delegated a committee to collect information concerning the extent and condition of the strawberry industry in that county. Compiling the results of a canvas, the committee reported: "In the six townships - Burlington, Beverly, Chester, Cinnaminson, Evesham and Newton - there were 520 acres of strawberries in bearing last season, yielding in all 29,030 bushels of fruit, worth in the market $\$ 133,737.41$. The average yield per acre was $55 \frac{1}{2}$ bushels, and the average price per bushel, \$4.60." In 1867 there were 1000 acres in the vicinity of Hammondton alone, chiefly Wilson and Triomphe.

The Delaware-Maryland peninsula. - The construction of the Delaware Railroad opened a new and fertile field. The story of the beginning of a big industry in a little state is told by A. W. Slaymaker, of Wyoming, Delaware: ${ }^{2}$ "The first attempts at berry growing in Delaware came with the northern settlers who located in middle Delaware at the close of the war. The business went up with a whoop. One of the first, if not the first, grower for market in the state was located at Milford, - Mr. Jester, who, in 1865, or 1866, shipped berries in thirty-six quart crates that brought $\$ 36$ per crate for eight crates in one shipment, in the New York market. A few years later, about 1870, Mr. E. H. Bancroft, of Camden, picked 4000 quarts from an acre of Wilsons grown in hills. Others began business about then near Smyrna, Felton, Bridgeville, Wyoming and Milford. Pickers soon became scarce, and the market much lower in price."

The planting soon extended down the peninsula into

${ }_{1}^{1}$ U. S. Agr., Rept., 1865, p. 282.

2 Rept. Peninsula Hort. Soc., 1905, p. 66. 
Maryland. Market reports prove that "the business went up with a whoop." There were 2,000,000 quarts of strawberries shipped over the Delaware Railroad in 1869. ${ }^{1}$ In 1871, according to A. M. Purdy's Small Fruit Recorder, 3,200,000 quarts were shipped north from New Jersey, Delaware and Maryland. The Horticulturist reports: "In 1871 the Delaware Railroad brought in $3,000,000$ quarts of strawberries to New York. Add to this about 2,000,000 from New Jersey and the neighborhood of New York." 2 In 1873 this magazine conceded: "The state of Delaware is the largest fruit state on the Atlantic Coast. Its strawberry crop of 1873 was over $3,000,000$ quarts." In 1874 the shipments from the peninsula aggregated 665 cars, or 5,280,000 quarts.

By this time the reaction had set in; 1874 was a year of poor profits or heavy losses for almost every grower. The set-back was only temporary, however. In 1888, according to William Parry, "The Delaware Railroad carried, from May 6th to June 13th, 637 carloads, a total of 5,096,000 quarts, or 159,250 bushels; of which there were destined for Philadelphia 44,250 bushels, New York 109,250 bushels, Boston 5,500 bushels, and large quantities passing on to Buffalo and other northern cities." Between 1888 to 1900 the increase in planting was marked.

Oswego County, New York. - Contemporaneous with the rise of strawberry culture in New Jersey, another important producing center was developing in western New York. The vicinity of Rochester had been noted for its berries since 1835. Large Early Scarlet was the most popular variety until 1858, when the Wilson supplanted it. Oswego County, on the south-east shore of Lake Ontario,

${ }^{1}$ Country Gentleman, 1870, p. 6.

2 The Horticulturist, 1871, p. 226. 
now began to realize that it had peculiar advantages for the production of late strawberries. As recalled by D. T. McInery, the industry began in 1863, when Morris Pierce brought a few quarts of strawberries to Oswego, where they were gazed at as a curiosity, and sold for one cent a berry. ${ }^{1}$ The first shipments were made in 1866 , by boat to Watertown and Syracuse. In 1872 Oswego berries were first expressed to New York, the charge being $\$ 1.00$ a forty-five quart crate; in 1873 the first strawberry train was started. By 1883 the movement amounted to 3000 crates, mostly to New York and Philadelphia, and the boom days of the Oswego berry industry had begun. Very high prices often were obtained for Oswego Atlantics, $\$ 7.00$ to $\$ 9.00$ a crate were not uncommon. The acreage increased rapidly until 1898; the output was 22,000 thirty-six quart crates in 1896 and 52,263 crates - nearly $2,000,000$ quarts - in 1898, when over 1000 acres were cultivated. This was the high-water mark; the industry declined rapidly after 1898 .

Michigan. - The most important extension of commercial strawberry growing in the central states, after the introduction of the Wilson, was stimulated by the demands of the lusty young giant on the shore of Lake Michigan. Growing with amazing rapidity, Chicago soon laid a wide territory under tribute. The warm soils and climatic advantages of the Lake Michigan shore "Fruit Belt" in south-western Michigan, and the ease with which it could be reached by boat, soon gave this region preëminence in the culture of peaches and strawberries for the Chicago market. The strawberry industry of Michigan began near Benton Harbor and St. Joseph, Berrien County. In 1861 T. W. Dunham, David Brown and several other pioneer ${ }^{1}$ Bul. 189, N. Y. (Cornell) Exp. Sta. (1901), p. 135. 
fruit growers of that neighborhood planted small fields of Wilson. ${ }^{1}$ The results were so encouraging that by 1865 there was a considerable acreage, and it was reported: "The average yield per acre was about 70 bushels, for which the growers received $\$ 5.00$ per bushel nett, that is, after deducting freight to Chicago, commission, etc., making the snug little profit of $\$ 350$ per acre." 2 Steamers left Benton Harbor about nine o'clock at night, reaching Chicago before daylight, delivering the fruit "fresh and unbruised, having suffered no jolts, as would be the case had it been shipped by the railroad." According to the $S t$. Joseph Herald for 1871, 30,000 bushels had been shipped to Chicago that year up to June 15 and the average price was $\$ 3.00$ a bushel. The total movement from St. Joseph in 1782 was 24,878 bushels, with an average net return of twelve cents per quart. ${ }^{3}$ By 1877 Berrien County shipped to Chicago 128,840 one-half bushel crates, while large quantities were marketed elsewhere by rail. ${ }^{4}$ This county has maintained its prominence in strawberry production.

Illinois. - An important strawberry territory along the line of the Illinois Central Railroad came to the front at about the same time as Berrien County, Michigan. B. F. Smith, then a baggage-man on this railroad, tells of these early days: "It was about the third of May, 1860 , that I received into the baggage car of the Illinois Central Railroad the first package of strawberries that was raised in southern Illinois for the Chicago market. It consisted of a small, flat-goods box that held from two ${ }^{1}$ Rept. Mich. State Bd. Agr., 1879, p. 129; also Proc. Mich. Hort. Soc. 1888, p. 16.

2 The Cultivator, 1865, p. 271.

3 The Horticulturist, 1872, p. 58.

${ }^{4}$ Proc. Amer. Pom. Soc., 1879, p. 109. 
to three gallons of berries - the largest quantity of strawberries I had ever seen up to that time. They were grown at Ullin station, twenty miles north of Cairo. They were the commencement of the immense trade that has since grown up along the line of the Illinois Central Railroad in southern Illinois. In 1861 Jonesboro and Cobden shipped a few packages daily, and in 1862-3 as many as 100 to 200 crates were shipped daily from Cobden and Jonesboro, the first berries to reach Chicago bringing about $\$ 1.00$ a quart. In $1864-5$ the business had grown so large that we attached to our train from two to three extra cars daily." 1

The Horticulturist for 1862 takes notice of the development of "quite a strawberry trade in 'Egypt' (Union County, southern Illinois) for the Chicago market," and states, "The fruit is shipped in round, quart boxes, the average net price being 20 cents per quart. The express charge is $\$ 1.00$ per hundred pounds." ${ }^{2}$ In 1867 there were 400 acres at Cobden and the Illinois Central put on a through strawberry train, the "Thunderbolt Express," running to Chicago on passenger train schedule. ${ }^{3}$ In 1869, Chicago received 800 bushels a day from this district at the height of the season, and by 1872, "Stations on the Illinois Central already ship their 10,000 bushels annually." In 1886, the strawberry train of the Illinois Central consisted of "thirty refrigerator cars per day, twenty-two of which go to commission men of Chicago whose 800,000 inhabitants consume 435,800 quarts a day." 4

${ }^{1}$ Rept. Mo. State Hort. Soc., 1879; also Rept. Ark. Hort. Soc., 1894, p. 30.

${ }^{2}$ The Horticulturist, 1862, p. 351.

${ }^{3}$ Country Gentleman, 1867, p. 189.

'Gardeners', Monthly, 1886, p. 302. 
Virginia. - The earliest commercial strawberry growing in the South was in the Chesapeake Bay region, about 1854, and was coincident with the beginning of trucking. The warm soils, equable climate and early season of that region, due in part to the proximity of the Gulf Stream, made it peculiarly adapted to the culture of early vegetables for northern markets; while the broken coast line made it easily accessible to water transportation, there being no railroads in that region then. Before 1850 small quantities of truck, including a few strawberries, were sent to Baltimore and Philadelphia in oyster boats. In 1854 the steamer Roanoke carried the first shipment of truck from Norfolk to New York. The boats then in use carried 400 to 600 packages, all on the deck and without refrigeration; the trip took thirty-six hours. Now, the steamers of the Old Dominion Line carry 25,000 packages; refrigeration and forced ventilation permit loading between decks, and the trip is made in nineteen hours. The strawberries in these early shipments often reached New York and Boston in poor condition. At that time, Norfolk berries were first on the market, and frequently sold for fifty cents to a dollar a quart.

The growing of strawberries and truck for northern markets, as an exclusive business and not as a side line, began near Norfolk about 1858. By 1861 the strawberry industry had begun to attain considerable prominence, then the Civil War shut off all communication between the trucker and his markets. At the close of the war the industry immediately revived. The Horticulturist for 1866 notes, "Norfolk sent 100 crates of strawberries a week, for three weeks, to New York, by boat." The superior value of the Wilson for this purpose was quickly established; it was an extra good shipping variety and 
reasonably early. In 1869 a committee of the Norfolk Horticultural Society reported that $3,000,000$ quarts of strawberries were shipped from that port, two thirds or three fifths of them being Wilson. ${ }^{1}$ In 1871, Norfolk "shipped 2,000,000 baskets of strawberries, two thirds of which are Wilson's Albany;" ${ }_{2}$ and The Horticulturist added, "Now Norfolk sends 10,000 crates a week by water, and 3000 a week by car, the fruit selling in New York for about 20 cents a quart." ${ }^{3}$ Those were golden days for the Norfolk trucker. According to Purdy's Small Fruit Recorder for 1871, "One man in Southampton county sold $\$ 10,000$ worth of strawberries off of ten acres, the buyer furnishing the baskets" ; the price was "only 25 to 30 cents per quart." If correctly quoted, this man probably holds the record of profits from a field of this size.

After the Civil War the size of individual holdings increased very rapidly. Before then the largest field grown by one man did not exceed sixty acres; the big fields were mostly in Anne Arundel County, Md. The difficulty of securing pickers made it impracticable to cultivate a greater acreage. At the close of the war many negroes were no longer restricted to one plantation, but were driven to the necessity, or opportunity, of seeking work where it might be found. Berry picking offered an inviting field; the hours were short, the pay good, and the opportunity for amusement unlimited. To a great army of this floating labor, berry picking was a picnic, eagerly anticipated and enthusiastically enjoyed. The great berry and truck industry of Norfolk and other parts of the South would not have been possible without free labor

1 Proc. Amer. Pom. Soc., 1869, p. 139.

${ }^{2}$ Ibid., 1871, p. 61. ${ }^{3}$ The Horticulturist, 1871, p. 259. 
which could be secured in large quantity at certain times of the year.

The increase in the supply of available labor immediately affected the size of the berry fields. In 1871 it was stated: " "Strawberries are grown around Norfolk on an extensive scale. A Mr. Anderson has fifty acres in strawberries and is planting much more. He expects to employ from 600 to 800 pickers. He is the largest cultivator, but there are about a hundred others whose operations are nearly as extensive." In 1879 J. R. Young, Jr., of Norfolk, was said to be the largest strawberry grower in the world. A current magazine stated: "He now has 225 acres planted and expects to have 440 acres. He employs in the neighborhood of a thousand hands." 2 These very large plantings were not generally as profitable as smaller areas cultivated more intensively.

South Carolina. - Charleston was a center of amateur interest in strawberry culture long before they were grown at Norfolk; the Charleston Horticultural Society had able discussions on the subject in 1836. There was no commercial interest at that point until about 1868 save for the very limited quantity grown for the home market. Beginning about 1856, truck crops were shipped from Charleston to northern cities. There is no record of strawberry shipments until 1871, when The Horticulturist observed, ${ }^{3}$ "On April 10th, 560 packages of strawberries were received in New York by the Charleston steamer," which indicates that the industry then must have been of several years' standing. The Gardeners' Monthly for 1875 says strawberries were a "drug on the market at

1 Amer. Journ. Hort., IX (1871), p. 148.

2 Proc. Columbus Hort. Soc., 1886.

The Horticulturist, 1871, p. 258. 
Charleston, though but eighty acres are grown. Neunan, a local seedling, is the chief variety." ${ }^{1}$ Two years later the Country Gentleman reported, " 30,000 quarts of strawberries were shipped from Charleston by steamer in one day." Oemler states that the Charleston crop for 1879 was 734,093 quarts. In 1888 the crop of Charleston berries was estimated at 800,000 quarts, valued at $\$ 80,000{ }^{3}$

The industry never attained as much prominence at Charleston as at Norfolk, and soon declined, doubtless because of recurring experiences like that described by A. Oemler, in $1885:{ }^{4}$ "The strawberry crop came so late into the market, in consequence of the frequent severe spring frosts, that Charleston berries were crowded out by arrivals from Norfolk, leaving thousands of quarts to rot unpicked in the fields, otherwise the shipments would have reached 1,200,000 quarts." The Charleston district was literally forced out of the market by its competitors, northern Florida, North Carolina and Norfolk.

Florida. - Commercial strawberry-growing in Florida for northern markets began in Bradford and Duval Counties about 1878. Before then it would have been regarded as folly to grow strawberries commercially in Florida, not only because transportation was lacking, but also because it was believed that this fruit could not be grown successfully in that climate. Water transportation being impracticable under the conditions prevailing then, nothing was done until the railroads came. In 1881, "Florida strawberries were in the Philadelphia market the middle of March, having been three days on the

1 Gardeners' Monthly, 1875. p. 304.

${ }^{2}$ Country Gentleman, 1877, p. 365.

3 Proc. Amer. Pom. Soc., 1889, p. 140.

${ }^{4}$ Rept. U. S. Com. of Agr., 1885, p. 611. 
railroad, and sold at 25 cents a quart. They were two weeks later this year than last." 1

There long had been a limited demand in New York and other northern cities for winter berries. Heretofore the demand had been met with forced fruit, which retailed at $\$ 3.50$ to $\$ 5.00$ a quart. The first Florida berries, mostly Wilsons, were shipped in open crates by express and sold for fifty cents to $\$ 1.00$ a quart. The express charges to New York then were fifteen cents a quart. The disastrous freeze of 1886 , which practically destroyed orange groves in northern Florida, stimulated interest in strawberry-growing in that part of the state. In 1888 Stephen Powers estimated the output from Florida at 20,000 bushels, of which Bradford county supplied 5000 bushels. Gainesville, Stark and Lawtry were the principal shipping points. Florida sent the first refrigerator car of strawberries to the North in 1889. About the same time refrigerator cases came into common use for the small express shipments early in the season. The introduction of refrigeration greatly stimulated the Florida industry, as there had been frequent losses hitherto from berries that spoiled on the way to market.

Some remarkable profits were made in those days. "Net profits of $\$ 400$ an acre were considered only average," Helen Harcourt stated in 1886 . "From $\$ 1000$ to $\$ 2000$ an acre are not infrequently made, and sometimes more." 2 She puts on record what is probably the largest profit ever made from an equal quantity of field-grown berries. "A shipment of 1050 quarts of strawberries from Jacksonville to New York in a refrigerator car gave a return of $\$ 2630$, being sold at $\$ 2.50$ per quart. The expense of picking

${ }^{1}$ Gardeners' Monthly, 1881, p. 151.

2 “Florida Fruits" (1886), pp. 187-98. 
and shipping was $\$ 283$, leaving a clear profit of $\$ 2346$.” Until the great freeze of December, 1894, and February, 1895, practically all Florida berries were grown in the northern part of the state and were marketed in March and April. The district in southern Florida, comprising Hillsboro and Polk Counties, which now ships from December to March, has developed since 1896.

North Carolina. - The important strawberry district of the coastal plain of North Carolina, centering at Mt. Tabor, Mt. Olive and Chadbourn, did not begin to develop until about 1890. It had been noticed for some years that there was a break between the Charleston and Norfolk berries, when the market was but scantily supplied. The North Carolina district was developed to fill this gap ; but, in doing this, it crowded Charleston berries off the market.

No strawberry district, with the exception of the Delaware-Maryland peninsula, had a more remarkable growth during its early years. In 1897 Chadbourn shipped 632 quart crates; in 1898, 6000 crates; in 1906, 317,000 crates, or 1623 cars. It was reported that 226 cars moved from the district on May 5, 1906, and more than 3000 cars that year, all in a rushing season of three weeks, two weeks shorter than the normal. ${ }^{1}$ Over 10,000 people took part in that great harvest. The North Carolina district led the world in strawberry production that year. This was the crest of the wave. The business had grown faster than the railroads and refrigerator car service could keep pace. Thousands of bushels were left to rot in the fields or at the depots, because there were no cars. In most cases the railroads paid damages, but this was not sufficient to cover the loss to the growers. Another discouraging factor was the difficulty of securing enough pickers to har-

1 Wilmington Messenger, May 6, 1906. 
vest this very large crop during such a short period. Beginning about 1906, the acreage of strawberries in the South generally, and in North Carolina especially, decreased considerably.

The Gulf States and the lower Mississippi Valley. - The market gardens of Mobile and New Orleans were famous long before the coming of the railroads made it possible to exchange their products for northern gold. The close of the Civil War ushered in a period of railroad building that opened new channels of trade between the North and South. "On April 21, 1868, a carload of vegetables, including sixty-four quarts of strawberries, were shipped from Mobile to Chicago." 1 Mobile continued to ship a few strawberries to the North for many years, mostly by express, but the industry did not become prominent in Alabama until after 1900 . The first carload shipment was in 1902, by the Castleberry Fruit Growers' Association of Conecuh County.

Although far south, Mississippi is a congenial home for the wild strawberry. "Pioneers of Mississippi," says W. H. McKay, "tell of the luxuriant and delicious wild strawberries of by-gone years; how they were accustomed to have great water buckets full brought in from the fields and prairies." Various points in Mississippi began to ship strawberries to Chicago about 1870, mainly along the line of the Illinois Central Railroad. By 1879 there were seventy-five acres at Madison, and about 500 acres altogether along the N. O. \& St. L. R. R. ${ }^{2}$ J. F.' Merry, of the Illinois Central Railroad, gives the following bit of history concerning the development of the strawberry industry of Louisiana: "The first shipment of straw-

1 Country Gentleman, 1868, p. 349.

2 Proc. Amer. Pom. Soc., 1879, p. 130. 
berries from Independence, Louisiana, was made in 1879, and consisted of sixteen crates shipped to Chicago by American express. The first carload shipment from south of the Ohio River was made by the Illinois Central from Greenfield, Weakley County, Tennessee to Chicago, in 1881." Strawberry-growing began at Memphis, Bartlett, Gadsden and Milan, Tennessee, about 1870, and a few years later at Columbus, Kentucky. Weakley and Gibson counties were the first centers of production in West Tennessee. The East Tennessee or Chattanooga district, comprising mainly Hamilton, Rhea and Knox counties, has developed since 1880, when J. B. Howell made the first shipment from his farm near Chattanooga.

The completion of the Iron Mountain and Southern Railroad across the state of Arkansas to Texarkana, about 1873 , soon was followed by strawberry planting at Judsonia and Beebe, White County. The strawberry district in the Ozark region of southwest Missouri and northwest Arkansas has developed since 1890. In 1883 John Carnahan planted the first strawberries at Sarcoxie, Missouri ; this was the first point to ship in car-lots. ${ }^{1}$

Pacific coast. - Strawberry growing first began to assume commercial importance on the Pacific coast about 1865, in the vicinity of San Francisco. In 1870 it was reported, "The San Francisco market received, about the first of May, $6000 \mathrm{lbs}$. of strawberries daily, and they sold at 10 to 15 cents per pound." 2 The Florin district, near Sacramento, and the Los Angeles district began to develop about 1885 .

Hood River, Oregon, was the first point in the Pacific Northwest to ship strawberries in car-lots. "In the fall

1 Rept. Mo. Hort. Soc., 1897, p. 227.

2 Jour. Hort., VII (1870), p. 354. 
of 1883 Hon. T. R. Coon, now of Lyle, Washington, came to Hood River to seek rural pursuits, and he immediately secured and planted several varieties of strawberries for the purpose of experimentation. Clark's Early was among those selected, and proved to be the only one of promise. In $1884 \mathrm{Mr}$. Coon sent a crate (24 lb.) of this variety to the Portland market and received in return $\$ 9.00$, and an inquiry for more of the same kind. The year following he began shipping them into Montana." 1

Canada. - Commercial strawberry growing in Canada began in Nova Scotia and Ontario about 1860. For several years before 1870 , late berries were shipped by boat from the Cornwallis and Annapolis valleys, Nova Scotia, to Boston. A little later, Prince Edward Island, where the normal ripening season is late July or early August, responded to the demand of Boston for late berries. The strawberry industry of Ontario began to assume commercial importance about 1865 . According to A. W. Peart, in 1860 there were only about fifty acres of all kinds of small fruits in the province; the largest acreage was in Burlington district. ${ }^{2}$ In 1869 Thomas Chisholm of Esquesing, Hilton County, reported to the Fruit Growers' Association that there were sixty acres of strawberries in bearing near Oakville and that the prospects for good prices were so bright that the planting had been increased to two hundred acres. "In one day," said he, "four hundred bushels were shipped to Toronto and Montreal. Wilson is the favorite variety." From 1879 to 1889 prices were good and the acreage increased rapidly, but the next ten years were discouraging, due largely to a wide-spread trade depression. Since 1900 the industry has prospered.

1 Rept. Ore. State Hort. Soc., 1907, p. 220.

${ }^{2}$ Rept. Ont. Fr. Gr. Assoc., 1909, p. 20. 


\section{CHAPTER III}

\section{HISTORY OF STRAWBERRY PACKAGES, METHODS OF TRAINING, AND POLLINATION}

THE packages used for shipping strawberries to market have changed with the generations to meet new conditions as they have arisen. The evolution of the modern, cheap, gift package from the clumsy and expensive return package of earlier days has reflected the rapid development of the industry.

\section{EARLy PACKages}

At the beginning of commercial strawberry culture in North America, about 1820, it was natural that the packages should be those approved by English gardeners. In 1821 Massachusetts strawberry growers were advised to carry berries to the Boston markets in "pottles, that is, in inverted cones of basket work." 1 The pottle used in England and Scotland at that time contained "nominally, one Scotch pint. These are packed one above another in square hampers and are conveyed to the market on a light carriage or frame work hung on springs. Near London it is customary to pack fifty or sixty of these pottle baskets in a large basket, which is then ${ }^{1}$ Memoirs Mass. Agr. Soc., VI (1821). 
placed upon a woman's head, on a small cushion. She trudges miles with it to market." 1

Another type of splint basket, called a punnet, was used in the strawberry trade of New York City between 1815 and 1850. The English punnet used in America was a shallow basket of woven wickerwork without handles (Fig. 5). A handled punnet was more popular in the New York market. C. W. Idell relates: ${ }^{2}$ "The first strawberries marketed in New York were wild ones from Bergen County, N. J. The negroes were the first to pick this fruit for the New York market and invented those quaint old-fashioned splint baskets with handles. The baskets were strung

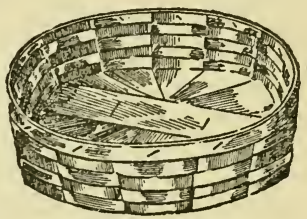

FIG. 5.- Type of punnet used for the New York City market, 1815-1850. on poles and thus peddled through the city." Originally the punnets were supposed to hold about a pint each, but eventually they became very uncertain as to size; many held less than half a pint.

About 1820, commercial strawberry growing for the New York market began in the vicinity of Hackensack, New Jersey. The berries were packed in punnets without handles; these were packed in large hampers. They were returned to the shipper when emptied. The problem of standardizing the cubic contents of fruit packages is not modern, as is evident from a market report of $1847:^{3}$ "The milk train of Tuesday night took to New York 80,000 baskets of strawberries. These are intended to

1 Trans. Hort. Soc. of London, VI (1826), p. 513; also The Cultivator, 1835 , p. 81.

2 Proc. N. J. Hort. Soc., 1877, p. 26.

${ }^{3}$ American Agriculturist, 1847, p. 260. 
contain one pint each; but say that three baskets contained one quart, which is quite within bounds." Punnets and pottles found little favor except in the vicinity of Boston and New York and were soon discarded for more convenient and less expensive packages.

From these very small receptacles the practice in some places swung to the opposite extreme of large tubs and drawers. In 1854 Robert Buist protested: "The present mode is disgusting in the extreme; large tub fulls, bruised and crushed, spooned into quart measure from vessels of very questionable character in both color and appearance. The denizens carrying home their quantum of mashed matter under the name of strawberries can know little, from such a mixture, of the delicious aroma and rich flavor of the pure fruit." 1

The Cincinnati stand of drawers. - "About 1848," says J. M. Smith, "such strawberries as were grown for market were first hulled and then sold by the quart or peck, dry measure, as needed." This practice was more common in the upper Mississippi Valley than in the East. There, the Cincinnati tray or stand of drawers, became the standard package, especially in Ohio, Illinois, Indiana and Missouri. The trays or drawers were made in various sizes. One of the first in use by Cincinnati growers was described by Charles Cist, in 1848, as "cases or stands of five to eight drawers, each drawer containing from 30 to 40 quarts, which lie an average depth of two or two and one half inches." 2 About 1864, the stand commonly used was two feet long, twenty inches wide, and held five drawers two inches deep, each holding one half bushel (Fig. 6). The bottom boards were one quarter inch

1 "Family Kitchen Gardener," p. 216.

2 U. S. Patent Office Report, 1848, p. 610. 
apart for ventilation. This stand cost about \$1.50. Only the top drawer of the stand was provided with a cover.

A little later a stand containing four drawers, each holding about sixteen quarts dry measure, was preferred. This remained the most popular type until about 1900, when all stands were discarded. This type of stand was described by A. M. Purdy in 1871: ${ }^{1}$ "The trays are three inches deep, sixteen inches wide, twenty-four inches long, inside measurement. The sides and ends are one half inch thick, the bottom one quarter inch thick, except the lower drawer, the bottom of which is one half inch thick. The end pieces pass by the sides one half inch. The posts, which are one inch by two and one half inches, are nailed strongly to each corner of the lower drawer, so that the other three slip inside of the post. The posts are then cut off even

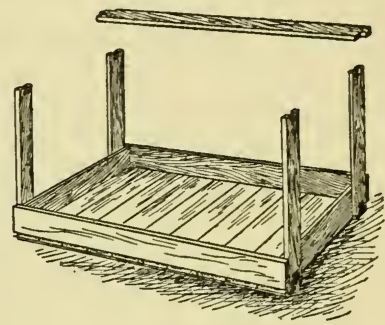

with the top of the cover. The cover is made of one half inch stuff fastened together by two pieces, one inch by two and one half inches. These pieces fit over the top of the posts, coming just to the outside. They are fastened on one side with light hinges and on the other by light pieces of hoop iron, six inches long, which are nailed on top of the top pieces, bent over and fastened to the posts by screws." When retailed, the berries were

${ }^{1}$ Small Fruit Recorder, 1871, p. 82. 
scooped into quart measures and the empty stands were returned to the shipper.

The Cincinnati stand was a fairly satisfactory package for berries shipped to near markets; it was cheap and easily handled, but there were too many berries in one package to make it serviceable for distant shipment. The fruit reached the market soft and settled; a shrinkage of 10 to 30 per cent was not uncommon. This led to the substitution of boxes in crates for distant shipments; for near markets, stands were used more or less until about 1900. In 1895 the stand of four one-half-bushel drawers was still in common use in Ohio. It cost forty cents new, but good second hand stands could be bought for fifteen to twenty cents.

The retail dealer preferred trays or drawers to boxes, because they "held out better." Usually the grower did not measure the berries into the drawer, but picked them in large baskets and poured them into the drawer until it was level full. Frequently the retailers were able to sell eighteen to twenty quarts from each half bushel drawer; they claimed that the buyer liked to see the berries measured out. According to W. W. Farmsworth of Ohio, "They buy by dry measure and sell by wine measure, and make a dollar a bushel by that operation. Many markets, however, prefer the Cincinnati stand as it gives the grocer a chance to do his own measuring and sell his thumb thirty-two times to the bushel at ten cents a quart and still have it left." 1 We are no longer privileged to observe this sleight-of-hand feat with strawberries, but modern substitutes are equally interesting. About 1885 many growers who used stands sold them with the berries, agreeing to buy them back again ${ }^{1}$ Rept. Ohio Hort. Soc., 1886-7, p. 55. 
at a fixed price, usually fifteen cents each. This modification of the gift package idea saved considerable bookkeeping. The modern counterpart of the Cincinnati stand is the chest of drawers used in California extensively.

\section{Evolution of the Box and Crate Package}

Thin wooden boxes have been used somewhat from the beginning of commercial strawberry culture in North America. In 1837, boxes of strawberries holding about a quart were quoted on the Boston market. "In 1848," said Charles Cist, "a considerable share of the strawberries marketed at Cincinnati were sold in tin boxes of a quart each or wooden ones of two quarts each. These usually command a better price, not only on account of more perfect keeping of the article, but also because they measure out more than when berries are filled into the ordinary quart measure." 1 The retailer always remeasured the contents of the boxes, presumably to protect his customer. These boxes, like the baskets and stands, were returnable; the name of the shipper was stamped upon each, and the dealer was supposed to return them when empty. When the berries were sold they were emptied into a paper bag.

Growers in the Mississippi Valley who used stands could see no value whatever in boxes. In 1866, A. M. Purdy, then of South Bend, Indiana, declared: "We have discarded the use of quart boxes to ship in for a number of reasons. First, shipping, as we do, from 50 to 100 bushels a day, it would be impossible to pack the number required properly. Second, they get mislaid and lost. Third, retailers and buyers are not satisfied with

${ }^{1}$ U. S. Patent Office Rept., 1848, p. 610. 
them, preferring to see the fruit measured out. Fourth, commission men do not like them, as it is too much trouble to gather them in, and in fact, an impossibility. Fifth, the cost is too great." These early boxes were shipped in various styles and sizes of heavy, home-made crates. Crates had long been used for shipping pint or half pint splint baskets to the New York market. Andrew M. Hopper, of Pascock, New Jersey, is said to have been the first to market strawberries in crates, about 1840 . "These early cases were skeleton cases, some with and some without lids, each grower making them to suit his own convenience for handling; but they generally contained from 100 to 200 baskets each. The number of baskets was marked either on the lid or the slats." 1

Introduction of the return crate and hox. - The introduction of the Wilson gave a great impetus to strawberry culture and the remarkable expansion of railroads soon after made it possible to grow strawberries at a greater distance from the markets. The modern crate and box package was developed between 1855 and 1870 to meet these new conditions, as none of the packages then in use were suitable for long distance shipping. The Gardeners' Monthly for 1859 says: "On one day, 60,000 boxes were shipped from Norfolk and other southern points to Philadelphia. The boxes are of thin wood containing a quart each and are put in small chests holding sixty boxes." The sixty-quart crate still is a standard package of the Norfolk district, but at that time the package was returnable, each box being stamped "owner's box."

One of the first to manufacture boxes in large quantities was Hallock, of Queens, New York, who began business before 1855 . In 1862 "Hallock's strawberry boxes"

${ }^{1}$ Rept. N. J. Hort. Soc., 1877, p. 28. 
cost $\$ 20$ a thousand, including the crates, which were mostly the forty-eight-quart size. These boxes were square and were made of two pieces of white-wood, onefourth to three-eighths inch thick. The use of Hallock's boxes became so general that in some sections all strawberry boxes were called "Hallocks" - and are to this day.

Hallocks were made in various sizes and were very heavy. Frequently they were packed in heavy, homemade crates. Jeremiah Haggerty has described the package used in Oswego County, New York, about 1855: ${ }^{1}$ "The crates were of several sizes and shapes, mostly of domestic manufacture. The lumber in them was from one to one and a quarter inches in thickness. They were made like tool chests, with handles nailed along the sides and extending at the end so as to allow two men to handle them conveniently. They contained from 120 to 160 quarts. The berry boxes at that time held two quarts and were made of wood one quarter to three-eighths inch in thickness."

These thick, heavy boxes were soon discarded for lighter ones. In 1869 W. F. Wall of Fayetteville, New York, used "a square quart box with the bottom set up into the box one inch, so that they may set above one another in the crate without jamming the fruit. The material for the box is white wood, one sixteenth of an inch thick; the inside diameter is $5 \times 5 \times 2 \frac{1}{2}$ inches; the cost about $\$ 15$ a thousand. They are shipped in crates holding 24, 36 or 48 quarts." 2 The Baker thirty-six quart crate was introduced into western New York by Baker Brothers in 1872 . It cost $\$ 2.25$ at that time.

\footnotetext{
${ }^{1}$ Rural New Yorker, 1898, p. 68.

${ }^{2}$ Southern Horticulturist, Oct., 1869.
} 
The first gift packages. - John Knox, of Pittsburgh, was the first to use a gift package. In 1861 Thomas Meehan pleaded for "cheap gift boxes, which the buyer can destroy after emptying, as does the London pleasure seeker the pottle of strawberries he bought at London bridge before taking the excursion boat to Gravesend." 1 The following year Knox introduced his "Pittsburgh" box, which was square and made of veneer. A gift crate holding fifty-four pint boxes cost eighty cents. The "Beecher Patent Basket" was introduced the same year; this was round, made of pasteboard and cost $\$ 1.00$ a thousand. In 1863 Knox said, "I market in boxes holding pints and quarts. These are packed in crates holding 24 quarts or 54 pints." 2

At his annual strawberry exhibition, in 1868, Knox offered a prize of $\$ 100$ "for the best type of gift box." The competition developed this fact: ${ }^{3}$ "Two distinct classes of boxes are demanded by growers and furnished by manufacturers; a cheap or gift box, to be given away with the fruit, and a better or stronger article to be returned by the dealer or consumer." By this time the pioneer manufacturers of return boxes, Hallock and Colby, of Queens, New York, were making gift packages also; and the "Burlington Free Fruit Box" was on the market. This was introduced by J. Churchman, of Burlington, New Jersey. It was made of wood veneer in two pieces, and put together without glue or nails; shipped in the flat, it cost $\$ 10$ a thousand quarts. ${ }^{4}$

Slow adoption of gift packages in the East. - The gift

${ }^{1}$ Gardeners' Monthly, 1861, p. 209.

${ }^{2}$ Rept. Mo. Hort. Soc., 1863, p. 39.

${ }^{3}$ Rept. Ohio Hort. Soc., 1868, p. 27.

${ }^{4}$ Country Gentleman, 1866, p. 222. 
package found favor in the Mississippi Valley much more rapidly than in the Atlantic States. This was partly because the stand of drawers, which had been used in the Mississippi Valley almost exclusively, was poorly adapted for long distance shipping, and western growers ship farther than eastern growers. By 1875, practically all the berries from this region, except those sold in near markets, were packed in gift crates. The sixteen and twenty-four quart gift crates, with square or octagonal boxes, developed in the Mississippi Valley. In 1875 twenty-four quart crates were used almost exclusively in that region for long distance shipping; the crates were returned but the boxes were not. The northeastern states always have preferred the thirty-two quart size, or larger, until quite recently.

In the East, the inconveniences of return packages were endured much longer, partly because markets were closer and partly because gift packages cost more. In 1893 a good return crate cost forty cents in Delaware and a gift crate thirty-two cents; gift boxes cost $\$ 4.00$ a thousand. That year, several bodies of eastern fruit growers adopted resolutions condemning the gift crate. The sixty quart return crate was used in the Norfolk district as late as 1902 .

The numerous disadvantages of the return package eventually forced nearly all sections to adopt the gift package. The grower was obliged to have enough crates for a week's picking, as he never could be sure that the crates would be returned promptly. When he shipped to a large commission house, rarely did he get back as many crates as he sent and the crates of different shippers nearly always were mixed. The retail grocers generally threw the empty boxes into one big pile. When the 
crates were returned, they were filled with baskets, promiscuously, from this pile; the grower who shipped in new boxes was likely to have old, stained boxes returned. There was a growing sentiment in the trade and among consumers for fresh, clean boxes. Another disadvantage, which the grower sometimes overlooked, was that the expense of returning the package was paid by him. In early years, the transportation companies returned empties free; later they charged for this service and became increasingly indifferent about returning them promptly. Commission men did not like to return packages; sometimes it took more labor to collect the empties than to sell the fruit. Thousands were not returned at all. Eventually the volume of business became so great that the return of empties was a physical impossibility. Then growers, profiting by the experience of the orange growers of Florida and California, were forced to adopt the gift package. At first, some used return crates and gift boxes, but this only half solved the problem. Now, gift packages are used almost exclusively for shipping to the general market, except for the pony refrigerators of Florida, and the chest of drawers used in California for near markets. Stout return crates, with gift boxes, still are used somewhat for near markets; also return trays. The return package was fairly satisfactory in the days when all commercial strawberry fields were only a few miles from market and the quantity of fruit shipped was small. It was made obsolete by the extension of transportation facilities and the enormous increase in the volume of business.

It is probable that within twenty-five years the wooden box will have been largely displaced by the paper box, as a matter of economy. 


\section{Early Methods of Training}

Until about 1840, most of the strawberries grown in North America were trained in hills. English methods were sedulously copied here before our fruit growers had developed sufficient initiative to question the fiats of Loudon, Miller and other great English gardeners. Hill training had been practiced in England for centuries. In his "Paradisus Terrestris," published in 1629, John Parkinson says, "Bohemia and all other strawberries will not bear kindly if you suffer them to grow with many strings, and therefore they are still cut off." As long as strawberries were grown only by country gentlemen who employed English gardeners and by a few market gardeners near the larger cities, hill training prevailed, even in the rigorous climate of Massachusetts. In 1835, C. M. Hovey wrote: ${ }^{1}$ "Strawberries are cultivated in beds, rows or hills; some adopt one and some the other method, and each has advocates." He contended, however, that hill training was the only really satisfactory method and gave the following explicit instructions: "The beds should contain three rows and should be six feet in width; and the alleys between each, three feet. The plants should be eighteen inches apart in the row and all runners kept off."

As more people began to grow strawberries for home use, most of them unable to afford the luxury of a private gardener, there was a tendency to let the plants run; it was less trouble and expense. The old line horticulturists protested against this with vigor. In 1845 William Cobbett voiced the outraged feelings of every true English gardener at this unseemly departure from the ${ }^{1}$ Mag. Hort., 1835, p. 304. 
orthodox method: " "To cultivate strawberries in beds, suffering them to cover the whole of the ground with their runners and young plants is a miserable method, proceeding from the suggestions either of idleness or of greediness, and sure to lead to the defeating of the object of this later. In my 'American Gardener' I have recommended the forming of the strawberry plantations into beds knowing that it was impossible to prevail upon the people in that country-to take the pains required to cultivate them in clumps." By this time there was a considerable area of commercial planting in the matted row, especially near Cincinnati and in Anne Arundel County, Maryland.

The era of broadcast training. - With the introduction of the Wilson, in 1854, hill training was abandoned under commercial culture, except in a few market gardens, especially near Boston. The Wilson did not make an excessive number of runners and thrived even under neglect. The prevailing practice quickly passed from one extreme to the other - from hill training to broadcast training. Between 1854 and 1870 practically all commercial growers made no attempt whatever to restrict the number of runners or to space them. In $1867 \mathrm{An}$ drew S. Fuller described this method : ${ }^{2}$ "The oldest method of field culture in this country, and the one practiced upon thousand of acres in the eastern states at the present time, is to plant in rows from two and one half to three feet apart, spacing the plants about one foot distant in the rows. The beds are hoed during the early part of the summer, or until the runners have covered the ground, after which no attention is paid to them until the next spring. Then paths about one foot wide and at a dis-

1 "The English Gardener" (1845), p. 249.

2 " Small Fruit Culturist," pp. 61-62. 
tance of four feet from each other are made, thus forming beds with narrow paths in which the pickers are expected to stand when gathering the fruit.

"Two or three crops are gathered from these beds before any change is made or cultivation given, except that of hoeing or plowing out the paths each season before picking time. When the beds have become so much crowded with weeds and plants that the fruit is likely to entirely fail, a plow is run through the center of each bed, forming a new path, the runners being allowed to take root and fill up the old ones. Another crop or two is taken and then the paths are again changed." The prevailing point of view concerning broadcast training was thus stated by a grower in 1854: "By allowing the ground to be fully occupied by the plants we save all the labor which would be consumed in removing the runners and we avoid the necessity of applying a mulch to keep the fruit clean."

Under broadcast training many plantations ran to vines completely. The Colfax, introduced in 1867, was a very notable plant-maker. In 1872 an Illinois grower stated : " "To my friends who wish to get rid of the weeds I recommend the Colfax. It will kill the weeds and everything else and completely occupy the ground. It is worse than white clover in this respect." It would be interesting, though hardly profitable, to watch a race between the Colfax and Wonder (of Shank), a recently introduced variety which the introducer triumphantly asserts will "drive out blue grass."

Prominent horticulturists continued to protest against broadcast training. "Unless these runners are kept in check," declared Patrick Barry in 1854, "the ground

${ }^{1}$ Rept. Ill. Hort. Soc., 1872, p. 58. 
becomes covered with a mass of starved and weakly plants, choking each other in a hard uncultivated soil and producing a sparse crop of small, insipid berries that dry up on their stalks before they are ripe unless rain happens to fall every day." By calling it "the lazy man's method" they endeavored to shame cultivators into adopting hill training. In 1862, Thomas Meehan said, "There is no question but that growing strawberries in hills, instead of letting them run in beds, will be the rule with all cultivators who are industrious." This subtle implication must have failed to hit its mark, for we read that in 1869 he took a 3000 mile trip through the leading strawberry districts of the Mississippi Valley and Atlantic States and "found the hill system nowhere in use except at York and Pittsburg, Pennsylvania."

The evolution of the matted row. - Broadcast training prevailed until about 1870. By that time complaints about small berries and loss from drought had become too numerous to be ignored. When the plants were crowded closely together over the entire area, with no opportunity for tillage, a severe drought not only reduced the yield but also killed the vines in many cases. It became necessary to seek a compromise between hill and broadcast training which would permit some degree of tillage, so as to prevent loss from drought, yet at the same time not sacrifice the heavy yield resulting from a thick stand of plants. This compromise was the matted row. At the same time methods of renewing the beds, so as to get a new stand of uncrowded plants, came into vogue. In some cases, especially in the Northeast, the life of the plantation was shortened from ten years to two years. Since 1870, the matted row has been the dominant method of training in commercial culture. The introduction of 
the Crescent, in 1876, gave a new lease of life to broadcast training, since this variety is remarkably prolific of runners; but Crescents produced in this way were too inferior to justify the practice.

Since 1880 there has been a steady drift towards fewer plants per acre and more uniform spacing. The first step was to narrow the matted row. Soon after broadcast training had been superseded by the matted row it was noticed that the best fruit was produced by the outside plants; these were least crowded and were benefited most by the tillage between the rows. The effort to secure a larger number of these productive outside plants was expressed in two ways; the distance between rows was reduced from five or six feet to about three feet, and each row was narrowed accordingly. There has been a gradual widening of the tilled area between rows and a corresponding reduction of the area occupied by plants. The matted rows of 1865 were about five feet wide, with narrow foot paths between; those of today hardly average fifteen inches wide, with room for a cultivator to run between them.

This restriction of the width of the matted row, together with various means of removing surplus plants in the row, has made it possible to produce a heavy yield of good fruit under this method of training; but those who have sought to produce the highest grade of berries have been forced to approach hill training even more closely. The hedge-row, which has been supposed by some to be of recent origin, was used under intensive culture before 1865. J. B. Moore, a market gardener of Concord, Massachusetts, grew a considerable acreage in triple hedgerows about $1870 .{ }^{1}$ He set two runners from every 1 Trans. Mass. Hort. Soc., 1870, p. 28. 
mother plant, one on each side. P. M. Augur of Middlefield, Connecticut, used this method about 1880 . The double hedge-row, or twin hedge-row as it was then called, was used by A. M. Purdy of Palmyra, New York, about the same time. The spaced row did not come into common use commercially until quite recently, although it has been used by a few of the more painstaking growers for many years.

Early methods of renewing the bed. - Before the introduction of the Wilson the problem of renewing hill plants, or preparing them to fruit another season, was comparatively simple. Usually it was accomplished simply by mowing and burning the leaves and adding fresh soil. This was not done, however, immediately after the crop was harvested, as at present, but in early spring, while the plants were still dormant. Mowing and burning came into favor early in the nineteenth century. In 1828, J. D. Legare, editor of the Southern Agriculturist of Charleston, South Carolina, said: "The practice of burning over old strawberry beds in the spring of the year has long been and still is practiced in this state." He favored letting all weeds grow in summer, "so that the plants are not unnecessarily exposed to the influence of the sun, which is entirely too intense for them," and then mowing and burning them in the spring. He stated that in the Northern States, also, "Strawberry beds are frequently burned over in early spring, dry straw being spread over them first, so that the fire will spread rapidly without injuring the plants."

Frequently hill plants were renewed in the way recommended by Kenrick in his "New American Orchardist," published in 1833: "In the vicinity of Boston the following method is often adopted. The vines are usually 
transplanted in August. The rows are formed from eighteen inches to two feet asunder. The runners during the first year are destroyed. In the second year, they are suffered to grow and fill the interval and in the autumn of that year the old rows are turned under with the spade and the rows are thus shifted to the middle of the space. This process is repeated every second year, often for ten to fourteen years." The strip turned under was sown to turnips. In 1845 A. J. Downing referred to this method as "so superior to the common one of growing them more closely in beds that we shall not give any directions respecting the latter." Still another method was advocated by Pardee, in 1854: "Every year or two, if a strong runner has struck itself beside an old plant, we pull up the old plant instead of the runner and are constantly thus renewing them."

After the introduction of the Wilson, in 1854, broadcast and matted row training became general and plantations were often fruited ten to fifteen years. At first there was little or no attempt either to restrict the number of plants that set or to encourage the growth of new plants to bear the crop of another year. Most growers simply mowed and burned the leaves after the crop was harvested without plowing or cultivating the land at all. This "wholesome neglect," as it was called by its champions, was especially advised for the Wilson. In 1860 a member of the Illinois Horticultural Society complained, "I have a bed of Necked Pine so thickly matted a mouse could not get through it. I get no fruit. How can I keep them thin?" O. B. Galusha replied, "Drag a harrow through them." This was advanced ground at that time. Methods of reducing the stand of plants, with plow, harrow or hoe, did not come into general use until some years later. 


\section{THE STRAWBERRY IN NORTH AMERICA}

Then, as now, some men were looking for the easiest way to grow strawberries. At the 1876 meeting of the Iowa Horticultural Society, Amos Kemble announced that he had found it: "The easiest way of growing strawberries that I know of is that used by James Smith of Des Moines; that is, orchard culture among trees ten to fifteen years old. The berries, Downer's Prolific, had been planted for five years and cultivated each year by running over the whole bed with a plow or harrow after the crop had been picked; and this was all the cultivation given. The only protection was the trees and the leaves that fell from them. I found a good crop of nice large berries grown at an expense of less than two dollars an acre for cultivation and protection." Fortunately, this easy-going method did not commend itself generally. Since 1870 the methods of renewing matted rows have improved constantly; now a renewed bed frequently is more profitable than a new setting.

\section{Early History of the Pollination Question}

The fact of the separation of the sexes in some kinds of strawberries was first observed by Duchesne in 1760 . Following Linnæus, all botanists had persisted in classifying the strawberry as hermaphrodite, since it is mainly so in nature; the effect of cultivation and hybridization upon the sexual organs of certain varieties either had been unnoticed or ignored. At the age of nineteen, Duchesne published his remarkable "Histoire Naturelle des Fraisiers," in which he described all the known varieties, classified them according to botanical origin and reported observations upon sex in the Hautbois. At that time it was the popular belief that the Hautbois 
was degenerating or "running out," since it had become less fruitful under cultivation. With unusual independence of observation, the youthful botanist proved that the real reason for this degeneracy was that the male plants, being unfruitful, had been gradually weeded out of gardens, leaving the female plants without pollinizers. This had escaped attention, since most of the plants of the Hautbois are apparently hermaphrodite, but in female plants the anthers bear little or no pollen, and in male plants the pistils do not function. Duchesne also observed that these conditions existed in the Chili strawberry, but to a less degree. When his observations were published he was reprimanded by his former teacher, Linnæus, who intimated that what Duchesne really had seen was blossoms that had been made abortive by frost!

Following Duchesne's discovery, French gardeners practiced mixed planting to advantage with both the Hautbois and the Chili. No application was made of it outside of France for over fifty years. The accuracy of Duchesne's observation was first verified in England by Michael Keens, a gardener of Isleworth, in 1809. In 1817 he said: ${ }^{1}$ "There are many different sorts of Hautboys; one has the male and female organs in the same blossoms and bears very freely; but that which I most approve is the one which contain the male organs in one blossom and the female in another. These bear fruit of the finest colour and of far superior flavour. In selecting these plants, care must be taken that there are not too many male plants among them; for, as these bear no fruit, they are apt to make more runners than the females. I consider one male to ten females a proper proportion 1 Trans. Royal Hort. Soc., Vol. II (1818), p. 396. 
for an abundant crop. I learned the necessity of mixing the male plants with the others by experience in 1809."

In 1826 James Barnet called attention to the fact that in the true Chili strawberry "the stamens are usually entirely abortive or very rarely produce anthers sufficiently supplied with pollen to fecundate the stigmas; hence, the plants are rarely productive." $1 \mathrm{He}$ advised: "A little attention, however, will remedy this defect, for it is not difficult to contrive to have plants of the Roseberry (a variety of $F$.Virginiana) or some other free and late-flowering variety, ready for the purpose." The first importation of the Chili strawberry consisted of pistillate plants, but part of the later importations were hermaphrodite.

The new varieties of the Pine soon drove the Hautbois and Chili from English gardens and with them the pollination problem. Practically all English varieties since then have been staminate. According to R. L. Castle, the Crescent, which sometimes is weakly staminate in America, but usually is pistillate, is strongly staminate when grown in England. ${ }^{2}$ Most English horticulturists seem to have lost faith in the existence of a separation of the sexes in the strawberry plant. As late as 1863 Lindley inquired: "Is it true that some plants of the American strawberry are absolutely female?" and expressed a doubt as to whether there really was, or could be, such a thing as a pistillate variety of strawberry, except as a result of very poor culture.

Early pollination troubles in America. - It was a very real and troublesome problem in America, however. The Hautbois was introduced into North American gar-

1 Trans. Royal Hort. Soc., Vol. VI (1826), p. 207.

2 Ibid., Vol. XXIX (1904), p. 146. 
dens about 1750 and gave trouble from the beginning. Profiting by the observations of Duchesne, Bernard McMahon, in his “American Gardeners' Calendar," published in 1806, warned his readers: "If the plants are promiscuously taken from the beds without care, a great number of them will become barren; these are, by the gardeners, termed 'blind,' which is when there are plenty of flowers but no fruit produced. If these flowers are well examined, they will be found to want the female organs of generation, most of them abounding with stamina, but there are few, if any, stiles. The Hautbois strawberry is more subject to this than any of the other kinds."

There does not appear to have been any attempt to apply this experience to the pistillate varieties of $F$. Virginiana then under cultivation, which included such standard sorts as Early Hudson, Hudson's Bay and Methven Scarlet, until about 1820. In 1822 William Curr, of New York, read a paper on the culture of the Hudson's Bay before the Horticultural Society of New York, in which he stated: "A great deal lies in choosing proper plants; if they are taken promiscuously, the greater part will prove barren, producing plenty of flowers, but no fruit."

The following year William Prince called attention to Keens' experience with the Hautbois in his "Short Treatise on Horticulture." In 1823 a correspondent of The American Farmer complained: "My strawberry vines are thick and luxuriant; they blossom well and then blight. How can the blight be prevented?" A New Jersey reader replied that it was due to the "undue proportion of male and female plants," and added: "It may easily be discovered by the stamens which are the male blossoms. This is a matter perfectly understood by 
our best gardeners, that an attention to the selection of the plants with reference to sex is well rewarded by an increased quantity of fruit."

As long as strawberry culture was confined to the home garden, where several varieties usually were grown, one of which was likely to be a staminate, there was less likelihood of loss; but the numerous complaints about "barren" plants and "blasted" blossoms, between 1800 and 1840, indicate that failure to set fruit, because of poor pollination, was quite general and very discouraging. The strawberry was known as a fickle fruit. "In those days," says Parker Earle, "a mystery overhung strawberry growing. Many people grew strawberry plants in their gardens, but an inscrutable providence withheld the fruit."

The secret of Abergust. - When field culture of the strawberry began, about 1820 , the loss from poor pollination became more impressive. There was not a great deal of complaint in the East, where the dominant varieties were Large Early Scarlet, Crimson Cone and Red Wood, which were staminate; but in the vicinity of Cincinnati, where Early Hudson, a pistillate variety, was the leading sort, the loss was serious. It was noticed that one man, a German gardener named Abergust, always had large crops of Early Hudson, which he sold for thirty-five to forty cents a quart and from which he made a competence. For many years he refused to tell his neighbors how he was able to secure these remarkable results. Evidently his wife figured largely in the enterprise, for in 1854, Nicholas Longworth related:1 "Until the secret was disclosed, Mrs. Abergust was our only gardener who could raise the strawberry profitably. From ${ }^{1}$ Western Horticultural Review, IV (1854), p. 288. 
the same space of ground she raised five times the quantity of fruit as her neighbors, much larger in size and commanding a higher price. In the spring she thinned her beds and threw plants in the street. Her neighbors, hoping to duplicate her excellent results, picked them up and planted them, but not a single fruit would they produce, for she had thrown out her staminate only."

A chance remark by one of the Abergust boys revealed the secret. As related by J. A. Warder : " "The boy was sauntering through Mr. Longworth's strawberry patch, whittling. Said the boy: 'Mr. Longworth, I reckon you won't have many berries; nearly all of your plants are males.' Mr. Longworth replied: 'Won't I have a few ?' 'Yes, I reckon so; you will have a few there, and there, and there,' said he, pointing to different spots in the bed. Mr. Longworth had his wits about him and stuck stakes where the boy said there would be fruit, and there the fruit grew." This was the clue that led him to investigate the subject. "I soon discovered," said Longworth, "that there were what he called male and female plants, and communicated this fact to our market gardeners," who immediately took advantage of it. Ten years later Cincinnati led the world in strawberry production; the price dropped from thirty-seven cents to less than ten cents a quart, and Abergust ceased to cultivate them. It was shown that he had practiced mixed planting for many years and had discovered its advantages independently. Being a plain, unlettered man, it was not likely that he had ever heard of the work of Duchesne or Keens. The "strawberry war." - Longworth called attention to his discovery in the Magazine of Horticulture for 1834, but it aroused little interest outside of Cincinnati.

${ }^{1}$ Rept. Ill. State Agr. Soc., III (1858-9), p. 384. 
The introduction of the Hovey, in 1838, was the signal for an awakening of interest in strawberry pollination. With the prestige of the Massachusetts Horticultural Society and the Magazine of Horticulture behind it, the Hovey was quickly disseminated to all parts of North America. In introducing his seedling, Hovey claimed: "In some varieties of strawberry there are both sterile and fertile plants, generally termed male and female. This is not the case with this new seedling; every flower is perfect and has a due proportion of both stamens and pistils." 1 When the Hovey reached Cincinnati, however, it was immediately identified by the keen observers there as a pistillate.

The first shot in what was soon to be called "the strawberry war" was fired by Longworth in $1842 .{ }^{2} \mathrm{He}$ in-

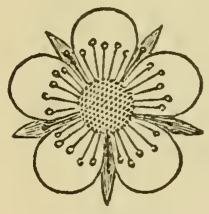

Male flouer.

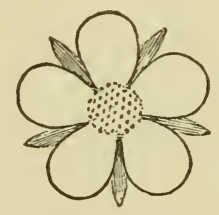

Femalc flower.
Fig. 7. - "A male and female blossom of the Hudson," as drawn by Nicholas Longworth, in 1842.

formed the Editor of the Magazine of Horticulture: "Your strawberry is, in common with the Methven Castle, Hudson, and other good berries that produce very large fruit, defective in the male organs, and requires other plants, perfect in the male organs, near them." He illustrated this article with a drawing of "a male and a female blossom of Hudson" (Fig. 7). The female blossom shown by Longworth is a pistillate, but the blossom he designates as "male" is hermaphrodite, which indicates that many of the plants called male at that

${ }^{1}$ Mag. Hort., 6 (1840), p. 293.

${ }^{2}$ Ibid., 8 (1842), pp. 257-262. 
time were really hermaphrodite. After examining his own stock of plants, Hovey admitted the contention of Longworth, and stated that part of his plants were pistillate and part staminate. The next year, however (1843), Hovey completely reversed himself, and declared positively: ${ }^{1}$ "We believe it is now generally the received opinion by all intelligent cultivators that there is no necessity of making any distinction in regard to the sexual character of the plants when forming new beds. The idea of male and female flowers, first originated, we believe, by Mr. Longworth, of Ohio, is now considered as exploded. That there may be fertile and sterile beds is not denied, but the cause of their sterile character is to be sought, not in a naturally defective organization of the blossom, but rather in the mode of cultivation applied to the plants." He considered "repletion," or too much nourishment, a cause of sterility, and cited beds of Hovey which were barren under high culture, trenching and heavy manuring, that became productive when neglected. He concluded: "Cultivation, alone, creates sterile, or fertile, plants."

Fortunately, Longworth was a gentleman with a pugnacious regard for his own convictions, and no respecter of authority. Not even Hovey's reference to "intelligent" cultivators was needed to incite him to battle. The issue was raised, and the controversy began. It was waged with much heat from 1842 to 1848 and harmony was not fully restored for several years thereafter. Longworth and the loyal Cincinnati Horticultural Society stood boldly against Hovey, Downing, Meehan and practically all other prominent horticulturists, both in America and in Europe. One can imagine the feelings of ${ }^{1}$ Mag. Hort., 9 (1843), p. 415. 
Longworth when he sent some pistillate plants to the President of the London Horticultural Society, who replied that he was not aware that there were strawberry plants that would not bear fruit without impregnation from other plants and suggested that the failure was due to frost!

Influence of culture on sex. - Both of the leading combatants were guilty of error. After denying that his seedling would be benefited at all by cross-pollination, Hovey finally settled down to the contention that it had been hermaphrodite when he introduced it, but had since become pistillate, having degenerated as a result of poor culture. Hovey had borrowed this theory from A. J. Downing, who, in turn, had absorbed it from England. English horticulturists, especially Lindley, stoutly maintained that if there were any such degenerates in America as pistillate strawberry plants they were the inevitable result of indifferent care, barren soil or an uncongenial climate; good culture - or transplanting them to England - would make them whole again. ${ }^{1}$ Downing reflected this view when he said," "Hovey's Seedling and some other sorts do vary from a state that is the normal or perfect one of the strawberry (that is, with perfect flowers), into a pistillate or staminate form." He cited, in support of his theory, beds of Hovey that he had examined in which practically all the flowers were perfect the first year they were planted. The second year, he says, "More than one-third of the plants now bear pistillate blossoms. Of the remaining two-thirds many bear perfect blossoms, as they had done previously, while a few bear imperfect staminate blossoms. Next year we predict that this bed will have changed almost entirely to pistillate."

${ }^{1}$ The Horticulturist, 1 (1847), p. $85 . \quad 2$ Ibid., p. 572. 
He concluded: "If varieties of the Pine are allowed to bear twice or more on the same roots, they will degenerate into pistillate or staminate forms. The staminate or pistillate forms once reached, we are inclined to think from experiments we have made, that it is permanent. Hovey's Seedling at first was a perfect sort in its flower, but at this moment (1847) more than half of the plants in the country have become pistillate." Downing combated the recommendation of Longworth, "of always making a plantation with a certain proportion of what he terms male plants - the only use of which is to supply stamens or pollen to the other imperfect plants. The true course is not to waste the ground by putting out barren or male plants, but carefully to select, when there is any tendency to sterility, only runners from the most fruitful perfect plants. In this way good plantations will be secured, with every plant productive."

While Downing's theory that varieties of strawberries change in sex under cultivation was a fallacy, in the main, there is enough confirmatory evidence to make it seem plausible. Few pistillate varieties are absolutely devoid of stamens and produce no pollen whatever. The Hovey belonged to the large group of pistillates that normally have very small stamens and, as a rule, do not produce a sufficient amount of pollen to properly fertilize the blossoms. Hovey said his seedling "had both pistils and stamens, the latter quite short and hidden under the receptacle." When these varieties are planted in rich soil they tend to become more nearly staminate. When Thomas Meehan planted pistillate varieties in pots and forced them in the greenhouse, many of the blossoms were staminate. This convinced him that sex in the strawberry is "merely a matter of nutrition." $\mathrm{He}$ 


\section{THE STRAWBERRY IN NORTH AMERICA}

held that the deficiency of stamens is "not constitutional, but accidental and perfectly under control." This extreme statement is not justified; but that sex in the strawberry can be modified somewhat by cultural conditions cannot be disputed.

The distinction between pistillate and staminate varieties is wholly relative. A pistillate variety is not one that lacks stamens, and produces no pollen whatever, but one that, under average conditions, is not dependable in self-pollination. Probably most of the conflicting observations concerning the sex of the Hovey arose from a misunderstanding on this point. It is certain that much confusion was due, also, to carelessness in propagation and culture. At that time the strawberry bed frequently was kept in the same place for many years; it was easy for varieties to run together and for seedlings to spring up in it. Another probable source of error was the fact that true male plants multiplied in the bed so much faster than the pistillate plants that they soon ran out the pistillate, if the beds were neglected. Charles Downing advised that staminate plants be set at the end of a short row with pistillate plants between them, in the same row. The two soon ran together and became indistinguishable.

Report of the Cincinnati Horticultural Society. - On the other hand, Longworth was equally in error. Although right in his main thesis that the Hovey, Early Hudson and other pistillate varieties could not be expected to be fruitful unless planted with a pollinizer, he was wrong in his contention that pistillate varieties were the only kind worth growing. He maintained that hermaphrodite plants were of little value for fruiting; they were serviceable only for pollinating pistillate sorts, and 
not nearly as valuable for that purpose as pure male plants, hence they should be discarded. At his request, the Cincinnati Horticultural Society appointed a committee to investigate the subject. On June 13, 1846, this committee reported: 1 "No staminate plants can be depended upon by the cultivator as heavy bearers, although, from some unknown causes, the pistils may be so well developed as to be followed by a good crop some years and in some situations.

" There is no such thing yet known to us as a perfect flowering strawberry plant in which the blossoms will all be uniformly so well provided with both sets of organs as to be followed with perfect fruit every year.

"The only method of producing this delicious fruit with any degree of certainty is to set out plants of both the sexual classes, the relative proportions of each to be determined by experience."

On April 15, 1854, "after examining millions of blossoms," J. A. Warder, the Secretary of the Society, published the following "finality" on the subject: ${ }^{2}$

"Wild or cultivated, the strawberry presents, in its varieties, four distinct forms or characters of inflorescence:

"First: Those called 'pistillate' from the fact that the stamens are abortive and not to be found without a dissection of the flower. These require extrinsic impregnation.

"Second: Those called 'staminate,' which are perfectly destitute of even the rudiments of pistils and are necessarily fruitless.

1 "Culture of the Strawberry," by Nicholas Longworth, in "The Culture of the Grape and Wine-making," by Robert Buchanan, 6th ed., 1860, p. 136.

${ }^{2}$ The Country Gentleman, 1854, p. 267. 
“Third: Those called 'hermaphrodite,' or 'perfect,' having both sets of organs (stamens and pistils) apparently well developed. They are not generally good and certain bearers as we should expect them to be. With few exceptions, they bear poorly, owing to some unobserved defect, probably in the pistils.

"Fourth: A rare class, a sort of subdivision of the preceding, has not only hermaphrodite flowers, but also some on the same truss that are of pistillate character, and sometimes in the same plant a truss will be seen on which all the flowers are pistillate."

It was also stated as the conviction of the Society, "that the sexual characters of each seedling will be retained in its increase by runners so long as the variety remains extant, except for minor variations."

This carefully prepared statement would seem to show, beyond question, that true male plants, wholly devoid of pistils, were common at that time. The most striking characteristic of these male plants was extreme vigor. "If you plant but one staminate to twenty pistillates, the staminate will, in two years, take entire possession and root out the pistillates," asserted Longworth. "Having no fruit to exhaust them, they make ten new plants where the pistillates form one." 1 As late as 1875 , J. M. Smith, of Green Bay, Wisconsin, warned growers not to allow male plants to take possession of the beds. Notwithstanding this disadvantage, Longworth and his neighbors preferred these exuberant males for planting with pistillates and could see no advantage in growing the hermaphrodite sorts, even as pollinizers for the pistillates. So firmly convinced was Longworth that

1 "The Culture of the Grape and Wine-making," by Robert Buchanan, p. 124 (6th ed., 1860). 
there was no virtue in hermaphrodite varieties that he offered five hundred dollars to anybody who would produce one that was really prolific. This challenge was accepted by W. R. Prince, of Flushing, New York, with his Primate, but no decision was made.

The final vindication of "Longworth's Theory." - Time justified the chief contention of Longworth. One of the first to be converted was Hovey himself. In 1845 he admitted: ${ }^{1}$ "Enough information has been elicited to show that with some sorts there is a tendency to barrenness when grown in a plantation away from other kinds. Let the causes be what they may, it is sufficient for all practical purposes to know that the most abundant crop can be produced by planting some sort, abounding in staminate flowers, in the near vicinity of those which do not produce

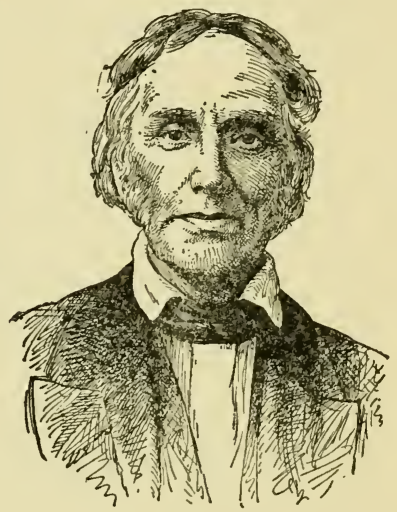

Fig. 8. - Nicholas Longworth, who directed attention to the pollination problem. them." The following year he unreservedly endorsed "Longworth's Theory." Possibly the fact that his Boston Pine, introduced in 1845, was a strong hermaphrodite, and immediately became popular among the market gardeners near Boston for pollinizing the Hovey, may have had something to do with his conversion. In 1851 Longworth, also, contributed to the humor of the situation by introducing the Longworth, a hermaphrodite variety; manifestly he could not continue to ${ }^{1}$ Mag. Hort., 1845, p. 293. 
preach the worthlessness of hermaphrodites thereafter. By 1855 the use of hermaphrodite varieties for pollinating pistillate sorts was quite general, and true male plants gradually disappeared. The introduction of the Wilson, three years later, placed in the field another variety that quickly and permanently disproved the theory that no hermaphrodite sort can be as productive as pistillates.

The "strawberry war" was waged on three propositions :

1. Are there pistillate varieties that must be planted near pollen-bearing sorts in order to be fruitful?

2. Can the sex of a variety be changed from staminate to pistillate by culture?

3. Are pistillate varieties more productive and valuable than staminate sorts?

The first proposition was answered in the affirmative; the latter two in the negative. Nicholas Longworth died on February 14, 1863. He won his fight, almost single-handed, against practically all the horticultural authorities of the East, and contributed largely to the advancement of the strawberry industry in North America. 


\section{CHAPTER IV}

\section{ORIGIN AND BOTANY}

THE strawberry has been in cultivation but a short time, as compared with other fruits. It has been grown in gardens less than 600 years and was not cultivated commercially to any extent until the nineteenth century. The garden strawberry of North America was developed very largely in Europe; it is necessary to consider the history of the strawberry in Europe in order to have a fair perspective of its comparatively short career on this continent.

\section{EARLy History in EURope}

De Candolle states that the strawberry was not cultivated by the Greeks or Romans. Columella does not mention the strawberry in his long list of cultivated plants. Probably the first mention of the strawberry in print was by Nicholas Myrepsus, a Greek doctor of the thirteenth century. Ovid refers to arbutus fructus montanague fragra; and Pliny to terrestris fragris, or ground strawberry. The lines of Virgil,

"Ye boys that gather flowers and strawberries,

Lo, hid within the grass, an adder lies;"

refer to the wild $F$. vesca, or Wood strawberry. The strawberry was first grown in gardens, to any considerable extent, in France. According to E. A. Bunyard, " "docu-

${ }^{1}$ Jour. Royal Hort. Soc., Vol. 39, Pt. 3 (1913), pp. 541-542. 
ments exist which prove that it was grown in the early part of the fourteenth century in France. The Royal Gardens of the Louvre, under Charles V, possessed no fewer than 1,200 plants, and many other records testify to the appreciation of the fruit by its presence in French gardens of this period."

References in early English writings. - The strawberry did not appear in English writings until about 1430,

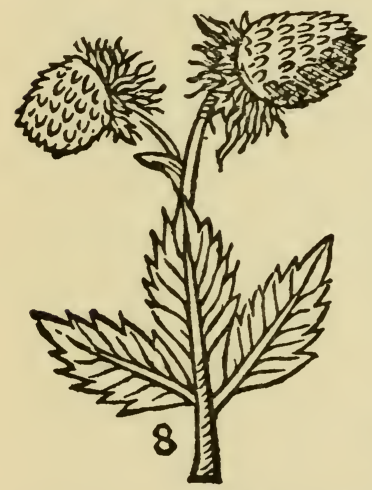

FIG. 9. - Drawing of the strawberry in Parkinson's "Paradisus Terrestris," published in 1629. when John Lydgate wrote a song called "London Lickpenny," in which he refers to "straeberry rype" as a street cry of London. The earliest illustration of the strawberry is in the Mainz "Herbarius," published in 1454, as "Fragaria." This old herbal describes its supposed medicinal properties at length, but no mention is made of culture. In the "Privy Purse Expenses of Henry VIII," for 1530 , there is an item for the purchase of "a pottle of strawberries" for $10 \mathrm{~d}$. The pottle was a very small basket, shaped like an inverted cone, often holding less than half a pint; it is evidence of the small size of the fruit at that time. The pottle was used somewhat near Boston about 1820 (page 76). The Wood strawberry must have been brought into cultivation about then, for in 1556 Ruellius said it produced larger fruit when grown in the garden. In Tusser's "Five Hundred Points of Good Husbandry" (1557), we read, under "September's Husbandrie": 
"Wife into the garden and set me a plot "With Strawberry roots, the best to be got; "Such growing abroad among thorns in the wood, "Well chosen and picked, proved excellent good."

At the close of the sixteenth century the Wood strawberry was common in English gardens, but no varieties had appeared; the garden plants were transplanted from the wild. In his "Gardeners' Labyrinth" (1593), Hyll says: "They be much eaten at all men's tables in the sommer time with wine and sugar, and they will grow in gardens until the bigness of the mulberry." According to him, the strawberry "requires small labour, but, by diligence of the Gardener, becometh so great that the same yieldeth faire and big Berries as the Berries of the Bramble in the hedge." In Richard III (1597), Shakespeare makes the Duke of Gloucester say:

"My Lord of Ely, when I was last in Holborn, "I saw good strawberries in your garden there; "I do beseech you, send for some of them."

Gerarde (1597) enumerates but three varieties, - the white, green and red fruited. In 1629 Parkinson wrote, in his "Paradisus Terrestris": "There be divers forts of Strawberries. The wilde Strawberry that groweth in the woods is our Garden Strawberry, but bettered by the foyle and tranfplanting." He describes the Red, Green, White, Bohemia and Virginia, the latter being "neere five inches about."

Origin of the name. - The wild strawberry, especially the Scarlet, well deserves its botanical name, Fragaria (from the Latin fragro, to emit a sweet odor), although this delightful aroma is sadly lacking in many modern 
varieties. From the Latin name there have come the Spanish Freza and the Italian Planta di Fragola. In the Spanish of South America it is Frutilla, or little plant. The French call it Fraisier from the name of the Frenchman who introduced the Chilean species into Europe. The German name is Erdberre, or earth berry.

The origin of the English name is in doubt. Some trace it to the ancient custom among children of selling the wild fruit strung on straws. This is mentioned by Browne in his "Britania's Pistoral." "As a boy in Ireland," related a correspondent of The Canadian Horticulturist, in 1884, "I used to string them on what we called "wind straw,' or straws of timothy grass." Others see in the name a reference to the common use of a straw mulch around the plants. In 1806, Sir Joseph Banks said: ${ }^{1}$ "The custom of laying straw on the strawberry plants when their fruit begins to swell is probably very old in this country; the name of the fruit bears testimony in favor of this conjecture, for the plant has no relation to straw in any other way, and no other European language applies the idea of straw in any shape to the name of the berry or to the plant that bears it."

It has been suggested, also, that the word refers to the resemblance of the old, dry runners to straw; or to the fact that the plant is commonly found growing among the straw, or dry, wild grass of old fields. None of these surmises, however, is as plausible as the explanation of the philologist, who concludes that strawberry is from the Anglo-Saxon word "streouberrie," which was first spelled in modern fashion by Turner, in 1538. This was derived from "strae" or "strahen" (to scatter), referring to the erratic habit of the runners in straying or wandering about,

1 Trans. Hort. Soc. of London, Vol. I (1806), p. 54. 
being strewed - anciently "strawed" - over the ground. It is significant that the first reference to this fruit in English writings, by John Lydgate, was to the "straeberry."

\section{Origin of the Garden Strawberry of Europe}

At the close of the sixteenth century the Wood strawberry, $F$. vesca, had shown little capacity for improvement as grown in English gardens. After having been in cultivation over a century, it had not produced varieties that were better than the wild form. On the continent, however, where $F$. vesca had been grown in gardens for three hundred years, one variety appeared a little later that had distinct merit. When Duchesne published his valuable monograph on this fruit, in 1766 , the favorite market variety near Paris was the Fressant, at first called the Cappron, or Chaperon. This was a seedling of $F$. vesca, with a large, pale berry, that had been produced about 1660 at Montreuil, France. It was the first cultivated variety and the first improved seedling of which there is record. The other European species, F. elatior, the Hautbois, had not been grown in gardens to any extent and had produced no valuable varieties. At the close of the sixteenth century there had been practically no improvement in the European species. There was little progress until the introduction of the two American species, $F$. virginiana and $F$. chiloensis.

The Virginian strawberry was introduced into Europe from North America early in the seventeenth century, possibly by Tradescant. In 1624 it was commended in France by Jean Robin, botanist to Louis XIII. The attractive color, large size, acceptable flavor and enticing fragrance of this species made it a favorite at once. At 


\section{THE STRAWBERRY IN NORTH AMERICA}

first it gave indifferent results in many places because it ran to vines under high culture. Parkinson said, in 1629: "The Virginian strawberry carryeth the greateft leafe of any other except the Bohemian; but fcarce can one Strawberry be feene ripe among a number of plants. I thinke the reafon thereof to be the want of skill or induftry to order it right. Strawberries will not bear kindly if you suffer them to grow with many strings."

According to Barnet, no improved varieties were produced from the Scarlet for more than one hundred years after it was introduced, either by seed or by importation from America. Perhaps its superfluity of runners was one reason why it was neglected at first. However, it showed a capacity for variation and improvement that the Wood strawberry did not. Early in the eighteenth century it was found that new varieties could be produced from it, differing quite materially from the parent, merely by sowing seeds. In 1766 Duchesne mentioned a distinct variety of the Scarlet. In 1824 Barnet described twenty-six varieties, most of which were quite superior to the type. During the latter part of the eighteenth and the first part of the nineteenth centuries, varieties of the Scarlet held almost undisputed sway in English gardens. According to Weathers, the Old Scarlet, which is the type of $F$. virginiana, still is grown in England and Scotland for making jam.

Introduction of the Chilean. - Although the Scarlet had shown greater capacity for improvement than the Wood and Hautbois, still its varieties were very little superior in size of berry to the best wild plants, and it was generally agreed that none surpassed the berries of the wild Scarlet in flavor. The strawberries of that period were of good quality, but small. 
The species that was to contribute the attribute of size to the modern strawberry was introduced into Europe in 1712 by a French officer named Frezier, who found it in his travels through South America. F. chiloensis is indigenous to Chile and other parts of the coast region of North and South America. Frezier found it in Chile, both wild and cultivated, and was so much impressed with the size of its berries - he described them as "the size of hen's eggs" - that he determined to carry it to his home in Marseille. The plants of this first importation are thought to have come from Concepcion, Chile, and not from the island of Chiloe. It is related that during the long voyage the supply of water nearly gave out and Frezier was obliged to divide his own allowance with his plants. Five plants survived. Unfortunately, these were all pistillate, so that for many years there was complaint that the Chilean was unproductive. Some of the later importations were hermaphrodite and were fairly productive.

One of the original plants was set near Brest, France, and was the foundation of a notable commercial strawberry industry at that point; in 1857 there were nearly 500 acres of the Chilean at Brest. In 1727 it was introduced into England by Philip Miller, but found little favor there. It was not grown in Europe to any extent except at Brest. In 1766 Duchesne noted that its cultivation had been abandoned "on account of its sterility." Later importations were more satisfactory, but the species was always considered a shy bearer, and tender.

The Chilean did not vary materially under cultivation. In 1824, a century after it was introduced, Barnet knew of but two, possibly three, varieties. These differed mainly in the color of the fruit. The flavor of the Chilean 


\section{THE STRAWBERRY IN NORTH AMERICA}

did not commend it. "As to the Chili," said pungent William Cobbett, "it is very little superior in flavor to the potato." There was little promise for the amelioration of the garden strawberry in pure $F$. chiloensis.

The advent of the Pine. - The plant that was to become the progenitor of the modern garden strawberry appeared

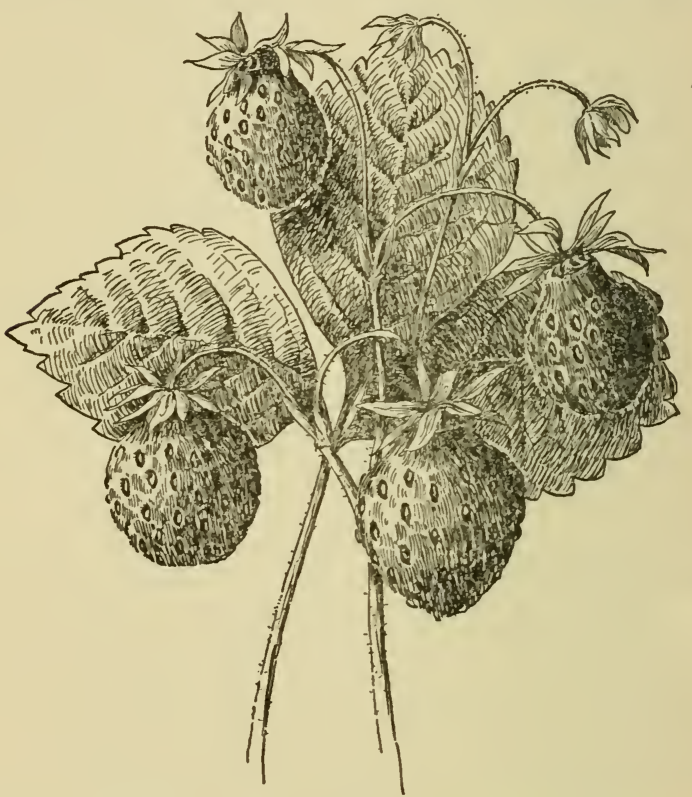

FIg. 10. - Old Pine, or Pineapple, the progenitor of the garden strawberry.

in Europe near the middle of the eighteenth century. It was first described and illustrated in the seventh edition of Philip Miller's "Dictionary of Gardening" (1759). The origin of the Pine strawberry ( $F$. grandiflora, or $F$. ananassa, referring to the pineapple fragrance of the fruit), 
is obscure. At one time it was supposed by some to have been introduced into Holland from Surinam, which is now the coast of Dutch Guinea; hence it was long called the Surinam strawberry. This can hardly be possible, since the strawberry is not indigenous to that region. Others believed it to be an importation from some part of North America, possibly Louisiana, Virginia, or Carolina. One type of Old Pine was long called the Carolina. IVilliam Prince, in his "Short Treatise on Horticulture" (1828), says of the Pineapple, or Carolina: "This is a native of our own country;" and in 1832, members of the Charleston (South Carolina) Horticultural Society, spoke of the Carolina as indigenous to that State. No wild Fragaria that resembles the Old Pine can be found in North America to-day. The robust prairie form of the Scarlet, $F$. virginiana, var. illinoensis, was thought by Decaisne to be the progenitor of the Pine, but the characters of the two are so distinct that this hypothesis hardly seems tenable.

There remain two much more plausible explanations of the origin of the Pine; first, that it was a seedling of $F$. chiloensis; second, that it was a hybrid between $F$. chiloensis and $F$. virginiana. It is possible that there were two or more forms of the Pine; the one introduced into France about 1750 and described by Poiteau was somewhat different from the one introduced into England from Holland and described by Miller. The difference between the Old Pine, the Carolina, the Bath, the Patagonia, Black, and other forms, was so slight, however, that they were all grouped as $F$. grandiflora by Ehrhart in 1792, and Comte de Lambertye, who reviewed the botany of Fragaria very thoroughly, considered them identical.

The hypothesis of Seringe, advanced in 1825, that the 
Pine is a direct modification of the Chilean, was accepted by De Candolle in his "Prodromus." This opinion was shared by Duhamel, who stated that the Pine could be raised from seeds of the Chilean. In more recent years, L. H. Bailey has marshaled the arguments of history, philosophy and botany, in support of this contention, adding thereto an observation upon the behavior of some plants of $F$. chiloensis that he transplanted from Oregon to New York. ${ }^{1}$ Within three years they changed from squat, blue-leaved, short-trussed, densely hairy plants to "tall-growing, green-leaved, high-trussed and thinly haired plants," closely resembling many modern varieties. This, however, is not necessarily proof that the modern strawberry descended from the Chilean; it may be merely proof of the remarkable plasticity of the species. Equally marked variations from the type may be found in the wild Chilean as it grows in different parts of the Pacific Coast.

The theory that the Pine is a hybrid between the Virginian and Chilean species has found wide acceptance. This explanation was first advanced by Duchesne in 1766 . It is based more largely upon the fact that the Pine is quite intermediate in botanical characters between the Scarlet and the Chilean than upon definite historical evidence. The argument in support of this contention was presented by Vilmorin in $1898:^{2}$ " The first detailed account of the large fruited strawberry was given by Miller in 1759, with a good figure. As both the Chili and the Scarlet, or Virginian strawberry, had been introduced some forty or fifty years, the opinion expressed by Duchesne ('Hist. des Fr.,' page 197), that it is a hybrid

1 "Survival of the Unlike" (1896), pp. 400-417.

${ }_{2}^{2}$ Trans. Royal Hort. Soc., 1898-9, pp. 318-319. 
between the two last-named sorts, seems to gain much credit. The original form, known in England as the Old Pine, and in France as fraisier ananas, is to be found in gardens to the present day, answering perfectly to the elaborate description given by Duchesne ('Hist. des Fr.,' pp. 191-194). It is, in fact, intermediate between $F$. chiloensis and $F$. virginiana, and the pale brownish color of the fruit is, in that respect, highly characteristic."

That the Old Pine was quite intermediate in character between its supposed parents is shown by the following comparison, which is compiled from the descriptions made by Barnet, in 1826 :

\begin{tabular}{|c|c|c|c|}
\hline & Old Scarlet & True Chili & Old Pine \\
\hline Season & Early & Late & Rather late \\
\hline Size & Medium & $\begin{array}{l}\text { Particularly } \\
\text { large }\end{array}$ & Large \\
\hline Form & $\begin{array}{r}\text { Globular, with a } \\
\text { distinct neck }\end{array}$ & $\begin{array}{l}\text { Irregular, but } \\
\text { usually ovate } \\
\text { orblunt-conic, } \\
\text { not necked }\end{array}$ & $\begin{array}{l}\text { Ovate conic, } \\
\text { early fruits } \\
\text { coxcombed, } \\
\text { with a neck. }\end{array}$ \\
\hline Color & $\begin{array}{l}\text { Uniform light } \\
\text { scarlet, } \\
\text { slightly hairy. }\end{array}$ & $\begin{array}{c}\text { Dull, varnished, } \\
\text { brownish red }\end{array}$ & $\begin{array}{l}\text { Uniform bright } \\
\text { scarlet, slight- } \\
\text { ly hairy }\end{array}$ \\
\hline Seeds & $\begin{array}{l}\text { Deeply im- } \\
\text { bedded, in- } \\
\text { tervals ridged }\end{array}$ & $\begin{array}{l}\text { Dark brown, } \\
\text { and project- } \\
\text { ing }\end{array}$ & $\begin{array}{l}\text { Slightly im- } \\
\text { bedded }\end{array}$ \\
\hline Flesh & $\begin{array}{l}\text { Pale scarlet, } \\
\text { firm, high } \\
\text { flavored }\end{array}$ & $\begin{array}{l}\text { Whitish, very } \\
\text { firm, hollow } \\
\text { in center, } \\
\text { with a small } \\
\text { core, flavor } \\
\text { moderate }\end{array}$ & $\begin{array}{l}\text { Pale scarlet, } \\
\text { generally } \\
\text { solid }\end{array}$ \\
\hline
\end{tabular}




\begin{tabular}{|c|c|c|c|}
\hline & Old Scarlet & True Chili & Old Pine \\
\hline Calyx & $\begin{array}{l}\text { Small, spread- } \\
\text { ing }\end{array}$ & Very large & $\begin{array}{l}\text { Large, spread- } \\
\text { ing, sometimes } \\
\text { partially re- } \\
\text { flexed }\end{array}$ \\
\hline Leaf stalks & $\begin{array}{l}\text { Abundant, } \\
\text { slightly hairy }\end{array}$ & $\begin{array}{l}\text { Tall, upright, } \\
\text { stiff, densely } \\
\text { hairy }\end{array}$ & $\begin{array}{cr}\text { Tall, rather up- } \\
\text { right, partial- } \\
\text { ly } & \text { covered } \\
\text { with } & \text { long } \\
\text { hairs } & \end{array}$ \\
\hline Leaflets & $\begin{array}{l}\text { Large oblong, } \\
\text { somewhat } \\
\text { folded, } \\
\text { coarsely and } \\
\text { sharply ser- } \\
\text { rate, smooth } \\
\text { above the } \\
\text { young ones, } \\
\text { pale, thin } \\
\text { texture }\end{array}$ & $\begin{array}{l}\text { Small, nearly } \\
\text { oval, concave, } \\
\text { serrations } \\
\text { very obtuse, } \\
\text { upper surface } \\
\text { slightly hairy, } \\
\text { shining light } \\
\text { green, under } \\
\text { surface very } \\
\text { downy, thick } \\
\text { texture }\end{array}$ & $\begin{array}{l}\text { Small, nearly } \\
\text { oval, spread- } \\
\text { ing horizon- } \\
\text { tally, rounded } \\
\text { serratures, } \\
\text { surface } \\
\text { smooth, shin- } \\
\text { ing dark green } \\
\text { on upper sur- } \\
\text { face }\end{array}$ \\
\hline Runners & $\begin{array}{l}\text { Numerous, } \\
\text { brown where } \\
\text { exposed }\end{array}$ & $\begin{array}{c}\text { Very strong, } \\
\text { thick, inter- } \\
\text { nodes very } \\
\text { long }\end{array}$ & $\begin{array}{l}\text { Numerous, } \\
\text { large, reddish }\end{array}$ \\
\hline $\begin{array}{l}\text { Flower } \\
\text { stalks }\end{array}$ & $\begin{array}{l}\text { Short, generally } \\
\text { one half the } \\
\text { length of the } \\
\text { leaf stalks; } \\
\text { peduncles of } \\
\text { moderate } \\
\text { length }\end{array}$ & $\begin{array}{l}\text { Short, strong, } \\
\text { very villous, } \\
\text { much } \\
\text { branched, } \\
\text { branches } \\
\text { spreading } \\
\text { horizontally, } \\
\text { and long stiff } \\
\text { peduncles }\end{array}$ & $\begin{array}{l}\text { Half the length } \\
\text { of the leaf } \\
\text { stalks, rather } \\
\text { upright, very } \\
\text { stiff, slightly } \\
\text { hairy, branch- } \\
\text { ing, with long } \\
\text { peduncles }\end{array}$ \\
\hline Flowers & $\begin{array}{l}\text { Abundant, } \\
\text { early, } \\
\text { medium size }\end{array}$ & $\begin{array}{l}\text { Not very large, } \\
\text { open late }\end{array}$ & Late, large \\
\hline
\end{tabular}


Intermediateness of character does not prove hybridity, but it is at least a strong argument for it. The fact that the Scarlet and the Chilean cross readily is well known. Wilmot's Superb, raised by John Wilmot, of Isleworth, England, in 1821, was a cross between the true Chili and the Roseberry, a variety of the Scarlet. It resembled the Old Pine. About the same time, Thomas Andrew Knight made many crosses between the two species and raised over 400 seedlings. One of these, the Downton, was presumably a virginiana-chiloensis cross. This variety was classified as a Pine.

The fact that all the plants of $F$. chiloensis first brought from Chile were pistillate has been noted (p. 115). This gives color to the hybrid hypothesis of the origin of the Pine since any seedlings of the Chilean that were raised at that time would be hybrids; and, as has been pointed out (p. 96), varieties of the Scarlet were commonly used for pollinating the Chilean.

Several recent students of the botany of Fragaria have dissented from the theory that the Pine was pure $F$. chiloensis. In 1914 C. W. Richardson, an English plant breeder, expressed this opinion: " "Something of the origin of the modern garden strawberry is known, but its whole history is not. It springs from an old form of garden strawberry, the result of crosses between vesca, Alpine, and Hautbois. This older form was again crossed with $F$. virginiana, introduced in 1629 , and with $F$. chiloensis, introduced in Marseilles in 1712 and to England in 1727 by Philip Miller. These crosses were again crossed with $F$. ananassa ( $F$. grandiflora), introduced from Holland during the eighteenth century. The origin of this plant is unknown. It was said to have been brought from 1 Jour. Genetics, 3 (1914), p. 173. 
Surinam, where today there are said to be no strawberries. It is also said to have been a variety of the Virginian brought from Carolina. It may be a chinensis cross, as Holland received many plants from China during the eighteenth century. Whatever its origin, all our best garden varieties of today are descended from $F$. ananassa crosses. I have selfed eight varieties of garden fruit, producing over 1000 plants. Not one resembles a vesca or an Alpine, but many show distinct traces of chiloensis, more of virginiana and not a few of chinensis."

E. A. Bunyard, another English student of Fragaria, believes that the original Pine was a seedling of $F$. chiloensis but adds:" "To Thomas Andrew Knight and Michael Keens must be given the honor of laying the foundation of the strawberry of the present day. The two most important species had existed for some time in English gardens and it was to the crossing of early descendants of $F$. virginiana and $F$. chiloensis that this success was due." And again, "The introduction of the Chilean strawberry, $F$. chiloensis, brought, however, the required size into combination with the flavor of the Virginian and thus laid the foundation of the fruit as we know it today." In 1907, the Count of Solms-Laubach, a German authority, made an extended study of the botany, classification and development of the strawberry. He concluded that the Pine developed in Europe as a result of hybridization between $F$. chiloensis and $F$. virginiana. ${ }^{2}$ Thus there seems to be fully as much evidence that the Pine was a chiloensis-virginiana hybrid as that it was a direct modification of chiloensis. The original Pine strawberry still is found in English gardens and conservatories.

1 Jour. Royal Hort. Soc., Vol. 39, pt. 3 (1913), p. 547.

${ }^{2}$ Bot. Ztg. 1 Abt. 65 (1907), Nos. 3-4, pp. 1-76. 
We have a reminiscence of this interesting plant in the Pineapple, a North American variety introduced in 1902.

Keens' Seedling. - Whatever uncertainty may exist concerning the exact botanical origin of the Old Pine, there is no question about the decided influence that it exerted in the evolution of the garden strawberry. Varieties of the Pine increased rapidly. When Barnet wrote his famous monograph, in 1824, there were twenty distinct varieties, including the Black strawberries, which were practically the same. The first variety to achieve marked prominence was Keens' Seedling. The introduction of this variety, in 1821, is the beginning of the modern race of large-fruited varieties. In 1806 Michael Keens, a market gardener of Isleworth, sowed seeds of the White Carolina, also called the Large White Chili, a variety which Barnet classified as a Pine. Most of the seedlings were white. One of the best he introduced as Keens' Imperial. This variety attracted little attention and is of interest only because it was the seed parent of Keens' Seedling, in 1819. Keens first exhibited this seedling before the London Horticultural Society in 1821. It so far surpassed all other varieties in size and flavor that it won instant and enthusiastic recognition. The Society executed an excellent colored plate of the variety (Fig. 11) and presented the originator with a silver cup, which still may be seen in London. Keens' Seedling became the principal parent of modern European varieties. It is still grown and valued in Europe.

Keens' Seedling was a typical Pine, as may be seen from the following description, made by Barnet, in $1826:^{1}$ "The fruit is very large, round, or ovate, when ripe of a very dark purplish scarlet next the sun, the other side 1 Trans. Hort. Soc. of London, Vol. VI (1826), pp. 200-201. 


\section{THE STRAWBERRY IN NORTH AMERICA}

paler, slightly hairy; seeds a little imbedded in the polished surface of the fruit, which has usually a furrow at the apex; the fiesh is firm, solid, scarlet, without any separable core, tolerably high flavor. The calyx is of

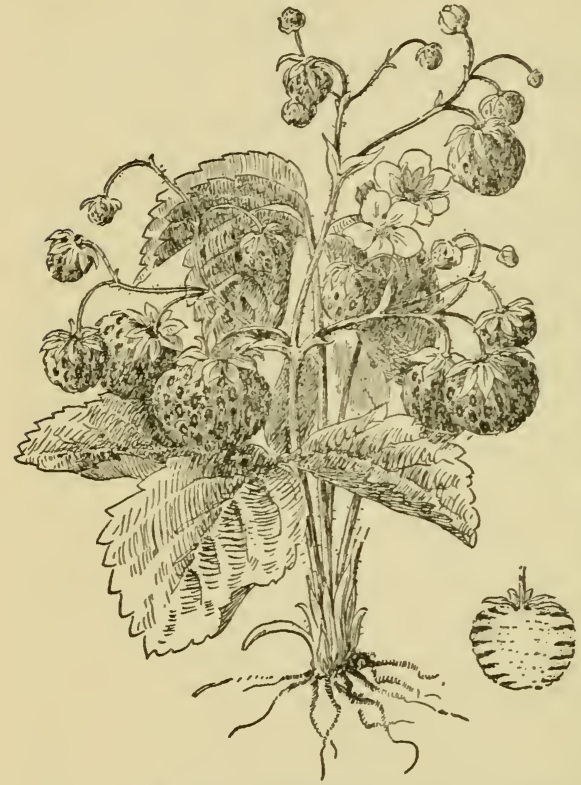

FIG. 11. - Keens' Seedling, the first improved variety; introduced in 1821. modern size, hairy, incurved. The foot stalks of the leaves are tall, slightly hairy; the leaflets very large, roundish, for the most part flat, reclined, of a very smooth shining dark green, with coarse serratures which are large and rounded. The runners are small, numerous, greenish yellow, and slightly hairy. The scapes are of moderate length, sometimes very short branched, with short, weak, clustered peduncles."

Keens' Seedling was not the result of hand crossing; it was produced from berries of Keens' Imperial that had been open to natural cross-pollination, so its exact parentage is not known. The first extended and accurate strawberry breeding was by Thomas Andrew Knight, who used $F$. virginiana, $F$. chiloensis and $F$. grandiflora in his crosses. Of his seedlings, only the Downton and the Elton achieved 
distinction; they have entered somewhat into the lineage of modern European varieties, though not as much as Keens' Seedling. As a result of his work with the three types, Knight concluded: "I believe all to be varieties only of one species, for all may be made to breed together indiscriminately; and I have found that similar varieties may be obtained from the seeds of any other."

\section{Origin of the Garden Strawberry of North AMERICA ${ }^{1}$}

In the evolution of the garden strawberry of North America, the native species, $F$. virginiana, has been much more prominent than it was in the evolution of the garden strawberry of Europe. In recent years, however, there seems to have been a tendency to consider it a rather negligible factor. A recent bulletin states: "This species has given but few varieties, and they have soon dropped out of cultivation." This conclusion is hardly justified from the historical facts now to be presented.

The Virginian or Scarlet strawberry was the only kind known in early colonial days. The Hautbois, Alpine, Wood and Chilean were not introduced until about 1750 , and the Pine about 1790 . With the exception of the Wood, none of these were grown here, save in the gardens of a few amateurs who could afford to pet them. The Red Wood was valued by market gardeners near Boston between 1820 and 1850. About 1820 several nurseries began to disseminate improved varieties of the Scarlet, notably Early Hudson, Hudson's Bay, Methven Scarlet, and Large Early Scarlet. The latter variety and

${ }^{1}$ First published in the Proceedings of the Twelfth Annual Meeting of the Society for Horticultural Science (1915). 
Red Wood dominated the Boston market until the introduction of the Hovey, in 1838. Between 1820 and 1840 the New York market was supplied chiefly with Crimson Cone or Scarlet Runner, a variety of the Scarlet, raised mainly near Hackensack, New Jersey. Anne Arundel county, Maryland, began to grow strawberries for Baltimore and Philadelphia about 1815; the varieties were Hart, Large Early Scarlet and Stewart, all varieties of the Scarlet. Following the production of Keens' Seedling, in 1819, a large number of varieties of the Pine were introduced here. None achieved prominence save the Mulberry, which was largely grown near Boston about 1835. At the close of this period, with the introduction of the Hovey in 1838, such small beginnings in commercial strawberry culture as had been made were almost wholly with varieties of $F$. virginiana.

The Hovey proved decidedly disappointing as a commercial sort, although valued highly for home use. It did not displace Large Early Scarlet, Hudson's Bay, Early Hudson, Crimson Cone and other varieties of the Scarlet in commercial culture. After 1848 it was rarely quoted in any market except Boston. Excluding the wild berries, which were brought to market in large quantities, it is probable that over ninety-five per cent of the strawberries marketed before 1858, when the Wilson rushed to the front, were pure varieties of $F$. virginiana. The Large Early Scarlet retained prominence in western New York until 1864 , and was a leading commercial variety at Dighton, Massachusetts, until 1865, under the name of "Old Virginia" (Fig. 12). It passed out of cultivation in North America about 1875, having been the dominant variety for seventy-five years.

Since the passing of Large Early Scarlet no varieties 
known to be pure $F$. virginiana have been grown largely except Cutter's Seedling and Crystal City. The former, introduced in 1859, was grown considerably in New England from 1862 to 1875 . William H. Hill assures us that it was pure $F$.virginiana. Crystal City, or Acme, introduced in 1876 , was a popular extra early sort, especially for home use, until about 1892 . This variety was very similar to Large Early Scarlet.

Several sorts introduced more recently have been supposed to be $F$. virginiana. Among these are

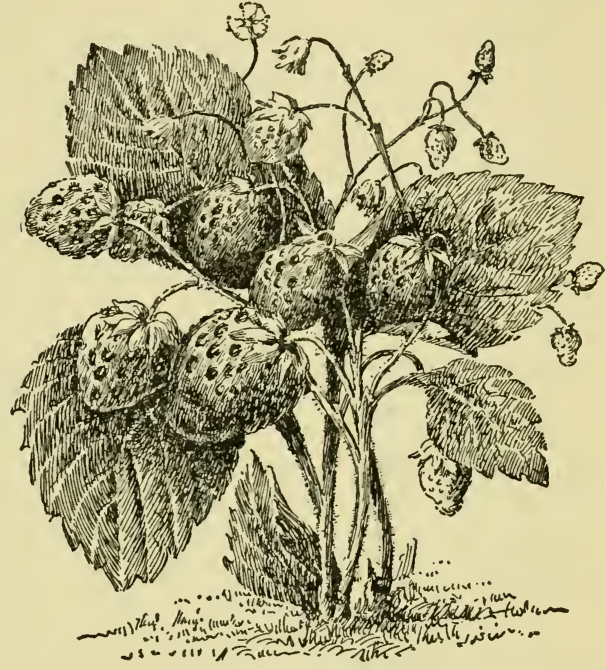

Fig. 12. - Large Early Scarlet, a form of $F$. virginiana; the dominant variety in North America, $1830-1860$.

August Luther,

Michel and Wonder (of Shank). The surmise as to their botany is not capable of proof, but they bear so much resemblance to the Scarlet that it seems probable they are of the blood of that species in some degree. In 1908 a variety known as Earliest was listed as "an improved variety of the Iowa wild strawberry." The prairie form of $F$. virginiana has been much more productive of improved sorts than the eastern form; it is larger, more variable, and responds more quickly to cultivation. 
This record of $F$. virginiana under cultivation in North America should be sufficient to clear the species of the charge that it has been but a negligible factor. Whether it enters into the lineage of modern varieties or not, it has contributed largely to the upbuilding of the strawberry industry. For over a century varieties of the Scarlet held almost undisputed control of the strawberry market of North America, limited though it was.

Historical evidence. - Turning now to the more speculative phase of the subject - the botanical origin of the garden strawberry of today - it must be keenly regretted that the parentage of the four varieties from which most modern sorts have sprung is so obscure. These stem varieties are the Hovey, Wilson, Sharpless and Crescent. I have been able to obtain records of 1853 varieties which have originated in North America. Of these the parents of only 348 are known definitely. Sixty-three are descendants of Crescent, sixty-nine of Sharpless, forty-eight of Wilson and fifty-one of Hovey. Thus approximately two thirds of the varieties of known parentage have come from the great four. It is a misfortune that the parents of none of the four are known with certainty, hence the subject must be one for speculation rather than for conclusive proof.

When C. M. Hovey produced his famous seedling he made the following six crosses by hand:

1. Methven Scarlet $\times$ Keens' Seedling.

2. Methven Scarlet $\times$ Melon.

3. Mulberry $\times$ Keens' Seedling.

4. Melon $\times$ Keens' Seedling.

5. Southborough $\times$ Prolific Hautbois.

6. Grove End Scarlet $\times$ Keens' Seedling. 
All were varieties of European origin; Methven Scarlet, Southborough and Grove End Scarlet were varieties of $F$. virginiana, while Keens' Seedling, Mulberry and Melon were Pines. Hovey was so unfortunate as to lose his labels, so that he never knew positively which cross produced the Hovey. In 1840 he asserted, "We can, however, state that the variety originated from one of the first four crosses and in all probability from No. 1 or No. 4 ; and we have always thought from the latter." Both of the parents of Cross No. 4 were Pines. It is this statement upon which the conclusion that the Hovey was a Pine has been largely based. It seems to have been overlooked that five years later, perhaps after more careful consideration, Hovey stated ${ }^{2}$ : "Our seedling we have supposed was from Methven Scarlet impregnated with Keens' Seedling." We are justified, therefore, in concluding that it is at least equally probable that the Hovey originated from Cross No. 1, in which case one parent was a variety of $F$. virginiana, as from Cross No. 4 , in which both parents were Pines.

Seedlings of the Hovey were scattered over the land, and became, in a large measure, the foundation stock of the modern strawberry. The fifty-one varieties known to have descended from the Hovey are listed on page 189. Practically all came down through two noted varieties, Green Prolific and Cumberland Triumph. A number, as Clyde, Ozark and Sons, are four generations removed from the Hovey; Roosevelt (of Cathcoit) is five, as follows :

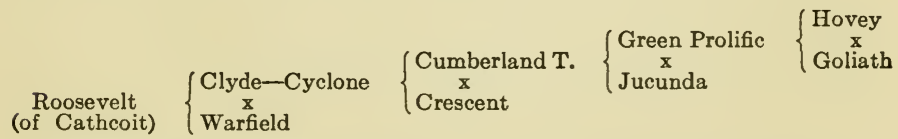
${ }^{1}$ Mag. Hort., 1840, p. $293 . \quad 292$. 
Monarch, which originated in 1867 , is but two generations from the Hovey; it is still grown in California and Colorado. The Hovey was also one of the probable parents of the Longworth, which originated in 1848 and is still a commercial variety in California, being the oldest North American variety in cultivation. Another probable parent of the Longworth was Taylor's Seedling, a variety of $F$. illinoensis, the prairie form of $F$. virginiana.

The parents of the three other varieties that have entered most largely into the lineage of modern North American sorts are equally in doubt. In 1851 James Wilson, a gardener near Albany, New York, sowed seeds of the Hovey, Black Prince, and Ross' Phœnix. Both of the latter were Pines, Black Prince being a seedling of Keens' Imperial and a direct descendant of the original Pineapple strawberry, while Ross' Phœnix was a seedling of Keens' Seedling. These seeds were the result of natural pollination, not of hand crossing. James Wilson was confident that his seedling was Hovey $\times$ Black Prince, according to a statement made after his death by his son, John Wilson, and this opinion was shared by his contemporaries. This surmise was based upon the appearance and behavior of the Wilson and its seedlings, not upon authentic records. If we assume that the Hovey was one of the parents of the Wilson, then the forty-eight varieties that are known to have descended from the Wilson are of the same lineage. These are listed on page 190.

The Sharpless was originated in 1872 by J. K. Sharpless, Catawissa, Pennsylvania, from hand-sown mixed seed of Jucunda, Charles Downing, Wilson and Col. Cheney. The originator believed that it was a seedling of the Charles Downing, but this must remain a matter for speculation. The Charles Downing was a seedling of Downer's Prolific, 
which was said to have been bred from the native strawberry of Iowa. If we assume that the surmise of Mr. Sharpless was well founded, then the sixty-nine varieties known to have descended from his seedling are of $F$. virginiana blood, in part. These are listed on page 191 .

The Crescent was a chance seedling found by William Parmalee, of New Haven, Connecticut, in 1870. It has been supposed by many to be a pure seedling of $F$. virginiana, and it certainly shows many of the characters of that species, both in plant and fruit; but this is mere conjecture. The sixty-three varieties that have descended from it are listed on page 191.

Thus a majority of the varieties of known parentage, those out of the Hovey, Wilson, Sharpless and Crescent, are supposed to contain the blood of $F$. virginiana in part. There are a number of varieties in which the surmise becomes almost a certainty. In 1854, J. S. Downer, of Fairview, Kentucky, produced Downer's Prolific. In 1876, James Smith, of Des Moines, Iowa, stated: ${ }^{1}$ "Downer produced his Downer's Prolific from seed of the native Iowa strawberry," which is a form of $F$. virginiana. Andrew S. Fuller called the Charles Downing, which was a seedling of Downer's Prolific, "a large representative of the western $F$. virginiana, var. illinoensis." J. L. Budd asserts, ${ }^{2}$ "We know that the Charles Downing sprang from the western wild species (Fragaria illinoensis) pollinated by a Chilean variety; and we also know that in habit of growth and runners and in choice aromatic flavor it follows the native, while the Chilean pollen has given size of fruit and decidedly modified the foliage. Our native species has also transmitted the required

1 Proc. Iowa Hort. Soc., 1876, p. 337.

2 "American Horticultural Manual," Vol. I, p. 265. 
hardiness." This view was commonly accepted by the horticulturists of that period. The rampant growth of runners and the deeply imbedded seeds of the Charles Downing were marked indications of $F$. virginiana blood.

The Charles Downing became a great commercial variety. Between 1875 and 1890 it was a close competitor of the Wilson. Ten of its descendants are in cultivation today, most of them coming through the Windsor. These are: Enhance, Ham, Hazel, Marconi, Mary (of Alley), Millionaire, Nina, Reba, Reliance and Robinson. We now have but two varieties, the Elma and the Robbie, that have descended from the Kentucky, another notable seedling of Downer's Prolific.

Several other varieties of some prominence have been, beyond question, of $F$. virginiana blood in part. One was the Bidwell, which was widely grown for home use between 1880 and 1895 . This variety was produced by Benjamin Hathaway, of Little Prairie Ronde, Michigan, by crossing, to quote from him, "what I call the Pistillate Scarlet, that came out through three or four generations from the old Virginia Scarlet," with Wilson, Sharpless and Glendale as pollinizers. ${ }^{1}$ 'The Michigan, another noted variety produced by Hathaway, was this same Pistillate Scarlet crossed with Burr's Seedling. It was widely planted between 1865 and 1875 . Hathaway's statement of the origin of these two varieties was verified by T. T. Lyon.

Botanical evidence. - This completes the evidence of history in support of the contention that $F$. virginiana has entered largely into the lineage of the modern strawberry. There remains the evidence of botany. At first thought it might seem that it should be comparatively easy to

${ }^{1}$ Proc. Amer. Pom. Soc., 1881, p. 55. 
determine from what species the garden strawberry has sprung by making comparative studies in anatomy, yet this has not given conclusive results. The genus Fragaria is a most flexible and unstable group of plants. Botanists rarely agree upon the limits of a species. Some would make several species out of the group of plants known loosely as $F$. virginiana.

A large proportion of the seedlings resulting from a strawberry cross tend to revert to a more primitive type; usually over ninety per cent of them are inferior to either parent. In 1886 E. Lewis Sturtevant reported his observations on this point." "The modern varieties under American culture seem to belong mostly to the species represented in nature by $F$. virginiana, although there are supposed hybridizations with $F$. chiloensis, and, in the high flavored class, with $F$. elatior. Certain it is that in growing seedlings from our improved varieties reversions often occur to varieties referable to the Hautbois and Chilean sorts, from which fact hybridization can be inferred. I have noticed as of common occurrence that seedlings from high flavored varieties are very likely to furnish some plants of the Hautbois class and scarcely if at all distinguishable from named varieties of the Hautbois with which there has been opportunity for close comparison. From large berries of diminished flavor and which occasionally throw hollow berries the reversion occasionally produces plants unmistakably of the Chilean type. In other cases we have noticed reversions to forms of $F$. vesca. These circumstances all lead towards establishing the mingled parentage of our varieties under cultivation." This conclusion agrees with that of Richardson, previously quoted, (page 121), that the modern strawberry is a com1 Trans. Mass. Hort. Soc., 1888, pp: 191-204. 
posite of several species, including the Hautbois and vesca, as well as the Virginian and Chilean.

While the anatomical characters of modern varieties furnish no conclusive clue to their botanical origin, there are several points worth noting. The position of the seeds is a character of segregation between the Chilean and the Virginian species. In the former they are commonly exserted or but slightly imbedded; in the latter they are sunk into deep, angular pits. Most of the early North American varieties had sunken seeds. According to Hooper's "Western Fruit Book," the seeds of the Hovey were "imbedded in a small cavity." Modern varieties show both contrasting characters, but those with exserted seeds are more numerous now, as the berries are less likely to be bruised.

A long neck characterized many of the varieties following the Hovey. The berries of $F$. chiloensis rarely have a pronounced neck, but this feature is quite common in the Virginian and in $F$. vesca. The Banana strawberry, introduced about 1870 , was the most conspicuous example of a necked variety (Fig. 18). This variety was a seedling of Agriculturist, which came from Green Prolific, which was a seedling of the Hovey. Long necks are not desired now, since such berries do not carry to market well.

The abundance of runners of many modern varieties may be an indication of $F$. virginiana blood. Some forms of $F$. chiloensis, as the Alaska beach strawberry, have numerous runners, but the species as a whole is characterized by a very moderate runner production, as compared with $F$. virginiana. The wild Scarlet makes runners in the greatest profusion. This habit always has been one of the greatest defects of the Scarlet under cultivation; it makes so many plants that the bed is over- 
crowded and consequently the fruit is very small. The Hovey was a moderate plant maker, but a large proportion of the varieties following it were exceedingly prolific of plants. The Colfax, introduced in 1867, was said to "kill weeds and everything else and completely occupy the ground." In $1860 \mathrm{~J}$. A. Warder recommended the Necked Pine as "death on blue grass; it will jump over the fence and escape everything that trespasses. Plant it thirty feet apart and let it run." The Crescent was so prolific of plants that many growers set it ten feet apart each way, and still got a good stand in normal seasons. Consider also the remarkable plant-making ability of Cumberland Triumph and many of its progeny, all descendants of the Hovey; and the rampant runners of the Charles Downing. It is exceedingly difficult to associate this free-running habit with a pure strain of $F$. chiloensis. Few of the varieties of more recent introduction produce runners as freely as this, because it is no longer desired. Some degree of runner restriction is considered essential to the production of good fruit; naturally this ideal is reflected in the selection of seedlings.

Most plant breeders agree that the attribute of hardiness cannot be acquired in a few years, by selection, unless the plant under consideration happens to be a heterozygote. As a general proposition, hardiness is the result of some hundreds or thousands of years of natural selection. Hence, if we wish to secure hardier varieties of a tender plant in our own generation the most practicable course is to infuse the blood of a hardier species.

There are some places where $F$. chiloensis is quite hardy, but for the most part it is a tender species. Its habitat is the more tempered regions of North and South America. The South American form, from which the Pine is sup- 
posed to have been derived, is especially tender. $F$. virginiana, on the other hand, is decidedly hardy. It grows close up to the snow line. It withstands temperatures of forty degrees below zero and survives even the extreme conditions on our northwestern prairies. It has been used recently by Hansen to breed greater hardiness into some of the common varieties, with marked results, so far as this one attribute is concerned. Modern English varieties are distinctly inferior to American varieties in hardiness. The race of strawberries that has developed in North America since the introduction of the Hovey, however, is sufficiently hardy to succeed under commercial culture in all parts of the continent except where climatic conditions are unusually trying, as in the Dakotas, Minnesota, Manitoba and Saskatchewan. It is difficult to conceive that a pure form of $F$. chiloensis could have acquired this remarkable degree of hardiness, so foreign to its nature in the wild, within so short a period. It is much more likely that the greater hardiness of North American varieties, as compared with English sorts, is due to a larger admixture of the more hardy species.

There are other characters of modern varieties, both in plant and fruit, that indicate a mixed origin. Some varieties show the division of the crown, the smooth, thin leaves, the deep-feeding, wiry roots and red flesh of $F$. virginiana; others show the undivided crowns, thick downy leaves, shallow-feeding, fleshy roots, very long root stalks and white flesh of $F$. chiloensis.

An argument for the hybrid origin of the garden strawberry is found in the record of pure $F$. chiloensis under cultivation. Although this species has been grown in Europe for two centuries, it has produced but few varieties and none of these has been found worthy of general culti- 
vation. It was offered for sale in one of the first North American trade catalogs, which was sent out by Prince's Linnæan Gardens, in 1771. The White Chilean was grown sparingly for preserves until about 1860, especially in California, but never was popular outside of the gardens of a few amateurs. It has shown but little tendency to vary under cultivation; the few varieties differ mainly in the color of the fruit. F. chiloensis is indigenous to our entire Pacific seaboard; yet I have not been able to discover a single variety that has sprung from it during the hundred years that have elapsed since there has been any considerable interest in strawberry culture on this continent.

It might be argued, with justice, that the South American form of $F$. chiloensis, from which the Pine is supposed to have sprung, may have possessed a tendency to vary into improved forms that is lacking in the North American representatives of the species. This phenomenon is seen in the native plum, Prunus americana. Practically all of the valuable varieties of this species have come from the Mississippi Valley; the eastern form shows little profitable variation. Yet it would seem reasonable to expect that if North American varieties of the strawberry are of $F$. chiloensis blood, and nothing else, the species should at least give us an occasional improved variety in these latter days. $F$. virginiana was the mainstay of strawberry culture in North America for over a century. Would it not be strange indeed if it were suddenly and completely dispossessed by a species that is known to have produced no valuable varieties in a pure form, either here or in Europe, during the 200 years that it has been in cultivation?

Extended study of the botanical characters of the several 
species, and of their behavior under cultivation and hybridization, is necessary to establish with certainty the origin of the garden form. This has not yet been given, but the presumption is strong, from the foregoing evidence, that both the Chilean and Virginian species are represented in modern varieties.

\section{Origin of the Everbearers}

The search for varieties that are consistently everbearing in the North has been long, and fraught with repeated disappointment. The first everbearing strawberry worthy of the name was the Alpine, also called the Alpine Perpetual and Monthly Alpine. This takes its name from the Alps Mountains of Europe, where it is indigenous. It is said to have been introduced into France and England about 1764, but it had been known for at least 200 years previous. Duchesne, writing in 1766, says: "The King of England was understood to have received the first seed from Turin. It was such a rarity that a pinch of the seed sold for a guinea." At that time the Alpine was supposed to be a distinct species; now it is classed as a form of the Wood strawberry, $F$. vesca. The only difference between the Wood and the Alpine is that the fruit of the latter is pointed instead of round, and the plant bears more or less continuously from April to November. Usually, the Wood bears but once a year, in the spring, but some seasons it shows a tendency towards fall fruiting. The essential difference between single-bearing and everbearing sorts may be found in their anatomical structure. The latter produces flowering stems from the axils of some of the leaves on the main stem, instead of runners. According to Henri de Vilmorin, the everbearing 
habit is so firmly fixed in the Alpine that all its seedlings possess this character in equal degree, although they may vary somewhat in other respects.

A number of distinct varieties of the Alpine are recognized. These cannot be reproduced absolutely true unless propagated by runners or division, but seed propagation is so much easier and gives so much better fruit that most gardeners prefer it. Seedlings differ from the parent only in minor respects. Seed propagation is especially necessary with the Bush Alpine, which has no runners. The original plant of this curious type was found at Gaillon, in the European Alps, by M. Labaube, in 1811. Several years later, probably in 1818, M. Morel de Vindé originated the white-fruiting Bush Alpine, which, also, comes fairly true from seed.

The Alpines were tested repeatedly in North America, but never gained a foothold. In 1833 it was reported that a man near New York City had "several acres of vines from which he sold upwards of a thousand dollars' worth of berries." 1 For many years the White Alpine was valued in the Province of Quebec, as it was hardy there without a mulch and bore good crops of small, sweet berries. In Quebec it was perfectly remontante, bearing from the latter part of June until late September. At one time some attention was given to the Alpines in California, but for the most part they have been grown only in home gardens, and occasionally in greenhouses. There is little interest in the Alpines now, except among amateurs.

From time to time the Alpines have been reintroduced into North America, with extravagant claims concerning their everbearing habits. Until 1910, our more voluble 1 The New England Farmer, 1833, p. 106. 
trade catalogs dilated upon the virtues of the "wonderful everbearing strawberry, which bears red, white, and green berries." This was mixed seed of Alpine varieties. The Mexican Everbearing, or Maximilian Prolific, introduced in 1867 , created a sensation - for a short time. This was said to have been discovered near Jalapa, Mexico. It was supposed to be a new species and was named $F$. Gilmani, by the Buffalo Academy of Natural Sciences, in honor of the introducer. It was introduced with great acclaim, and sold for $\$ 3$ a dozen plants, but proved to be almost identical with the old Red Alpine, and practically worthless. There is no reason for doubting that the Mexican Everbearing came from Mexico, for the Alpine, or a closely related form, called $F$. Mexicana, is widely naturalized there in the higher altitudes, and bears continuously. L. E. Benton has written an interesting account of the Mexican strawberry industry. He says $:{ }^{1}$ "In the city of Mexico we have strawberries every day in the year. In some months they are more plentiful than others, but they are always here in more or less quantity. They are from plants that are practically everbearing, but at no time of the year do they bear one-third as heavily as do the strawberries in the United States. They are known as the strawberries of Irapuato because it is in that district that practically the entire crop is grown. This is about two hundred miles north of the city of Mexico. The fruit is sent by express just as it was picked, loose, in twenty-pound baskets. The growth of the fruit is slowly spreading and now some is grown at Guadalajara and Obregon.

"The Irapuato strawberry, in leaf, resembles the common northern one. It is distinct in throwing out few ${ }^{1}$ Rural New Yorker, 1911, p. 314. 
runners; it prefers to grow in a bunch. In this it resembles the Alpine, and it may be a cross or variety of the two types. It is called here fresa, which means the common running strawberry, and is distinctly understood not to be the freson which means the Alpine kind. The freson we have here, but it does not succeed as well in the Irapuato district, nor is it as productive. The better American varieties have been tried here many times, but always dwindle and die off. In French catalogues there are both fresas and fresons and it may be that these here were imported from France."

European everbearing varieties. - The chief faults of the Alpines are their small size and light yield. Beginning soon after the Alpines were introduced, numerous attempts were made, mainly in France, to cross them with the common large-fruited sorts. One of the first of these crosses to be widely advertised was Gloede's Perpetual. This was brought to North America about 1865 and advertised as a large-fruited everbearer, but proved worthless here. In Europe it met with some favor, but was not as dependable as the Alpine. A bush Alpine, the Inexhaustible, originated by M. Mabille, created considerable excitement in Europe and America about 1872.

The first really good perpetual strawberry was the St. Joseph, which was originated by Abbé Thivolet, of Chenoves, Saône-et-Loire, France, in 1893. It was the result of thirteen years of crossing of the Alpine with the large-fruited varieties. Subsequently, he introduced the St. Antoine de Padoue, a seedling of the St. Joseph, and several other everbearing sorts of the same lineage. Louis Gautier, another French variety of this class, was introduced into North America in 1894 as "the great twice-fruiting French strawberry; the old plants bear 
in May and their runners in September." None of the European varieties were successful here. Almost invariably they have proved to be tender, weak-growing, and the everbearing habit is scarcely in evidence. If irrigated and fertilized heavily, they throw out runners which bear as soon as rooted, giving a partial fall crop, but not enough to justify the trouble. In Europe, however, especially in France, these varieties are thrifty and truly everbearing. Henri de Vilmorin says: "They flower and bear fruit continuously from May to November and produce a moderate amount of runners. Their chief value is for the home garden, but with extra care and management they may even prove profitable as a market crop for late summer and early autumn." In 1902 P. de Vilmorin said of the St. Joseph and the St. Antoine, as grown in France, "Whenever the water supply has been sufficient to keep them growing they gave all through the summer and as late as October a great crop of large, well-flavored fruits, fetching high prices when sent to market." 1

Early failures in North America. - Meanwhile, American growers were disappointed repeatedly in their search for an everbearing variety adapted to conditions here. Aside from failures with the Alpines and the European hybrid everbearers, a number of native sorts that at first seemed to hold some promise proved to be worthless. One of the first of these was reported by Nicholas Longworth, in 1852. ${ }^{2}$ He said: "There is a wild everbearing variety in our State (Ohio) that would cross with the Scarlet and Pine and is the only kind I have ever seen worthy

${ }^{1}$ Mem. Hort. Soc. N. Y., Vol. I (1902), p. 255.

2 "Culture of the Strawberry," by Nicholas Longworth, in "The Culture of the Grape and Wine-making," by Robert Buchanan (1852), p. 133. Also in Country Gentleman, XI (1858), p. 366. 
of the name of Everbearing; for the Alpine, after the first crop, rarely produces much fruit through the season. Thirty years ago I met with a solitary strawberry plant on Mt. Adams, then in bloom. I removed it to my garden, and the plant not only bloomed freely till frost, but all the runners threw out blossoms at the same time that they made roots and bore abundantly till late in the fall. The fruit was small, but of fine flavor." Longworth was assured by Mr. Lewis, a pioneer of Green county, Ohio, that this everbearing sort abounded in that county in earlier years. No further mention is made of it.

About this time the Crescent Seedling Perpetual achieved notoriety. It was originated by Henry Lawrence, of New Orleans, Louisiana, and was said by him to be British Queen $\times$ Keens' Seedling. He introduced it in 1848. As grown at New Orleans, it "bore continuously for six months, from Christmas until the fifteenth of July." The Horticulturist warned its readers that this statement was "preposterous," but many northern growers paid eight dollars a dozen for plants. In the North, it produced only a spring crop of rather inferior berries and soon was discarded. It took a number of experiences like this to convince northern horticulturists that the everbearing habit of the strawberry in the far South is due to climate, and is not an inherited character. About 1854 Charles A. Peabody, of Columbus, Georgia, achieved a national reputation for his supposed skill in being able to make the Hovey and Large Early Scarlet bear continuously for six months. His method was to train the plants in hills, use no manure or other stimulating fertilizer, and let the beds stand for ten or twelve years. "A few years of this culture," said he, "will check their disposition to 
run and encourage them to fruit perpetually." 1 But northern growers who followed his system faithfully were unable to secure the same results. In $1874 \mathrm{~T}$. T. Lyon, of Michigan, reported: 2 "Among the new native varieties is Golden Perpetual, a curiosity, as it produces a continuous crop till frost on the young runners, which fruit before taking root. The berry is large and excellent." Three years later, however, he described the berries as "few and small," and no more was heard of this variety.

One of the greatest disappointments was the Oregon Everbearing, which was introduced in 1890 with sweeping claims. It was first exhibited at the Portland Exposition, Oregon, during that year. This variety was a chance seedling, supposedly of Triomphe, found by Seth Winquist, of Russellville, Oregon, in 1882. In western Oregon itwas, in fact, more or less of an everbearer under certain cultural conditions, but in most places it failed completely to meet the expectations of those who had paid five dollars a dozen for the plants. This variety was introduced into France in 1894 and was valued there until the introduction of the St. Joseph. The Repeater, introduced in 1900, was another failure, so far as everbearing is concerned.

The genesis of modern North American everbearers. - The variety that marked the beginning of the successful culture of everbearing strawberries in North America was discovered by Samuel Cooper, of Delevan, New York, in the autumn of 1898. As related by him: "The Pan-American strawberry was found by me in the fall of 1898 , growing in a row of Bismarck plants that I had secured from W. F. Allen, of Salisbury, Md., and set the previous spring. This

1 "Manual for the Cultivation of the Strawberry," by R. G. Pardee, pp. 93-103.

2 Proc. Mich. Pom. Soc., 1874, p. 270. 
plant had made sixteen runner plants, all of which had either ripe or green fruit or blossoms on them. I did some roguing for several years to eliminate those that were not fall-bearing, for occasionally one would make runners freely and not fruit. These were destroyed with all their runners. I do not think one plant has failed to fruit for the last three years. The Pan-American is undoubtedly a sport by bud variation from the Bismarck." 1 This surmise as to its origin is not capable of proof. If true, it is the only authentic instance on record of bud sporting in the strawberry. It is more probable that the PanAmerican was a seedling that had become mixed with the plants of Bismarck ; possibly it is a seedling of that variety, which it resembles in some respects. There were no Alpine, French or other everbearing varieties growing on his grounds at that time.

The Pan-American so-called because it was first exhibited at the Pan-American Exposition, Buffalo, New York, in 1901, was introduced in 1902, and

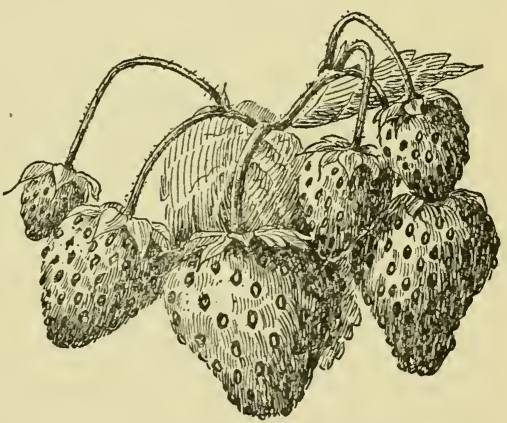

FIG. 13. - Pan-American, the first North American everbearer. received immediate recognition. The berries proved to be rather small, unattractive in color, and mediocre in quality, but the plants possessed the everbearing habit to a marked degree. It made few runners, sometimes none, so that it was necessary to propagate it by division. This made the price of plants high. When the attempt ${ }^{1}$ Rept. Iowa Hort. Soc., 1910, p. 274. 
was made to overcome this fault by stimulating the plants highly with nitrogenous fertilizer, runners were produced freely, but the plants reverted to the spring-bearing type. The Pan-American never became popular, but it furnished the starting point of the long-desired race of dependable everbearers. The originator immediately began to raise seedlings from it. The first of these to show value was Autumn; later he introduced Productive, Superb and several others, all of Pan-American stock. The Superb is the best of Cooper's varieties.

Meanwhile, another breeder had been working on the problem independently. About 1896, Harlow Rockhill, of Conrad, Iowa, began work with Louis Gautier, which showed considerable inclination to bear fruit on part of its runners, in wet seasons. He soon became convinced that the everbearing character could not be fixed in this variety by selection and began crossing it with a number of American sorts. Some of his seedlings of Louis Gautier $\times$ Sample were quite promising. In 1904 he secured the Pan-American and crossed it with Louis Gautier, with this result: "Seeds were sown in window boxes in February, 1905, from crosses made the preceding fall. Some of the resulting seedlings fruited the following August and September. These were, perhaps, the first strawberry plants on record, of the large-fruited varieties, to bear the same year the seed was sown. There were many freaks among these seedlings. One sent out runners twelve to sixteen inches long, which rooted and produced three to five trusses of fruit each. Most of the runners produced no plant buds; after fruiting, all such runners died back to the mother plant. Another seedling had running fruit stems about twelve inches long with three separate settings of fruit. These 
were of no value except as curiosities. From among these seedlings I selected the Francis and America." 1 These two varieties, and the Progressive, a later introduction, are distinctly superior to Pan-American and have given a decided impetus to the garden culture of the everbearers.

Other plant breeders who have labored in this field with considerable success are Charles F. Gardner, of Osage, Iowa, E. H. Riehl, of Alton, Illinois, and Albert F. Etter, of Ettersburg, California. Except for the Ettersburg seedlings, the basis for improvement has been the PanAmerican or its descendants. A remarkable instance of precocity in everbearing seedlings is reported by C. F. Gardner: ${ }^{2}$ "Good specimens of ripe fruit were picked May 28th and planted the same day in an ordinary seed bed. The little plants began coming in sight ten days afterward. On August 6th the seedlings were set in the field and kept absolutely clean. The first fruit buds were seen on August 28th; the first petals expanded on August 30th, and the first ripe berries were found on October $2 \mathrm{~d}$, less than five months from the seed." The term "fall-bearer," as applied to varieties of this type, should be discarded; "everbearing" describes their distinctive habit more accurately. They are fall-bearing only when the cultivator so desires; if left to themselves, they will begin bearing in the spring and produce more or less fruit all the season.

\section{Botany of the StrawberRy}

The wild strawberry is one of the most widely diffused plants. It is abundant in all of northern and central

${ }^{1}$ Rept. Iowa Hort. Soc., 1909, p. 185.

${ }^{2}$ Ibid., 1911, p. 124. 
Europe and extends from Lapland, the Shetland Islands and Lake Wetter in Sweden (north latitude 60 degrees), to Spain, Sicily and Greece. In Asia, it is found north of 60 degrees north latitude, from Russian Siberia to Armenia and the northern part of Syria. In South America it is common throughout the Andean Range; at the equator it climbs the mountains to find a congenial habitat. The wild strawberry grows over practically all of North America, including Iceland, Newfoundland, Labrador, to the very border of the Arctic Zone. It extends in an almost unbroken chain from Iceland and Alaska and the 64th parallel in the North, through Mexico and Central America to South America. No continent or large body of land is without an indigenous species.

The genus Fragaria is so variable that many of the numerous species are not clearly defined. There are, however, four quite distinct type or groups, all but one of which are represented in North America. These are $F$. virginiana, $F$. chiloensis, $F$. vesca, and $F$. elatior.

$F$. virginiana. - This is the most widely distributed North American species. It grows from sea-level to an altitude of 12,000 feet and is found in practically every State and Province. In Colorado, it fruits abundantly at the timber line. The plant is small, slender, erect, smooth or slightly silky, with small blossoms. It throws out long runners in great profusion, many of them appearing at the time of blossoming. When the plant stands in the same place for several years the crown divides, instead of elongating and pushing out of the ground, as in F.chiloensis. The roots are wiry, and the plant sets deeply and firmly in the ground. The leaflets are large, light green, rather thin, slightly silky when young, glabrate when old, sharp toothed and often folded. The fruit is borne early in 
the season on short, stout, rather weak-rayed scapes, which are slightly villous, and somewhat shorter than the leaves; it is small, globular, with a distinct neck, very light scarlet. The yellow seeds are sunk deeply into angular pits; the

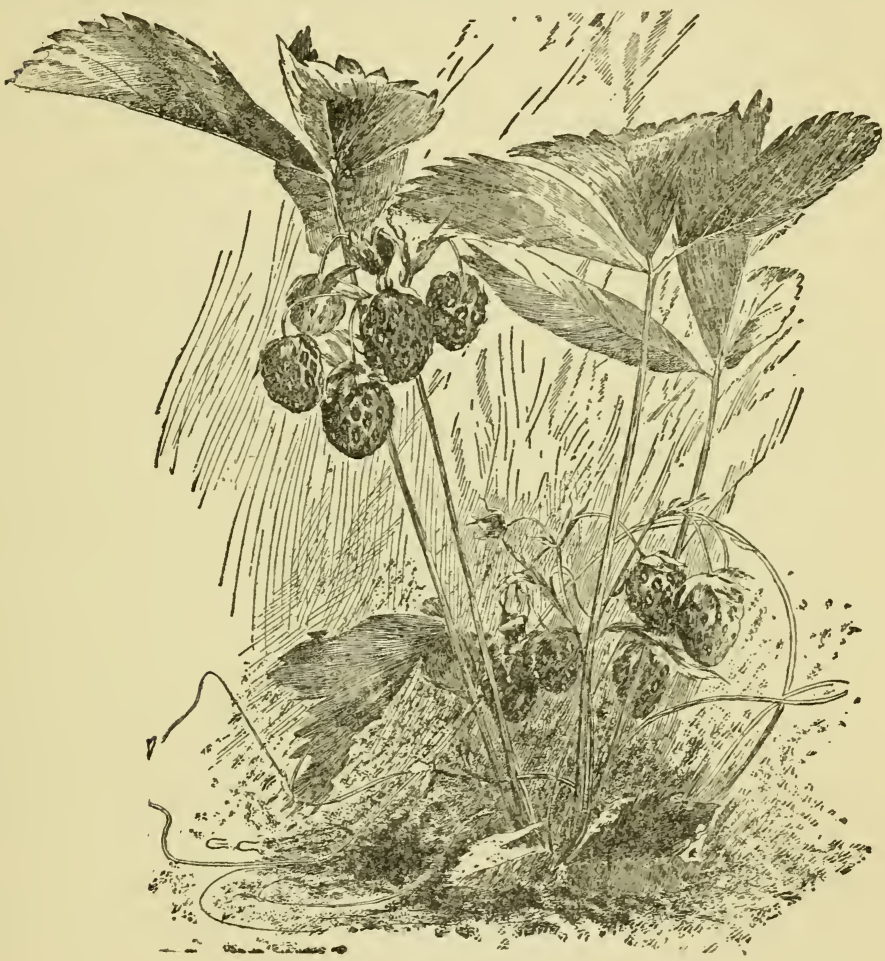

FIG. 14. - F. virginiana.

calyx is small. The flesh usually is pink, pleasantly acid, and the berry has a pronounced aroma. The northern form of this species, $F$. canadensis, differs from the type chiefly in being of lower stature and having pointed fruit. 
It is found in the Northeast as far south as southern Michigan and central New York. The robust prairie form of the Scarlet has been called $F$. ioensis and $F$. illinoensis, but it does not differ materially from the type save in size, and is now known as $F$. virginiana, var. illinoensis.

F. chiloensis. - This species is found on the Pacific Coast of North and South America, particularly on the western slope of the Rocky Mountains and the Andes. It also is indigenous to sandy beaches of the Pacific Coast. It is one of the few species of plants common to both North and South America. The plant is large, stocky, densely hairy, with large blossoms. It throws out a moderate number of short, stout runners mostly after the fruit has matured. The roots are rather thick, fleshy and usually are more superficial than those of $F$. virginiana. When a plant grows in the same place for several years the crown does not divide low down, as in $F$. virginiana, but makes several large crowns high up, all attached to the main root stalk. The plant is pushed upward out of the soil and new roots form above the old ones. The leaflets are large, thick and coriaceous, round-toothed, smooth and shining above, very silky on the under side, strongly reticulate. The fruit is borne late in the season on short, strong, very silky, much branched scapes and long, stiff peduncles. The berry is large, globular or conic, sometimes hairy, scarcely necked, dull brownish red. The prominent brown seeds project slightly, or are even with the surface in shallow pits. The calyx is very large. The flesh is whitish, usually hollow, of sweet, but weak, flavor. F. crinita and californica differ but slightly from this type. The true $F$. chiloensis is mostly a beach form, with very long root stalks, often eight to ten inches long, 
which are buried deeply in the sand. The species found in inland locations is mostly $F$. californica.

$F$. chiloensis produces very large berries in South America. According to Burbidge: ${ }^{1}$ "In the equatorial

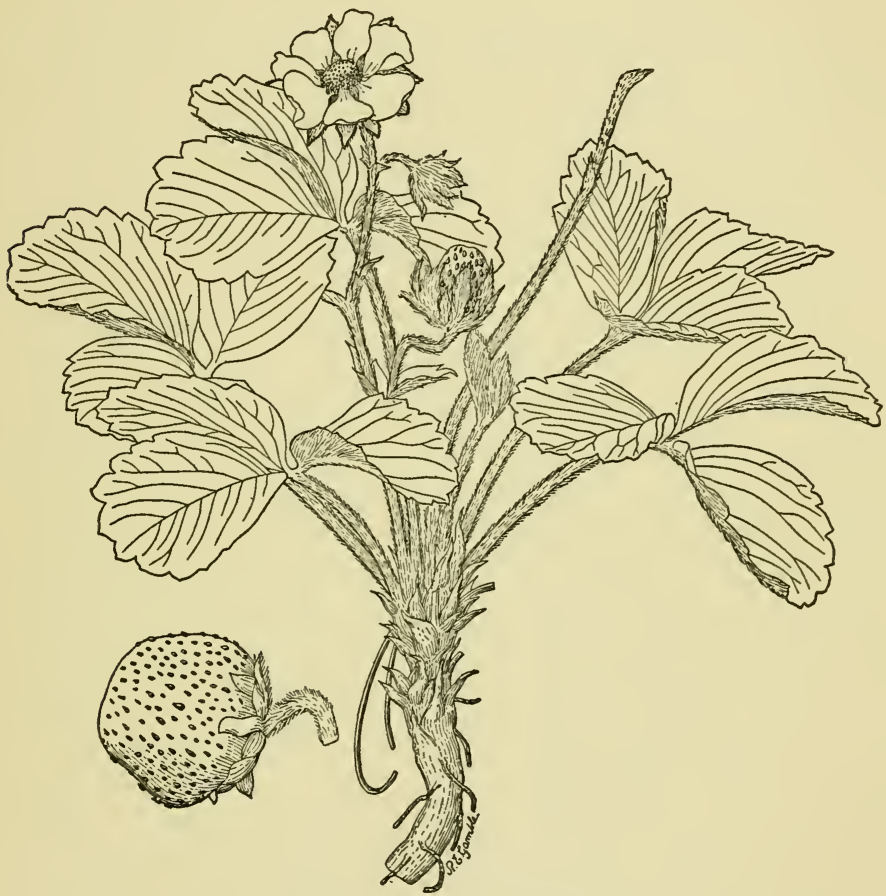

FIG. 15. - F. chiloensis.

Andes, the Province of Ambato is famed for its strawberries, which equal in size and flavor some of our best varieties and are to be seen exposed for sale in the market 1 "The Propagation and Improvement of Cultivated Plants," p. 473. 
place of Ambato every day in the year. They are cultivated at an altitude of from 7,000 to 9,500 feet above the sea where the mean temperature of the year ranges between 59 degrees and 67 degrees." In the Copiapo Valley, Chile, the berries grow to a circumference of over six inches. On the Pacific Coast of North America the species is equally abundant, but smaller. According to J. R. Cardwell, in Oregon it is "abundant and very prolific, so that in some regions, it is said, hogs fatten on them. The berry is not large, but improves under cultivation, and, by some, is classed superior in flavor to the cultivated kinds." 1

There are marked variations from the type in different parts of the Pacific Slope. One of the most conspicuous of these is the Alaska beach form, which C. C. Georgeson reports as "growing in almost pure sand along the beach just beyond the waves and disputing the ground with the mosses, grasses and other plants peculiar to the region." ${ }_{2}$ This beach type has procumbent fruit stalks and very weak peduncles. A large proportion of the leaves have four leaflets. One of the forms of $F$. chiloensis used by Albert F. Etter of California in his breeding work has light green foliage, and the petioles are covered with a coarse, dense pubescence; another form has glossy dark green leaves, practically free from pubescence. The beach form, or sand strawberry, thrives under such unfavorable conditions that it is used on the Pacific coast to cover dry slopes and exposed places.

When transplanted to the East, the fruiting season of $F$. chiloensis is scarcely longer than that of $F$. virginiana; but on the Pacific Coast its season is extended. In

1 Rept. Ore. State Bd. Hort., 1907, p. 137.

2 Rept. Alaska Exp. Station, 1906, p. 12. 
Bolivia wild strawberries are on the market four or five months of the year. Wild berries have been picked near San Francisco from January until August. The North American form of $F$. chiloensis has not given any valuable varieties.

$F$. vesca. - This is the common wild strawberry of Europe. The Wood strawberry of England, which has round berries, and the Alpine, or Monthly strawberry of the continent, which has long berries, both belong to this species. The European type has been naturalized in eastern and central North America to some extent, but a widespread native species, $F$. americana, resembles the European form so closely that many botanists consider the two identical. It differs chiefly in the shape of the fruit, which is ovoid or subconic, instead of hemispheric, usually has a distinct neck and is somewhat less pubescent and more slender. It is common in the East from Newfoundland to North Carolina and southwest to Oklahoma, preferring shady, rocky places, especially in mountains. The plant is tall, slender, erect, softly villose with small blossoms and long, slender runners. The leaflets are thin, light green, silky when young but glabrate on both sides when old, and sharp toothed. The fruit is borne on weak scapes, much longer than the leaf stalks. The berry is very small, long, hemispheric or conic, pointed, often necked, light scarlet. The prominent seeds are close together, but are not imbedded in the flesh. The calyx is small and recurved; the flesh whitish and of rich flavor. No valuable varieties have come from the American form of $F$. vesca, nor does the species show much promise. The white-fruited form is common from New York and Massachusetts to Kentucky and Ohio. 
$F$. elatior. - The Hautbois strawberry is not indigenous to North America. It is common in central Europe, especially in Germany. Unlike $F$. vesca, the Hautbois

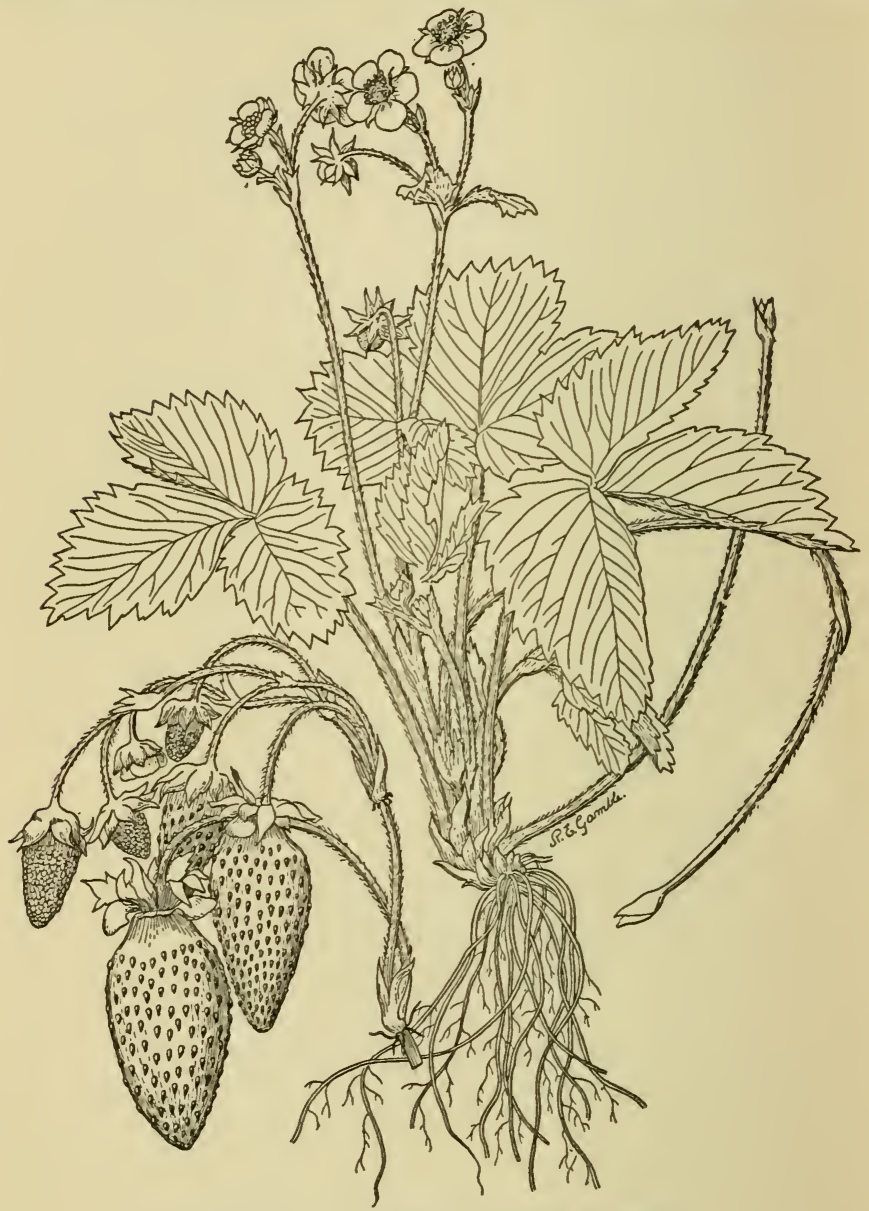

Fig. 16. - The Alpine form of $F$. vesca. 
is found more commonly in woods and in open fields. Possibly this may explain its name, which means "high wood," but more likely this refers to the habit of the species of bearing fruit on long, stout stems, elevated above the leaves. The foliage is large, tall, pale green, downy beneath. The ripe berries are round or oval, larger than in $F$. vesca, brownish or pale red, occasionally greenish, and have a strong musky flavor, which has been described as "a sort of mixture between the black currant and the raspberry." The flavor, while rich, is not agreeable to most people, which accounts for the slight interest that has been shown in the improvement of this species. Another serious defect of the Hautbois is its unproductiveness. Some plants bear no flowers at all, or only abortive flowers. Many plants show a distinct tendency to be diœcious, some of the blossoms being pistillate, others almost purely staminate, with no pistils whatever. There are also perfect flowered plants; but one or the other sex of an apparently perfect flower may not function. The Hautbois served a very useful purpose in directing attention to the sex of the strawberry; the experiments of Duchesne were with this species. In spite of its faults, the Hautbois was widely grown in European gardens until the middle of the nineteenth century. The first named variety of the strawberry was of this species. According to Parkinson, it was introduced into England about 1600.

The Hautbois never achieved popularity in America. William R. French states: "The Hautbois was introduced in America in early colonial days, but the bisexual plants were mixed with pure staminate, which soon ran out the others, leaving the beds unfruitful. By the time the sexual selection of the strawberry was better understood there were better native varieties." The only variety grown in 
America to any extent was Prolific Hautbois, a bisexual sort, which was found in the gardens of amateurs until about $1850 . \quad F$. elatior is thought by some to have entered into the lineage of the modern large-fruited strawberry, but this is in doubt. The species is now neglected and there are no varieties of prominence.

These four species, and several very closely related forms that are designated by some botanists as distinct species, are the types from which practically all progress in strawberry breeding has come. Several other species are of incidental value. The handsome, yellow-flowered Asiatic species, $F$. indica, which is used as an ornamental plant in the conservatories of Europe, is naturalized to some extent in Europe and North America. The deep red berries much resemble those of $F$. virginiana, but the scarlet seeds project from the burnished surface, making the berry very firm and seedy. The flavor, however, is quite flat. A. S. Fuller, E. P. Roe, and others attempted to hybridize it with edible varieties in order to secure firmer berries, but without success. The flowers and fruit of $F$. indica are produced, more or less, throughout the summer, the runners bearing both leaves and flowers. Some Chinese forms of $F$. indica are fairly palatable, but the species has shown little promise thus far. 


\section{CHAPTER V}

\section{DESIRABLE CHARACTERS IN A VARIETY}

THE first step in breeding strawberries, and in selecting varieties or seedlings, is to have a clear conception of the kind of plant and fruit desired. Different men have described "the ideal strawberry." No two descriptions agree. There are likely to be as many ideals as there are men to describe them or conditions of climate, soil and market to be satisfied. The ideal is never attained; if it were, there no longer would be need of new varieties. As varieties approach the ideal, we set the mark a little higher, so that there still may be incentive to effort. Furthermore, ideals change with the times; a strawberry that was quite satisfactory in 1840 would not secure recognition now. The characters of plant and fruit that make a seedling worthy of introduction, and a variety worthy of culture, according to present standards, are considered in this chapter.

\section{Desirable Characters in the Plant}

Many sorts, otherwise quite desirable, fail because of their susceptibility to disease, especially leaf blight. The Hunn was an excellent late variety in most respects but was so seriously attacked by this disease that it was soon discarded. Spraying to control leaf blight is only partially 
effective; most growers prefer to plant varieties that do not need to be sprayed.

Vigor is the prerequisite of productiveness; weakgrowing varieties of superior quality may satisfy a few amateurs, but not commercial growers. There is considerable difference in the ability of varieties to endure drought, due partly to differences in the texture of the foliage, but mostly to the fact that the roots of some sorts penetrate the ground more deeply than others. The Arizona, for example, has a deeper root system than the Jucunda.

Productiveness is the most desirable quality in a commercial variety. If a variety lacks this it is soon discarded, even though it may be desirable otherwise. A heavy yield depends not only upon the vigor of the plant and the number of fruit stalks, but also upon the average size of the berries and the length of the picking season. Judged by present standards, a variety that will not yield 100 to 300 bushels to the acre under ordinary field culture, and 300 to 500 bushels under intensive market garden culture, is not worth keeping. Fifty years hence this standard may be considered as low as it would have been thought high half a century ago. The Trebla, one of the seedlings of Albert F. Etter of Ettersburg, California, is reported to have yielded at the rate of twenty.tons to the acre, which is over 40,000 quarts. $^{1}$

In the North, hardiness must be considered. During the winter of 1905-6 many of the strawberry fields of Canada and northern United States were covered with ice for a long period. Most of the 200 varieties on trial at the Central Experiment Farm, Ottawa, Canada, were destroyed, although they had been heavily mulched.

${ }^{1}$ Jour. Heredity, VI (July, 1915), p. 328. 
A few varieties suffered little injury; among these were Beder Wood, Dunlap, Crescent and Pokomoke. In 1896 the South Dakota Experiment Station reported the Princess, Warfield, Clyde and Beder Wood as the hardiest sorts. The soil and method of training have much influence upon the hardiness of plants.

The vigor and productiveness of a variety vary greatly under different conditions of soil, climate and culture. No variety or seedling should be condemned from a single trial. Usually a variety is most at home in the region or locality where it originated and is less successful elsewhere in proportion to the extent of the variance from these conditions. Occasionally a variety is more successful elsewhere than where it originated. The Clark is soft and unprofitable in the Willamette V.alley, Oregon, where it originated, but is exceptionally firm and profitable in the Hood River Valley of the same state. The Dollar, which originated in New Jersey, was soon discarded there but still finds a sphere of usefulness on the opposite side of the continent, near Sacramento, California. As a rule, the seedling or variety most worthy of propagation is one that is cosmopolitan or able to adapt itself to a wide range of conditions of soil and climate.

Foliage. - The leaves should be abundant, large, tough, not easily torn by winds or scorched by the sun. One reason why most English varieties fail here is because their foliage is sparse, tender, and easily sun-burned. In different varieties the leaflets vary from thin and narrow to thick and rounded; and their color from very dark green, almost black, to nearly yellow. None of these characters denotes superiority, but size and toughness of foliage are essential. Some varieties hug the ground, with comparatively few and straggling leaf stalks; others 
are erect, sometimes eighteen inches high when the plants are grown in hills. An erect habit is an advantage; if the foliage straggles on the ground there is more likely to be injury by mildew, mold, and leaf blight, and the blossoms are not as well protected from frost.

Runners. - The successful variety must be a good plantmaker. Fifty years ago, varieties that produced runners very freely, and hence required little attention to secure a full stand, were preferred. This is one reason why the Crescent was so popular. In recent years, the advantages of restricting and spacing runners have become so generally recognized that a variety which produces a great many plants is handicapped somewhat; it costs too much to remove the surplus runners. On the other hand, a variety that makes very few runners cannot hope to become popular. The growers look upon it with disfavor because the stand is likely to be poor in a dry season; and the nurserymen will not push it, which is an even more effective way of consigning a variety to oblivion.

Only a small part of the strawberries in North America are grown in hills; the other methods of training require a variety that is certain to produce a number of runners under average conditions. The Jewel was an excellent variety for the intensive hill culture practiced by its originator, P. M. Augur, who claimed, as one of its strong points, that it did not "exhaust itself in making useless runners." It failed under field culture for this reason. English varieties, which are not successful here as a class, make few leaves and runners; the plants are not well protected by foliage from the extremes of temperature of both winter and summer. Few runners are an advantage in varieties that are to be grown under hill or hedge-row training. A moderate number of runners are an advantage 
in matted row or spaced row training, especially for light or poor soils. The prevailing methods of training in North America involve moderate runner restriction; hence varieties with moderate plant-making proclivities, like the Bubach, Chesapeake, Williams and Glen Mary, are preferred, other things being equal.

There is considerable variation in the character of the runner cords of different sorts. Some are thin and wiry, others thick and fleshy. In certain varieties the cord is short, so that the runner strikes only three or four inches away from the mother plant. In others, the runner strikes twelve or fourteen inches from the mother plant. The most desirable length of the runner cord depends upon the method of training that is practiced. In matted or spaced rows, maximum yields are secured on average soils when the plants are five to six inches apart. In hedge-rows, this distance may be increased to advantage.

Fruit stalls and blossoms. - It is a decided advantage for a variety to have very stout fruit stalks, with stiff branches that hold the berries off the ground. When the berries lie on the ground they may become dirty or decay. This is especially important in sections where irrigation is practiced and no mulching used; also in Florida, where the berries ripen very slowly during the cool season. The fruit stalks should be tough, not easily broken by the pickers.

It is not desirable that the fruit stalks be elevated above the foliage; the blossoms then are exposed to frost and beating rains. Some varieties blossom much later than others. This is a decided advantage in localities subject to late spring frosts. In general, there is a close relation between early blossoming and early ripening, but there are many exceptions. Erect blossoms are more subject to 
frost injury than those that turn down. Varieties that have perfect flowers, abundantly supplied with pollen, are preferred by most growers. Some, however, prefer pistillate varieties in spite of the inconvenience of planting pollinizers, being convinced that they are more productive and more resistant to frost. If the variety is staminate, it should be strongly so throughout a long blossoming season, as is the case with Beder Wood and Dunlap. Weak pollinizers and semi-perfect varieties, like the Glen Mary, are at a disadvantage.

\section{Desirable Characters in the Fruit}

Varieties are classified as early, midseason and late, but these terms are wholly relative. The time of ripening depends as much upon the location, site, soil, method of culture and weather as upon the variety. Weather conditions not only modify the date of ripening, but also lengthen or shorten the fruiting season. Some varieties, as the Gandy, have short seasons; normally they give only three or four pickings. These are not likely to be as sure croppers as varieties that give at least six good pickings.

Very early or very late varieties seldom yield heavily. The longer the season of ripening, the greater the likelihood that there will be favorable weather at least part of the time. Nearly all the heavy-cropping varieties are mid-season sorts that ripen over a long period. There has been a decided drift toward midseason sorts in recent years. The extension of strawberry planting both North and South has made it possible to secure late and early berries without being obliged to grow the light-yielding extra early and extra late sorts. In Florida, the Gulf Coast and southern California, the season of ripening is so 
greatly extended, on account of the sub-tropical climate, that there is no occasion for considering this point.

Size. - When strawberries were grown only for home use and near markets, the larger they were the better. As soon as the development of transportation facilities made it possible to grow them at great distance from markets, it was found that very large berries do not carry as well as those of medium size. Not only are they less firm, but also they are likely to be irregular in shape and hence more liable to be bruised. The greater the distance from market the more desirable it is to produce berries of uniformly medium size; berries an inch in diameter are large enough for long-distance shipping. This is one reason why the Clark is profitable in Oregon and the Klondike over a large part of the South. For near markets, on the other hand, the larger the berry, within reasonable limits, the better.

It is important that good size be maintained from the beginning to the end of the shipping season. Many sorts give large berries the first pickings, but smaller berries thereafter, running down to nubbins at the close. Uniformity of size is desirable also. A variety in which practically all the fruit is uniformly medium in size is easier to grade, and sells better than one that gives fruit of all sizes at the same picking.

Since the introduction of the Hovey there has been little if any improvement in the average size of North American varieties until quite recently. In 1869, Seth Boyden, a prominent strawberry breeder, predicted that in a few more years strawberries would be produced "as large as pineapples." 1 His prophecy is not likely to be realized. When the size is increased beyond a certain point, the ber-

$$
1 \text { Jour. Hort., VI (1869), p. } 29 .
$$


ries are too tender to ship. Some berries have been grown over four inches in diameter, showing the possibilities in this direction; but commercial berries are rarely over two inches in diameter, even for a special trade, and the average size is one inch. Marshall P. Wilder remarked, "We already have strawberries sufficiently large to fill any mouth of decent dimensions."

Records of "mammoth" berries. - These have not been confined to this generation. In 1613 the "Hortus Eystettensis" reported berries one and three-eighths inches in diameter. In 1708 Simon Paullus, a Dane, published his "Quadripartitum Botanicum" in which he claims to have seen strawberries "of the kind Bauhin called prunesized, which produced a fruit nearly the size of the peach." Probably this was the Chili, which Frezier reported, in 1712 , as bearing berries "the size of hen's eggs." In 1830 the Fruit Committee of the Pennsylvania Horticultural Society awarded a silver medal to Daniel Kochersperger, "for the production of the largest strawberries - sixty of which fill a quart, and measuring four inches round, less one sixteenth of an inch." 1 The same year J. Buel reported in the Albany (N. Y.) Argus, that he had picked "a pail of strawberries which had an average circumference of three inches each." Both of the foregoing records were for varieties of $F$. virginiana.

The Hovey was the first of the large-fruited varieties of North American origin. For many years it captured most of the prizes at strawberry exhibitions because of its size and beauty. In 1851 two notable records were established with this variety. One was reported by A. J. Downing: " ${ }^{2}$ "We understand that Mr. Pell, at his cele-

1 The Southern Agriculturist, III (1830), p. 446.

${ }^{2}$ The Horticulturist, 1851, p. 383. 
brated orchard farm, near Pelham on the Hudson, has raised the largest strawberries ever grown in this country. The variety was Hovey's Seedling. The largest berry weighed two ounces and measured $8 \frac{1}{4}$ inches in circumference." ${ }^{1}$ The same year C. M. Hovey stated that Mr. Cunningham of New York "grew the Hovey Seedling to such perfection that thirty-nine were laid on a flat surface and covered a space nine by ten inches, that is one to every two and one half inches. I saw one weighed and found it weighed two ounces and was $8 \frac{3}{8}$ inches in circumference." Hovey states that these berries were the largest ever grown in North America.

Since the introduction of the Hovey, there have been many attempts to "break the record" in size of individual berries. Some of the early feats are recorded in Chapter I. The field of Jucunda raised by John Knox of Pittsburgh in 1865 is especially worthy of note. Thomas Meehan said these berries "might easily be mistaken by a nearsighted observer for tomatoes." He failed to measure them, however, which leaves us in doubt whether to compare them with the cherry tomato or the Ponderosa.

In 1878 James Smith of Des Moines, Iowa, reported : ${ }^{2}$ "The past season a specimen was measured by the officers of the New York State Horticultural Society that proved to be $14 \frac{1}{2}$ inches in circumference and nearly five inches in diameter." This was the Great American, originated by E. W. Durand, Irvington, New Jersey. Referring to this mammoth berry the following year, Matthew Crawford said, "This would be large for an apple, but is really not as large as one would think, because these monstrous berries are very irregular in shape and measurement is taken

${ }^{1}$ Mag. Hort., 1851, p. 326.

${ }^{2}$ Rept. Iowa Hort. Soc., 1878, p. 322. 


\section{THE STRAWBERRY IN NORTH AMERICA}

over and between these irregularities. If this berry had been of regular shape, it would have weighed over twelve ounces, while the heaviest berry ever grown weighed but about three ounces."

Regular berries of exceptional size were grown in 1899 by A. T. Goldsborough of Washington, D. C. He sent some berries to the Secretary of Agriculture, "the average

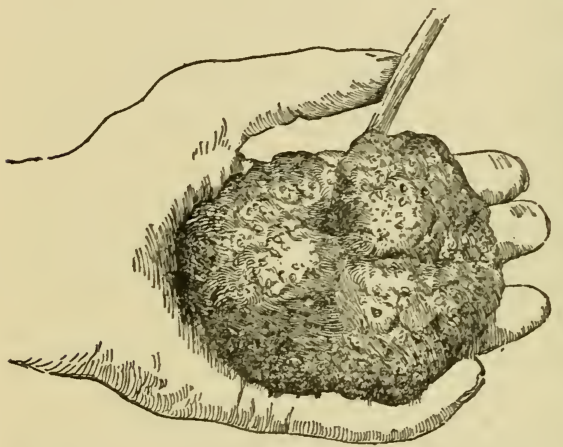

Fig. 17. - A "mammoth" berry; it weighed $4 \frac{3}{4}$ ounces.

weight of which was 3.06 ounces. The largest berry weighed four ounces and was $10 \frac{1}{2}$ inches in circumference. It took but six of them to fill a quart basket." 1 On June 5, 1904, the same propagator sent a specimen of his St. Louis to G. B. Brackett, pomologist of the United States

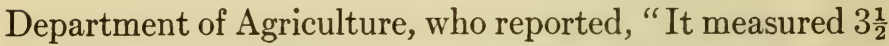
by $3 \frac{11}{16}$ inches in diameter and weighed $4 \frac{3}{4}$ ounces. Two filled an ordinary glass. This beats all records in the size of strawberries" (Fig. 17).

This record was approached, if not bettered, by a specimen of the Mary grown by Henry Jerolamen, Hilton, New Jersey, and exhibited at the Jamestown exhibition in 1908. It was $4 \frac{1}{2}$ inches in diameter; the weight was not given. According to A. D. Webb, of Bowling Green, Kentucky: "At a strawberry show held at Louisville, Kentucky, in 1899 under the auspices of the Kentucky Horticultural

${ }^{1}$ Washington Evening Star, June 17, 1899. 
Society, J. Hawes exhibited two quarts of berries, one containing five berries, the other six. The variety was Clyde." 1

Mammoth berries are interesting, but not profitable. Nobody wants a strawberry that must be carried in cotton batting and has to be sliced before it can be eaten. Berries from one to two inches in diameter and weighing about an ounce are as large as it is practicable to grow them under present conditions.

Shape. - As long as strawberries were grown only for home use or near markets, the shape was of little consequence. A large proportion of the berries introduced before 1870 were very irregular. Coxcomb varieties were quite common then; now they are seldom seen. Since the strawberry has been grown at great distances from market there has been a tendency to standardize the shape. Irregular berries do not ship well; the projecting points are likely to be bruised. The more nearly a berry approaches a spherical shape, the less likely it is to be bruised.

The standard shape today is round-conic, or heartshaped, although there are many conic or long-conic varieties. Practically all modern varieties are roundish, ovate, conic, oblate or flattened, long conic, oblong, or slight modifications of these types. Obovate berries now are rarely seen. Pointed tips are objectionable, as they are easily bruised. It is likely that future varieties will be more nearly roundish than round-conic.

Uniformity of shape is desirable. Most sorts are quite variable in shape, even on the same plant. Although every variety shows marked differences in shape as grown in different localities, each variety has a dominant type.

\section{American Gardening, 1899, p. 509.}


The first berries to ripen usually are more irregular than later ones. The surface should be smooth; seams, fur-

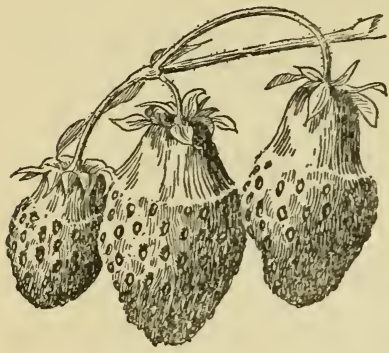

Fig. 18.-Banana, introduced in 1870. The long neck would be considered undesirable today. rows and ridges make the berries less attractive, and more subject to bruising. A slight neck is an advantage, as it facilitates hulling, but it should be very short. Varieties with pronounced neck, like the old Crimson Cone, cannot be shipped a long distance.

Calyx. - A large calyx is a disadvantage in long distance shipping, especially if it is recurved. When first picked, these berries lie quite loosely in the baskets, but they soon settle and unless the baskets are heaped, they do not reach the markets full enough. The Glendale had a very large, recurved calyx; O. B. Galusha claimed that only a pint could be put in a quart box. Possibly some would consider this an advantage, if the berries are to be grown for local markets. A green calyx makes a pleasing contrast with red berries. Brandywine has a large calyx but it wilts and turns yellow a few hours after picking. A small calyx which keeps bright green for several days after picking is preferable.

The calyx should be only moderately adhesive; varieties that are difficult to cap are not favorites with the housewife. Years ago strawberries were sold "hulls off." The desire to reduce the labor of capping led to the introduction of the Mt. Vernon or Shuckless, which left the cores as well as the hulls on the vines when picked. This met with little favor, as the hulled berries did not carry well or keep well. The development of the canning 
industry may bring about a revival of shuckless varieties. Those who sell all the crop to the cannery, not merely the later pickings when prices are low and berries small, would like to have a variety that meets the ideal recently defined by an Oregon canner : "One that is self-stemming, that is, leaving the hulls on the stems when picked, so that it comes off perfectly clean like a raspberry." The Mt. Vernon did this, but it did not have the color and firmness necessary in a good canning variety. Some of the varieties produced by Albert F. Etter of California are picked without hulls and scarcely any abrasion.

Color. - The color of different varieties varies from whitish to dark maroon, almost black. The most desirable color in strawberries, as in apples and other fruits, depends chiefly upon the preference of those who buy them. If the eye is pleased, the desire to eat follows. Fifty years ago, bright orange-scarlet berries were in demand; many candidates for favor were dismissed with the disparaging statement, "Its dark color is against it." Light-colored berries were preferred then for the same reason that red apples are preferred to green varieties now. In time, the public may come to like green apples and light-colored strawberries, but now it wants red apples and dark red strawberries. If the Cumberland Triumph had been introduced in 1915 instead of 1874 it would have received scant consideration because of its light color. The standard of excellence in color is artificial and changes with generations.

Several attempts have been made to popularize white varieties, but without success. They are rarely pure white, but a rather unattractive dirty color, sometimes flushed with pink. Even the acknowledged high quality of some white sorts, as the Lennig, has not saved them 
from neglect. At present they are grown only as curiosities. A white variety of $F$. vesca was mentioned by Ruellius in 1536. Wild white-fruited forms of $F$. vesca, $F$. virginiana and $F$. chiloensis are common in North America, especially of $F$. vesca.

While color is largely a matter of taste, it should be said that dark red varieties show bruises somewhat less than light sorts. The color can be too intense; blackish sorts, like the old Black Defiance, would not sell well now. Some dark red varieties, as the Brandywine, are dull in color and fade quickly after picking. A bright, glossy, dark red, one that is "live" and does not fade or wilt, is most desirable. A glossy, mahogany red, as in the Warfield and Brunette, rarely fails to command approval. A very few markets prefer bright, light red berries, like the Jucunda, for the same reason that Rhode Island Greening apples sell better in New York than in St. Louis, - the market is used to them.

There has been much indefiniteness in describing the color of strawberries. Quite frequently the terms scarlet and crimson have been used interchangeably. According to the Century Dictionary, scarlet is "a highly chromatic and brilliant red color inclining toward orange"; while crimson is "a highly chromatic red color somewhat inclining towards purple; deep red." It has been proposed that the terms light red, medium red and dark red be used, but these are hardly suitable, since the difference between scarlet and crimson is in quality of color as well as in intensity of color. The berry should ripen evenly and be uniformly red all over. White tips are no longer tolerated. This is a defect of Sharpless and is present to a lesser degree in Glen Mary and several other contemporaneous varieties. 
Seeds. - Part of the color effect of a strawberry, and part of its shipping quality as well, is due to the abundance, size, color and position of the seeds. If there are many seeds, and especially if they are crowded close together near the apex, the berries look seedy and unattractive. The seeds should be inconspicuous, few and small, certainly not over $1 \frac{1}{2}$ per cent of the total weight. Bright yellow seeds are most attractive, especially if the berries are to be canned. If the seeds protrude slightly or are flush with the surface, the flesh is protected somewhat and the berry carries to market better than if the seeds are sunk into pits.

Flesh and shipping quality. - White flesh is decidedly objectionable. If the skin is broken slightly in handling, the berry looks unattractive. Dark red flesh is preferable. If the variety is to be canned, it is imperative that the flesh be dark red to the center and hold its color well after being cooked.

The texture of the berry is of special importance in these days of long distance shipment. Fifty years ago some varieties were described as "melting"; the flesh was so soft that it dissolved readily in the mouth. Manifestly these sorts were valuable only for home use. Now, most strawberries are shipped long distances and firmness is imperative. Firmness is especially desirable in berries grown for canning; those that lose their shape after being cooked sell poorly.

Shipping quality is considered more important in a wholesale market variety than high flavor. Shipping value does not depend altogether on the firmness of the flesh. Juiciness, solidity of core, texture of skin, position and abundance of seeds and an inherent ability to stand rough treatment after picking, all help to determine whether a variety is a good or poor shipper. These are 
not necessarily correlated with firmness, but firmness is the most important factor in shipping quality. The only way to find out the shipping value of a variety is to ship it. No new variety can hope to compete with established sorts unless it is at least moderately firm when fully mature. Firmness does not mean greenness; a soft variety is often picked while still unripe, at a sacrifice of size and quality, in order that it may carry well to market. Furthermore, soft varieties have to be picked more frequently than firm sorts, which is an added expense.

The texture of the flesh, whether fine grained or coarse, is not of special consequence unless it is stringy. The core should be only moderately solid. Some varieties have very hard, stringy cores, which are decidedly objectionable. As a rule, very juicy berries are not firm. Some sorts are quite dry; they will hang on the vines without injury for several days after they are ripe. The Staples is a notable example. Recently a group of varieties called the "fig type" has been introduced; these are said to be very sweet and dry and to possess "self-preservative properties so that they can be cured by drying in the sun in the manner of figs." Whatever may be their value for this purpose, they have roused the enthusiasm of at least one grower; he declares, "They are religious berries; it is not necessary to pick them on Sunday."

Flavor. - The flavor of strawberries is sweet, sub-acid or acid. Most varieties are sub-acid, or mildly tart. No flavor pleases all palates alike; some people prefer a sweet strawberry, others an acid sort. A variety is considered rich in flavor when it contains a large amount of sugar and acid combined in the right proportions; that is, enough sweetness to balance the acidity, but not entirely neutralize it, so as to preserve the racy flavor. 
Some of our best dessert varieties contain about five per cent of sugar and one per cent of free acid. Tart or brisk sub-acid berries are preferred for canning as they retain the distinctive strawberry flavor after cooking; milder sorts are more desirable for eating while fresh. There is no demand for a sour or acid berry or for a variety with a flat, neutral flavor, and but little for a very sweet berry. Sub-acid sorts appeal most strongly to a majority of consumers. Berries as sweet as the Ladies Pine and Burr's New Pine would not find as much favor on the market now as sub-acid varieties like Marshall, although appreciated by the few people who cannot eat any kind of acid fruit with impunity.

The best English varieties are sweeter than ours; they are more commonly eaten without sugar. What the English varieties gain in sweetness, however, is lost in sprightliness; they lack the racy, wild flavor of our William Belt and Brunette, which is perhaps due to the larger infusion of $F$. virginiana in North American varieties. There is no evidence that the flavor of a variety is affected to any extent by the soil in which it is grown; but climate, especially the amount of sunshine and water, modifies flavor as well as firmness and color.

Quality. - Quality in a strawberry is a combination of flavor, texture and aroma. The aroma of a fresh, ripe strawberry, derived mainly from volatile oils and esters, is most enticing. The appeal of the strawberry is to the sense of smell as well as to that of taste. Commercial ideals have so completely dominated strawberry breeding since the introduction of the Wilson that it is doubtful if the varieties most commonly grown now average as high in quality as in 1854 . Then the strawberry was mainly a garden fruit, although grown in limited quantities for 


\section{THE STRAWBERRY IN NORTH AMERICA}

near markets. We have few commercial varieties today that compare in quality with the Pines grown by the amateurs of that period. No modern sort has the exquisite flavor of Burr's New Pine, not even Marshall or William Belt, our acknowledged standards of excellence. The rush of commercial planting that followed the introduction of the Wilson swept aside the attributes that had hitherto made a variety meritorious for amateur cultivation and substituted a single standard, that of profit. Quality has been sacrificed to productiveness and firmness. Modern varieties are mostly of the lineage of Wilson, Crescent and Sharpless. These three sorts are of very ordinary quality; this mediocrity has been impressed upon most of their descendants.

Aroma has been sacrificed as well as flavor. A handful of the early Pines and Scarlets perfumed a room with delightful and appetizing fragrance. Few contemporaneous sorts have more than a faint and fleeting aroma. There can be no criticism of the efforts to secure productiveness, hardiness, firmness, size and attractiveness; commercial sorts must have all these in order to be valuable. But it does seem that quality has been sacrificed needlessly. Few of the leading commercial varieties of today are above medium in quality even when at their best, which is when ripened on the vines. When shipped long distances they are necessarily picked before fully mature, often while still somewhat green. These berries are likely to be sour or insipid; they bear little resemblance to vine-ripened strawberries.

Redness in strawberries is a no more reliable sign of ripeness than blackness in blackberries; some varieties are still sour and immature when they turn red, and are not fully ripe for several days thereafter. The Black 
Defiance was severely condemned as poor in quality when it was first introduced, because it was very sour when red and apparently ripe; but when the berries were left on the vines until almost maroon in color they were of excellent quality. The grower who has a near market should pick late, and thus secure for his customers the higher quality and larger size that come only with full maturity.

The foregoing are some of the points that make a variety worthy of recognition, according to present standards. No variety approaches perfection; every one is deficient in some important respects. The "ideal strawberry" never will be discovered or originated. As varieties are produced that are close to the ideal that we have ourselves created, the standard of perfection is advanced still farther. It may be approximated but is never quite reached. There always will be incentive for the plant breeder. "We shall always have to make a choice among varieties," said E. P. Roe, "as we do in friends. There is, however, one perfect strawberry in existence, the strawberry of memory - the little wildings that we gathered, perhaps with those over whom the wild strawberry is now growing. We will admit no fault in it, and although we may no longer seek for this favorite fruit of our childhood, with the finest specimens of the garden before us, we sigh for the berries that grew on some far off hillside in years still farther away."

\section{Describing AND Scoring VARIETIEs}

The varietal characters of the strawberry are so profoundly modified by climate, soil, altitude, cultural methods and other environmental factors that no one set of terms can describe a variety so as to fairly represent its appearance and behavior in all sections. Size, form, 
flesh character, flavor, plant-making habits, season and sex frequently are modified. Moreover, the differences between varieties are so slight that the most detailed description would not enable a novice to identify them. Only the man who has grown many sorts, and has come to know them by personal contact, can distinguish them. However, it is desirable to have complete descriptions of varieties as a matter of record and as an aid in determining synonyms.

Form for describing varieties. - Until quite recently, there have been few full descriptions. Most of the early varieties were described in a fragmentary fashion, without including the historical data on origin, parentage and introduction that are essential in a permanent record. Practically all of the early records were merely horticultural descriptions - a brief statement of the points that are of interest to the practical grower, as affecting the value of the variety for commercial culture, such as size, color, firmness, season. These descriptions do not enable one to distinguish the variety from all others. It is necessary to have anatomical descriptions, also ; these record minute details of structure and appearance, such as would be of little interest to the practical grower but which enable the pomologist to distinguish between varieties that are very similar in general appearance. These descriptions should be based on botanical characters and should approach botanical descriptions in conciseness and clearness.

There is no generally accepted form for a full anatomical description, but data on the following points should be included :

\section{Plant}

Constitution. - Vigor; hardiness; drought resistance; resistance to disease; productiveness. 
Runners. - Number; length; time of making; size, texture and color of runner cord.

Roots. - Abundance; length ; fibrous or fleshy.

Foliage. - Abundance and size; habit; shape; color; thickness; toughness; serration of leaflet; length and thickness of petiole.

Fruit stalks. - Length; thickness; branching habit; single or double; length and thickness of individual peduncles; blossoms erect or drooping.

Blossoms. - Season of blooming; closed or open; sex; abundance of pollen; shape of petals.

\section{Fruit}

Season. - Time of ripening; duration of picking season.

Size. - Vertical and transverse dimensions and weight; uniformity of size; ability to maintain good size throughout the picking season.

Form. - Regular or irregular; shape (ovate, conic, oblate, oblong, long conic, or gradations of these) ; uniformity of shape; necked or not; apex acute or obtuse ; surface smooth, ridged or creased.

Calyx. - Adherence; size ; color ; permanence of color ; number, size and length of sepals; recurved or spreading. Surface. - Color; permanence of color after picking; gloss; thickness and toughness of skin.

Seeds. - Comparative number ; arrangement, especially near tip; prominent or inconspicuous; sunken or protruding; size; shape; color.

Flesh. - Color ; texture ; firmness ; juiciness.

Core. - Hollow or solid; hard, soft or stringy.

Flavor. - Sour, sub-acid, mild sub-acid, flat or neutral, sweet; aroma present or lacking. 
Quality. - Very poor, poor, fair, good, very good, excellent.

Shipping quality. - Dependent upon size, shape, texture, firmness, thickness of skin and other qualities. Ascertained by shipping tests.

Freedom from disease.

Historical data. - Time and place of origin ; parentage ; by whom originated; date of introduction.

Score cards. - When a variety of fruit is exhibited in competition with other varieties, or seedlings compared, it is necessary to have a score card, or standard of excellence, so as to reach a fair estimate of the relative worth of each and to eliminate personal preferences as far as possible. The first North American score card for strawberries was suggested by F. W. Card in 1895 . He proposed that the perfect score for seedlings and varieties be ten points, one each for the following characters : vigor, disease resistance, frost resistance, productiveness, appearance, fragrance, size, texture, regularity, quality.

In 1897 a committee of the American Pomological Society, H. E. Van Deman, Chairman, recommended the following score card :

American Pomological Society Score Card

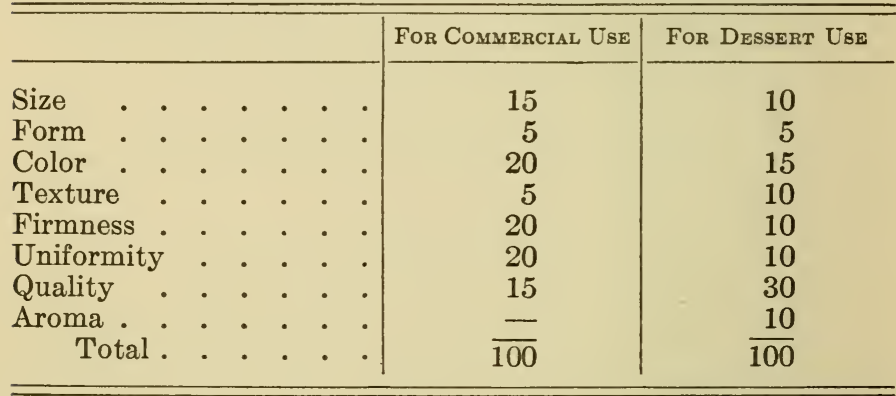


This score card applies only to the fruit. A score card for both plant and fruit was prepared in 1902 by J. R. Reasoner of Urbana, Illinois, after conferring with a number of strawberry specialists. ${ }^{1}$ In this score card, which is reported below, Warfield and Dunlap were scored by B. C. Warfield, of Sandoval, Illinois, Splendid by J. L. Hartwell, of Dixon, Illinois, and Brandywine, Marshall and Parson by Matthew Crawford of Cuyahoga Falls, Ohio.

Reasoner Score Card

\begin{tabular}{|c|c|c|c|c|c|c|c|}
\hline $\begin{array}{l}\text { Scale } \\
\text { OF } \\
\text { PoINTS }\end{array}$ & Character & 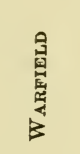 & 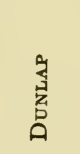 & 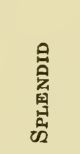 & 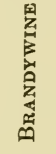 & 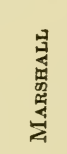 & 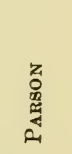 \\
\hline 5 & Rootage . . . & 4.5 & 4.5 & 5 & 4 & 4 & 4.5 \\
\hline 5 & Stock and foliage & 4 & 4.5 & 4.5 & 4 & 5 & 5 \\
\hline 7 & 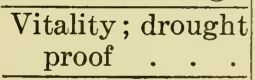 & 5.5 & 6 & 4.5 & 5 & 5 & 6 \\
\hline 10 & Plant-makers . & 10 & 10 & 9 & 6 & 5 & 6 \\
\hline 5 & $\begin{array}{l}\text { Healthfulness; } \\
\text { rust-proof . }\end{array}$ & 4 & 4.5 & 5 & 3 & 3 & 4 \\
\hline 5 & $\begin{array}{l}\text { Blossoms; stami- } \\
\text { nate-pistillate. }\end{array}$ & 5 & 5 & 4.5 & 4 & 4 & 4.5 \\
\hline 25 & Productiveness. & 20 & 20 & 20 & 16 & 14 & 20 \\
\hline 10 & Size.$\quad \cdot \quad \cdot$ & 7 & 8 & 8 & 9 & 10 & 8 \\
\hline 5 & Shape . . . & 5 & 5 & 5 & 4 & 5 & 4 \\
\hline 5 & Color . . . & 5 & 5 & 4 & 4 & 5 & 4 \\
\hline 8 & Flavor. . . & 8 & 7 & 7.5 & 6 & 7 & 5 \\
\hline 10 & $\begin{array}{l}\text { Firmness; ship- } \\
\text { ping quality }\end{array}$ & 9 & 9 & 9 & 8 & 7 & 8 \\
\hline 100 & Totals . . & 87 & 88.5 & 86 & 73 & 74 & 79 \\
\hline
\end{tabular}

${ }^{1}$ Rept. Ill. Hort. Soc., 1902, p. 266. 
The Reasoner score card also had a "supplemental score" in which length of nodes, earliness of bloom, earliness of ripening, duration of picking season and holding size of berries to end of season each counted ten points.

In 1903 A. T. Goldsborough, a strawberry breeder of Washington, D. C., used the following score card on his seedlings :

\section{Goldsborough Score Card}

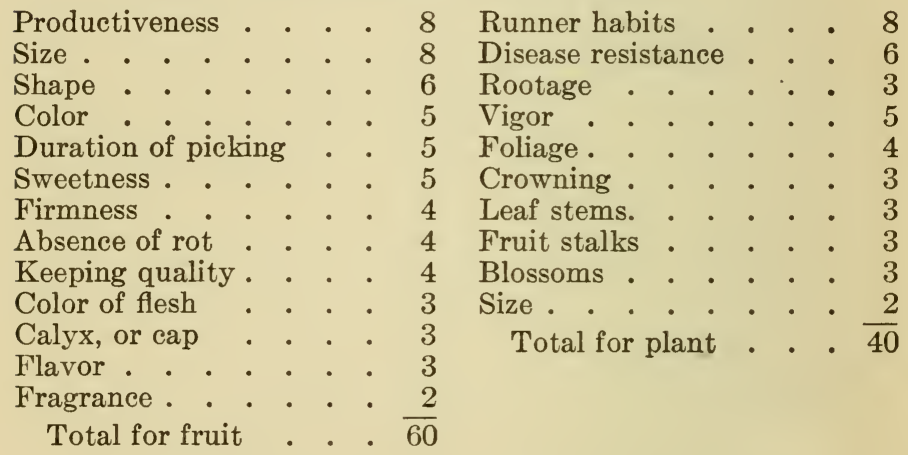

There is bound to be wide divergence of views as to the relative importance of different characters. It is not practicable to subject varieties or seedlings to the same score card in all sections. Under some conditions a certain character may be of prime importance, under others quite incidental ; drought resistance, for example, would be accorded more weight in western Nebraska than in western Washington. The following score cards are suggested for average conditions; they should be modified to fit local conditions. It is more satisfactory to score fruit and plant separately. 
Score Card for Fruit

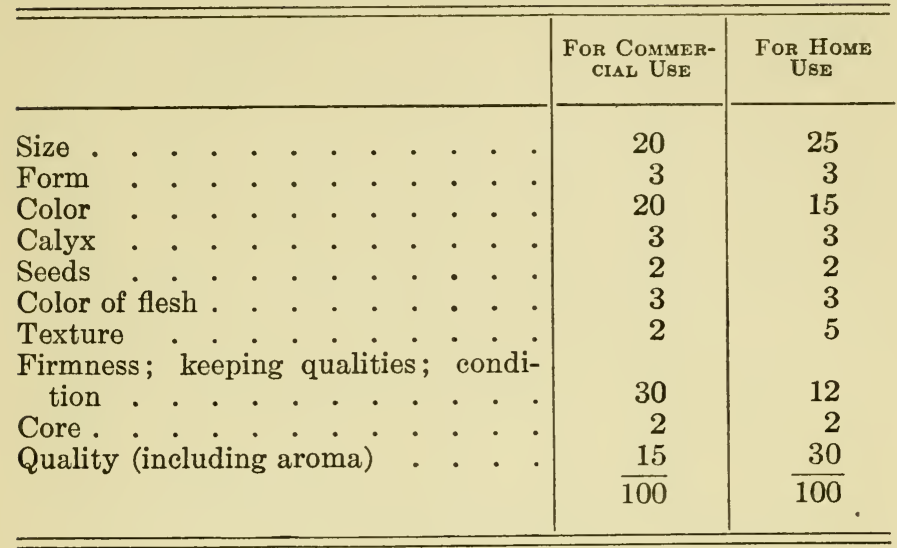

Uniformity to be considered, especially in scoring size, form and color.

Score Card for Plant

Vigor

Hardiness . . . . . . . . . . . . . 10

Drought resistance; rooting habit . . . . . . . 5

Resistance to disease . . . . . . . . . . . . . 10

Foliage; habit . . . . . . . . . . . . . . 5

Runners. . . . . . . . . . . . . . . . . 10

Season of blossoming; frost resistance . . . . . . . 5

Fruit stalks . . . . . . . . . . . . . . 5

Blossoms . . . . . . . . . . . . . . . . . 10

Productiveness . . . . . . . . . . . . . . 20

Season of ripening; duration of picking season . . . . 5

Holding size of fruit until end of season . . . . . $\frac{5}{100}$

\section{Food Value}

The strawberry is more appetizing than nutritious. It consists chiefly of sweetened and pleasantly acidulated 
water. It is valued more for its vegetable acids, combined with sugar and water, than for the very small amount of nutrients it contains. The Horticultural Department of the Ohio State University, averaging many analyses, found that strawberries contain 8 per cent of carbohydrates, three-tenths of 1 per cent of proteids and but a trace of fats. W. R. Lazenby points out that since the minimum daily ration of nutrients for an average person is about 17.8 ounces of carbohydrates, 4.2 ounces of proteids and two ounces of fats, he would have to eat eighty-eight pounds of strawberries daily in order to secure enough proteids to be properly nourished. ${ }^{1}$ This is a gastronomic feat that few would care to attempt.

The low food value of strawberries is shown in the following analyses by G. W. Shaw : ${ }^{2}$

Table I. Food Valde of the Strawberry

\begin{tabular}{|c|c|c|c|c|c|}
\hline & WATER & $\begin{array}{c}\text { DRY } \\
\text { MATTER }\end{array}$ & Protein & $\begin{array}{c}\text { NITROGEN } \\
\text { FREE EX- } \\
\text { TRACT, FAT } \\
\text { AND FIBER }\end{array}$ & AsB \\
\hline $\begin{array}{c}\text { Fresh prunes (Ore- } \\
\text { gon Italians) }\end{array}$ & 77.07 & 22.03 & 1.09 & 20.56 & .86 \\
\hline Cherries (Oregon) & 81.30 & 18.70 & .90 & 17.30 & .50 \\
\hline Potatoes . . & 78.30 & 21.70 & 2.20 & 17.50 & 1.00 \\
\hline $\begin{array}{l}\text { String Beans } \\
\text { Strawberries (Qre- }\end{array}$ & 89.20 & 10.80 & 2.30 & 7.70 & .80 \\
\hline gon) . . . & 88.57 & 11.43 & .86 & 9.41 & .41 \\
\hline
\end{tabular}

In 1892, W. E. Stone, of the Tennessee Experiment Station, analyzed twenty varieties of strawberries. ${ }^{3}$ He found

1 Trans. Mass. Hort. Soc., 1910, p. 92.

${ }^{2}$ Bul. 62 , Ore. Exp. Sta. (1900), pp. 6-8.

${ }^{3}$ Bul. 4, Vol. II, Tenn. Exp. Station (1892), p. 71. 
the dry matter averaged but 9.5 per cent, less than in any other fruit, apples having 16 to 20 per cent, pears 15 to 20 per cent, peaches (flesh) 11 to 14 per cent, plums (flesh) 18 to 20 per cent, currants 11 to 14 per cent, grapes 15 to 20 per cent. About one-half of the dry matter is glucose. The free acid in strawberries is largely malic; in his samples it averaged 1.37 per cent of the dry matter, while in apples it averages 0.8 per cent; pears, 0.2 per cent; plums, 0.9 per cent; currants, 4.7 per cent. The large amount of acid in the strawberry, as compared with other dessert fruits, is responsible for its disfavor with a few persons.

Are wild strawberries sweeter than cultivated varieties? Fragrant memories of the wild strawberries of our childhood make them seem sweeter than they really were. Most wild strawberries are sourer than the best cultivated varieties. W. E. Stone found the proportion of acid to sugar in wild strawberries to be 1 to 2 . In cultivated varieties it was 1 to 3.5. According to Shaw, an average of North American analyses shows a ratio of acid to sugar of 1 to 7, and, of European analyses, 1 to 5 . In 1879, Goessman found the ratio in wild strawberries to be 1 to 2 . It is quite evident that there has been a marked improvement in the sweetness of strawberries since they were brought under cultivation. The sweetest berries, except those of memory, are no longer in the woods and meadows; they are in the gardens. This applies, however, only to berries that are allowed to stay on the vines until fully ripe; most of the berries on the market are sour, because they were picked green.

The best European varieties are sweeter than ours, as is shown by the analyses of Stone and Shaw. The latter gives the following table: 
Table II. Proportion of Acid to Sugar in Strawberries

\begin{tabular}{|c|c|c|c|c|c|c|c|}
\hline & W $\triangle$ ATER & $\underset{\text { MATTER }}{\text { DRY' }}$ & $\begin{array}{l}\text { Pro- } \\
\text { TEIN }\end{array}$ & $\begin{array}{l}\text { TOTAL } \\
\text { SOGAR }\end{array}$ & ACID & Fiber & AsH \\
\hline $\begin{array}{cc}\text { European } & \text { varieties }(\mathrm{J} . \\
\text { König) } & \cdot\end{array}$ & 87.66 & 12.34 & .57 & 6.28 & .93 & 2.32 & .81 \\
\hline $\begin{array}{l}\text { Tennessee varieties (W. } \\
\text { E. Stone) } \\
\text { Oregon varieties (G. }\end{array}$ & 90.52 & 9.48 & .99 & 5.36 & 1.37 & 1.55 & .62 \\
\hline $\begin{array}{l}\text { Oregon varieties (G. W. } \\
\text { Shaw) }\end{array}$ & 85.57 & 11.43 & .86 & 5.80 & .75 & - & .41 \\
\hline
\end{tabular}

Supposed medicinal value. - The earliest books referring to horticulture were the herbals, printed four and five centuries ago. These catalogued and described plants for their supposed medicinal properties. The strawberry must have been more potent then than now, if we are to accept the authority of the herbals. In his "Paradisus Terrestris," published in 1629, John Parkinson discourses freely upon The Vfe of Strawberries.

"The leaves of Strawberries are alwaies vfed among other herbs in cooling drinkes, as alfo in lotions and gargles for the mouth and throate: The rootes are fometimes added to make it the more effectuall, and withall fomewhat binding. The berries themfelves are often brought to the Table as a reare ferince, whereunto claret wine, creame. or milke, if added with fugar as everyone liketh; af alfo at other times, both with the better and meaner fort, and are a good cooling and pleafant difh in the hot fvmmer feafon: The water diftilled of the berries if good for the paffions of the hearte, caufed by the perturbation of the fpirits, being eyther drunke alone or in wine, and maketh the hearte merry."

In folk medicine, or the doctrine of signatures, straw- 
berries were supposed to cure all diseases of the heart, because they were red and shaped like that organ. It was believed that to dream of strawberries was an excellent omen, especially to the young bachelor, as "such a dream will insure him a wife who will not only be angelic in temper, but also a prolific bearer of boys."

As grown in North America, the strawberry was found to have lost but little of this remarkable efficacy. In his Young Gardener's Assistant, published in 1812, Thomas Bridgman recommended them unreservedly to his fellow sufferers: "Physicians concur in placing strawberries in their small catalogue of pleasant remedies as having properties that render them, in most conditions of the animal frame, positively salutary; they dissolve the tartarous incrustations of the teeth; they promote perspiration. Persons affected with the gout have found relief from using them very largely; so have patients in case of the stone; and Hoffman states that he has known consumptive people cured of them." Downing was able to subscribe to "the oft-quoted instance of the great Linnæus curing himself of gout by partaking freely of strawberries, a proof of its great wholesomeness."

Value of the strawberry in the diet. - Modern strawberries are sadly degenerate in curative properties. For the past twenty-five years, at least, no severe cases of gout, gallstone, consumption, or passions of the heart have been reported as cured by their use. In fact, there is a tendency to ascribe evil to this fruit, rather than good. Because there are more cases of insanity in early summer than at other times of the year, some have concluded that strawberries are responsible for it. The press frequently contains articles purporting to prove that the strawberry is the most unwholesome of fruits, causing digestive disturbances, rashes 
and rheumatism. Nearly every kind of food is harmful to an occasional person. Some cannot eat pork; to others tomatoes are "poison." Veal, melons, cucumbers, chocolate, apples and many other staple foods, are harmful to a few people. Not one person in a thousand is harmfully affected by strawberries, when eaten in moderation. To a very few persons strawberries are distinctly injurious, but the number is insignificant compared with the multitude who are benefited by using them freely.

Most of this unjustified criticism of the strawberry is due to the fact that it contains more acid than other dessert fruits. This condition is aggravated when the fruit is picked before fully ripe in order that it may be shipped to distant markets. Strawberries disagree with people chiefly because they are picked and eaten when unripe. Berries that are fully matured on the vines, in home gardens, rarely cause trouble. The less sugar used on strawberries, the better. Nothing spoils the flavor and aroma of a perfect strawberry more effectively than an excess of sugar. If the berries are unripe and sour, the sugar that is added does not take the place of the sweetness that nature would have provided had they ripened on the vines.

Over two centuries ago, while Izaak Walton was showing a young friend how to catch fish and, at the same time, was expounding a genial philosophy of life, he gave point to his instruction by quoting the words of "good Doctor Boteler," who said: "Doubtless, God could have made a better berry than the strawberry, but, doubtless, God never did." This remark since has been credited to Lord Bacon, Henry Ward Beecher, Reverend Sydney Smith and several lesser lights. Whatever fame good Doctor Boteler may have achieved in other respects, it is likely 
that he will be remembered longest for this bit of wisdom, enshrined in the discourse of the fisherman-philosopher. His discerning estimate of the strawberry is received with as much approbation today as Walton gave it. The chemist tells us that the strawberry has but little fuel value; that it is mostly sweetened water. How futile to measure the worth of this fruit in calories! As well value the sunbeam only for its heat, or the cloud only for its water. The rich color, enticing fragrance and racy flavor of the strawberry make an appeal to the senses that cannot be expressed in terms of food value. Opinions differ as to the palatability of the strawberry, but the remarks of "Josh Billings" express the convictions of most people: "Cherrys is good, but they are tew much like sucking a marbel with a handle tew it. Peaches is good if you don't get any of the pin feathers intew your lips. Wattermelons will sute anyboddy who is satisfied with half sweetened drinks; but the man who kan eat strawberrys, besprinkled with kream (at someboddy's else's expense) and not lay his hand on his stummuck and thank the Author of strawberries and stummucks, iz a man with a worn-out conscience - a man whose mouth tastes like a hole in the ground, and don't care what gose down it." 


\section{CHAPTER VI}

\section{BREEDING}

A FRUIT is improved either by the raising of seedlings from hand-sown seeds, whether hand-crossed or not, or by the discovery of superior chance seedlings. In either case the improvement results from interest and effort on the part of man. A superior chance seedling does not contribute to the improvement of the species unless some one is alert to detect it, and takes the trouble to protect and propagate it.

Notwithstanding the ease with which new varieties of strawberry may be raised, most of the older varieties were chance seedlings. The parentage is known of only about one-sixth of the 1879 North American varieties. Many of the most prominent commercial varieties were chance seedlings. The list includes such standard sorts as Crescent, Warfield, Bubach, Michel, Marshall and Brandywine. On the other hand, the Hovey, Wilson, Sharpless, Dunlap, Haverland, Gandy, Aroma and Klondike were produced from hand-sown seeds. It must be admitted that wayside seedlings have contributed almost as much to the improvement of the garden strawberry as varieties produced by definite breeding. The strawberry escapes from cultivation so easily and produces self-sown seedlings so readily that this will continue to be a prolific source of new varieties. During the past ten years the varieties produced by breeders have in- 
creased in number and in value. It is probable that in the future most of the improvement will be through definite breeding rather than through chance seedlings.

\section{The Four Stem-Varieties}

The varieties that have contributed most to the improvement of the strawberry in North America through their seedlings are the Hovey, Wilson, Crescent and Sharpless. Of the 1879 varieties of North American origin, the parents of only 348 are known with certainty. Sixtythree are descendants of Crescent, sixty-nine of Sharpless, forty-eight of Wilson and fifty-one of Hovey. Thus, approximately two-thirds of the varieties of known parentage have come from these four stem varieties. It is natural that such noteworthy sorts should have been used for breeding more than others. The Crescent and Sharpless seem to have possessed more virility, or ability to produce valuable seedlings, than the Hovey or the Wilson.

Descendants of the Hovey. - There are fifty-one varieties of the lineage of the Hovey, most of them descending through Green Prolific and Cumberland Triumph. The most notable of these are Aroma, Clyde, Cumberland Triumph, Cyclone, Monarch and Ozark. The complete list follows. Those that are starred are in cultivation today.

$\begin{array}{lll}\text { *Aroma } & \text { Charles' Favorite } & \text { *Cyclone } \\ \text { Babylon } & \text { *Charles Newman } & \text { *Daisy (of Zane) } \\ \text { Banana } & \text { Chorlton's Prolific } & \text { Elizabeth (of Ohio) } \\ \text { Black Defiance } & { }^{*} \text { Clyde } & \text { Eureka (of Town- } \\ \text { *Bountiful } & \text { Columbus } & \text { send) } \\ \text { *Brownie } & \text { Cumberland } & \text { *Frances Cleveland } \\ \text { Burr's New Pine } & \text { Triumph } & \text { Genesee }\end{array}$


Green Prolific

Hiawatha

Huddlestone's Favorite

Malvina

*Marie

*Monarch

Monroe Scarlet

Morgansteoma

Mote's Seedling

Ohio Mammoth

Onondaga
Orient

Ottawa

*Ozark

Peak's Emperor

President Wilder

*Robbie

*Roosevelt (of Cathcoit)

Scarlet Melting

Scarlet Prolific

Seth Boyden

Shawnee
*Sheppard

*Shuster

*Sons

Sucker State

Superlative

Viola

Woodruff

*Wooster

Yahoo

Zula

Descendants of the Wilson. - Fewer valuable varieties have descended from the Wilson than from either Crescent or Sharpless. The most notable are Early Hathaway and Excelsior (of Bubach). The forty-one sorts that are of Wilson blood are given below:

$\begin{array}{lll}\text { Abington Blush } & \text { *Early Harvest } & \text { Kramer } \\ \text { Alpha (of Arnold) } & \text { *Early Hathaway } & \begin{array}{c}\text { Maggie } \\ \text { Arena }\end{array} \\ \begin{array}{l}\text { Endicott } \\ \text { Arnold's Pride }\end{array} & \text { *Ecelsior (of Hu- } & \text { Miami } \\ \text { Backett's Prolific } & \text { bach) } & \text { Moore's Early } \\ \text { Big Bob } & \text { Fleming } & \text { Nicanor } \\ \text { *Bisel } & \text { Florence } & \text { Old John Brown } \\ \text { Boudinot } & \text { Gamargua } & \text { Ottawa } \\ \text { Bright Ida } & \text { Golden Queen } & \text { *Ozark } \\ \text { Bryan's Satisfaction } & \text { Haight } & \text { Peak's Emperor } \\ \text { *Charles Newman } & \text { *Hubach and Hath- } & \text { Prouty Seedling } \\ \text { *Cobden } & \text { away } & \text { *Satisfaction } \\ \text { *Cobden King } & \text { Huddlestone's Fa- } & \text { Smith's Seedling } \\ \text { Crimson Favorite } & \text { vorite } & \text { Sucker State } \\ \text { Duncan (of Lucas) } & \text { *Jim Dumas } & \end{array}$

Descendants of Sharpless. - Sixty-nine varieties have come from the Sharpless. The most notable of these are Enhance, Haverland and Jessie. Four of them Haverland, Manokin, Tennessee (of Hodges) and Williams (of Ontario) have Crescent blood also : 


$\begin{array}{lll}\text { Arrow } & \text { *Heritage } & \text { *Ninety-six } \\ \text { Auburn } & \text { Hobson's Choice } & \text { Ona } \\ \text { *Barton } & \text { *Howard (of Black) } & \text { *Oom Paul } \\ \text { Benoy } & \text { *Hubach and Hath- } & \text { *Oregon } \\ \text { *Berlin (of Schild) } & \text { away } & \text { *Paul Jones } \\ \text { *Buster } & \text { Hunn } & \text { *Philips } \\ \text { *Carrie } & \text { *Jerry Rusk } & \text { *Porto Rico } \\ \text { *Carrie Silvers } & \text { *Jessie } & \text { *Purdue } \\ \text { Chair's Favorite } & \text { *Jim Dumas } & \text { *Quality (of N. Y. } \\ \text { *Columbia (of Wild) } & \text { *Joe } & \text { Ex. Sta.) } \\ \text { Dutter } & \text { *July } & \text { Rio } \\ \text { Effie (of Beaver) } & \text { *Lady Jane } & \text { *Rose Ettersburg } \\ \text { *Elma } & \text { Leo } & \text { *St. Louis (of Bauer) } \\ \text { *Enhance } & \text { Leviathan } & \text { *Sparta } \\ \text { Felton } & \text { *Lindenwald } & \text { *Stella } \\ \text { *Fisher } & \text { *Luxury } & \text { *Tennessee } \\ \text { Gamargua } & \text { *Manokin } & \text { Hodges) } \\ \text { Gillespie } & \text { *Marconi } & \text { Tom Walker } \\ \text { *Glastonbury } & \text { Mark } & \text { *Velvet } \\ \text { Governor Hoard } & \text { *Midnight } & \text { Viola (of Kershaw) } \\ \text { *Haverland } & \text { *Mrs. Fisher } & \text { *Virginia } \\ \text { *Helen Gould } & \text { Mrs. Garfield } & \text { *Warren (of Thomp- } \\ \text { Henry Ward } & \text { *Nettie } & \text { son) } \\ \text { Beecher } & \text { *Nicaragua } & \text { *Williams (of Ont.) }\end{array}$

Descendants of Crescent. - Sixty-three varieties have come from the Crescent, of which the most notable are Clyde, Haverland, Parker Earle, Ridgeway and Tennessee.

Arrow
Auburn
*Berlin (of Schild)
Bessie (of Schadle-
bach)
*Bismarck
*Bountiful
*Bradley
*Carrie
*Carrie Silvers
*Clyde
*Columbia (of Wild)
*Cyclone
*Daisy (of Zane)

*De Wet

Dora

*Enormous

Gillespie

*Glastonbury

*Ham

*Haverland

*Hawaii

*Heath

Hobson's Choice

*Indiana (of Schild)

*Ionia

*Johnson

*July
*Kevitt

*Lady Jane

Lehigh

*Louis Hubach

*Luxury

*Manokin

May King

*Mele

*Midnight

Morgansteoma

*Nicaragua

*Olive

Ona

*Parker Earle 
*Paul Jones

*Philip

*Porto Rico

*Red Prolific

*Ridgeway

*Robbie
*Robinson

*Roosevelt (of Cathcoit)

*St. Louis (of Bauer)

*Shuster

*Stone
*Tennessee (of Hodges)

*Van Deman

Vineless

\section{Breeding for a Specific Purpose}

Considering the ease with which new varieties may be produced and the great number that have been introduced, there has been surprisingly little progress since the introduction of the Longworth, in 1851; this variety still is with us for comparison. We have few, if any, varieties that are superior in size, attractiveness and quality to the Hovey of 1836 . None is more vigorous or productive under indifferent care than the Wilson of 1854. There has been improvement, but it has not been as marked as might have been expected.

Changing ideals. - The ideals in strawberry breeding change with the generations. Until about 1870, the efforts of northern breeders were directed mainly to securing extra early varieties, even though this involved a considerable sacrifice in yield. Then came the rapid extension of railroads and the introduction of refrigeration. Southern berries began to reach Northern markets long before the earliest local berries were ripe. There has been little demand in the North for the extra early but light-yielding varieties since then except for supplying a personal market. Forty years ago, light scarlet berries were accepted as readily as dark crimson berries, and sometimes were preferred. Now it would be difficult to find a market for a variety as light colored as the Cumberland Triumph. In the days when nearly all com- 
mercial strawberry culture was within a few miles of cities, the larger the berries were, the better. It did not make much difference if they were quite irregular in shape. Only berries of medium size - not much over an inch in diameter, and of regular shape, can be shipped one thousand miles or more with assurance that they will reach the market in perfect condition.

Breeding for one thing at a time. - The first essential in undertaking to produce a valuable new variety, therefore, is to know what kind of strawberry is wanted. The desirable characters of varieties, according to present standards, are considered in Chapter V. In one section certain of these characters are more important than in others. The object of the breeder is to produce a variety that will more perfectly fulfill one or more of these conditions than any now grown. It is not possible to produce a variety that excels in all particulars. High quality rarely accompanies marked firmness; the best shipping varieties are usually of indifferent quality. It is best to breed for one quality at a time. If hardiness is most essential, the hardiest known varieties or species are used, even though they may be deficient in some other respects; these defects may be corrected after seedlings of the desired degree of hardiness are secured.

The time has passed when strawberry breeders can seek to produce, as they once did, "the best all-round variety." Our horticulture has become greatly diversified. The adaptations of certain varieties to certain regions are marked, and different markets require different types of berries. Those who breed for a specific object are more likely to reach their goal than those who raise seedlings indiscriminately. Before making a cross, some specific ideal should be clearly in mind, such as a 
Klondike that is ten days earlier; a variety adapted to the hot climate of the Imperial Valley, California; a William Belt that is more resistant to leaf spot; a variety that has the qualities of color, firmness, acidity and productiveness that make it especially valuable for canning.

The way in which a strawberry breeder should direct his efforts toward a specific object is illustrated by the work of N. E. Hansen and C. C. Georgeson. The winters in northern Minnesota, North and South Dakota, Manitoba and Saskatchewan are so severe that most of the common varieties winter-kill outright, even under a heavy mulch. Others are not killed, but are so weakened that the stand is poor and the yield light. In 1899 and 1900 N. E. Hansen, of the South Dakota Experiment Station, began work to produce "varieties that will be hardy without winter mulch or protection of any kind." The Dakota prairie strawberry, a form of $F$. virginiana, was crossed with some of the hardiest of the standard sorts, including Princess, Warfield, Enhance, Van Deman, Beder Wood, Bisel, Seaford and Glen Mary, which were found hardy in about the order named. The prairie strawberry does not winter-kill but it is defective in other respects, especially in size, and in multiplicity of runners. Efforts were made by Hansen to improve the native berry by making selections of pure seedlings as well as by crossing it with good varieties. The result was a number of seedlings that are able to endure forty degrees (F.) below zero without being mulched; but they are so small in berry that they are of value only where the standard varieties winter-kill. This work is being continued with the wild strawberry of Alaska, which has larger fruit than the prairie strawberry. The work of C. C. Georgeson, at the Alaska Experiment Station, is another illustration 
of strawberry breeding to secure varieties adapted to a certain region. In 1906 he crossed an unknown cultivated variety with a species which is indigenous to the Alaska coast from Muir Glacier to Prince William Sound; it is considered to be a form of $F$. chiloensis. Some of the varieties thus produced are valuable for the coast region of Alaska, but not for the interior.

Selecting the parents. - Having conceived an ideal of a variety that will be superior to existing sorts in at least one important respect, the next step is to secure for its parents those varieties or species that possess this character to the most marked degree. Usually improved varieties are selected, but, if necessary, wild forms of Fragaria may be used. The various native species, $F$. virginiana, $F$. chiloensis, $F$. californica and others, hybridize readily, including those marked departures from the type that some botanists distinguish by separate specific names, as $F$. canadensis and $F$. americana. For many years, Albert F. Etter, of Ettersburg, California, has been crossing $F$. chiloensis, $F$. californica and $F$. vesca upon some of the standard varieties, especially the Sharpless and Parry. The Ettersburg Trebla is a composite of all these forms. Recently he has used $F$. indica, also. $F$. mexicana, which is quite similar to, if not identical with, $F$. vesca, has been used successfully. Rarely can $F$. elatior, the Hautbois strawberry, be used to advantage; it does not cross readily with $F$. virginiana or the common cultivated varieties, neither does it have characters that are desired in the strawberry at this time.

Luther Burbank, of Santa Rosa, California, describes one of his remarkable hybrids between the strawberry and the raspberry, as follows: ${ }^{1}$ "Out of seven or eight hun1 "New Creations of Fruits and Flowers," June, 1893, p. 35. 
dred of these curious hybrids not one has ever produced a berry, though blooming with the greatest profusion. As the blossoms fade, a bunch forms resembling a miniature strawberry, but it never matures. The plants, when young, are practically strawberry plants, but, with age, produce canes five or six feet high, multiplying by curious underground stolons. The leaves are trifoliate invariably; the canes are thornless, or nearly so." A cluster of blossoms and some of the leaves, shown in the photograph accompanying this description, resemble the raspberry more than the strawberry.

During the past few years the results of crossing have been made somewhat more predictable by the discovery and application to breeding of Mendel's law. ${ }^{1}$ C. W. Richardson, reporting upon some crosses between a runnerless Alpine strawberry and a running variety, showed that in this case runner production was "marked dominant." 2

Botanical relationships and morphology. - A knowledge of the anatomy of the strawberry plant and of its botanical relationships is of value to the breeder. The following statement by $\mathrm{H}$. de Vilmorin is of interest: ${ }^{3}$ "The species included in the genus Fragaria appear to stand on the very border between herbaceous and shrubby plants. Potentillas, which are next to them in botanical classification, have a still wider range of organization; some of them, as $P$. anserina, being perfectly herbaceous, and others, as $P$. fruticosa, being decidedly shrubs, with woody permanent stems. Strawberries are mostly placed

1 The reader is referred to "Plant Breeding," by Bailey and Gilbert, for a full discussion of the principles and practice of plant breeding.

\footnotetext{
${ }^{2}$ Jour. Genetics, 3 (1914), No. 3, pp. 171-177.

${ }^{3}$ Trans. Royal Hort. Soc., 1898-9, pp. 318-319.
} 
just on the intermediate step between the two. Their short-jointed, thick stems bear from eight to twelve leaves, at the axil of which a bud develops, which seldom becomes abortive, and mostly develops either into a branch similar to the main stem or into a runner, or into a flower stem, these appendages being, in a manner, equivalent and, so to speak, interchangeable with one another.

"The runner, at first sight, appears as different as possible from the ordinary leaf-bearing stem; it becomes very plain, however, upon closer inspection, that it is merely an elongated branch, dissimilar to the original one simply in the great length of the internodes and in the diminutive size of the leaves, which are mostly reduced to mere bracts. But the runners show their identity with the normal branches in producing from their knots exactly the same appendages as the primitive stems do, viz.: regular stems, runners, and even flower stems; and in bearing, also, abortive axillary buds occasionally."

The very short stem of the cultivated strawberry is a form of rhizome. It develops largely underground and roots at the nodes. As the plant grows older, the stem elongates or divides: New roots form each year above the old ones, which die at the close of the season;

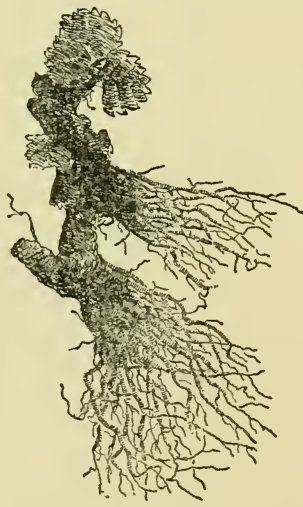

Fig. 19. - The long root stalk of a very old plant. hence, the plant becomes more shallow-rooted each year. Eventually, the plant pushes itself out of the ground. Unless new soil is drawn over the 
roots, the roots become more and more exposed; finally the plant succumbs to cold or drought. In early spring the roots are fresh and vigorous, and stay so until after the crop is off; then they turn black, die and new roots start. The roots of some varieties, as Jucunda, are fleshy and shallow, resembling, in this respect, the roots of $F$. chiloensis. The roots of other varieties are wiry and anchored deeply in the ground, as is the case with $F$. virginiana. At first a young strawberry plant has only one crown, but if the runners are kept off it will have many crowns. The crown is a fleshy stem and bears buds like any other stem. Some of these buds become runners ; others become fruit stalks.

When fruit buds are formed. - In the North the fruit buds are formed in late fall. The conditions that determine the time of fruit bud formation in Wisconsin have been studied by E. S. Goff. He reports: 1 "The elaboration of the initial flower cells into flowers takes place, mainly, after the development of runners has ceased, because the branches that form flowers beneath the terminal bud are later in order of development than the later formed runners. It seems probable that the elaboration of the flowers takes place rather late in autumn, when growth is declining, and that the rapid development of the flower stalk in spring is but the expansion of the autumn-formed cells, as is the case with most of the early flowering shoots. Since the flower stalk is the terminal or leader shoot of the plant, it follows that the seedling strawberry plant and young runner plant form but one flower stalk the first season that the plant blooms; but, as the stem of a plant more than one year old may have more than one branch, so an old strawberry plant may ${ }^{1}$ Rept. Wis. Exp. Sta., 1898, p. 235. 
have more than one flower stalk." Goff made a microscopic study of the formation of flowers in the Clyde. ${ }^{1}$ Beginning July 5th, samples were taken weekly, both of old plants wintered over from the preceding year and of runners. There were no indications of flower development until September 20th, when the initial stage suddenly appeared, both in the old plants and the runners. By September 27th the terminal flowers and several axillary flowers could be distinguished readily. "The flowers appeared to start about the same time in the younger rooted runner plants as in the parent plant. This shows clearly that it is not age alone that determines the time of formation of the flowers." He explained the sudden appearance of the flower buds on September

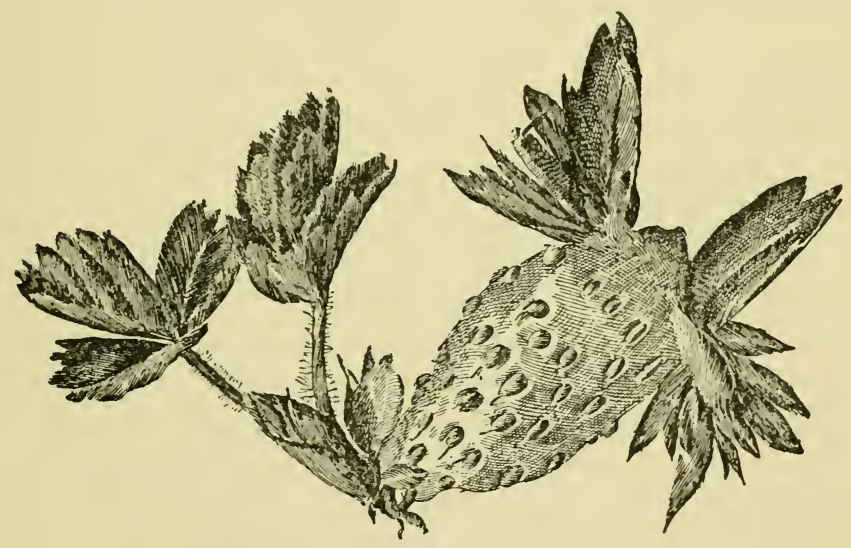

FIG. 20. - Proliferous strawberry.

20th in this way: "It appears that a decided decline in the maximum temperature occurred at almost exactly the time the flowers commenced to form." These obser-

${ }^{1}$ Rept. Wis. Exp. Sta., 1900, pp. 227-9. 
vations indicate that in the North any treatment designed to increase the number or strength of the flower buds must be given the season before the plants fruit.

Farther South, the flower buds are formed much later. In Missouri, W. H. Chandler was "unable to find the flower parts of the strawberry earlier than February or March, and experience indicates that the number of fruit stems sent up from any crown can be influenced by spring treatment." 1 It is probable that any decided check in growth, whether due to low temperature or lack of moisture, will cause the plant to make flower buds, provided it has arrived at a certain period of maturity. A midsummer drought causes plants to bloom and produce a fall crop; if conditions are favorable, the crop borne by these plants the following spring may be nearly

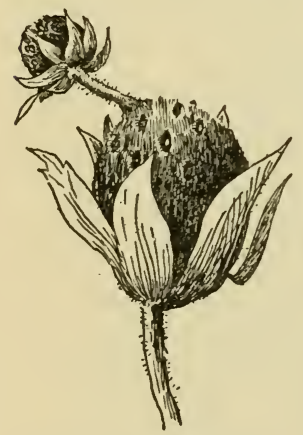

FIG. 21. - An abnormal structural form. or quite as large as usual. In southern California, flower bud formation and fruit bearing are more or less continuous, but a severe check in growth, such as is produced by withholding irrigation and cutting off runners, causes the plants to fruit more abundantly at certain seasons. Abnormal structural forms. These frequently appear, especially a fruit with a stem growing beyond it (Fig. 20). A Bubach berry with a short stem coming directly from the flesh of the berry and bearing a tiny flower set in the midst of three small leaves was reported in $1900 .^{2} \mathrm{~A}$ more unusual form was found by M. T. Cook in

${ }^{1}$ Bull. 113, Mo. Exp. Sta., p. 279.

${ }^{2}$ Rural New Yorker, 1900, p. 482. 
Cuba." "There was an extension of the stem through the fruit. In some cases it was simply extended as a leafy shoot, while in others a small berry wasproduced about an inch beyond the first one" (Fig. 21). Since the fruit stalk is merely a metamorphosed runner which has become erect, it can be seen

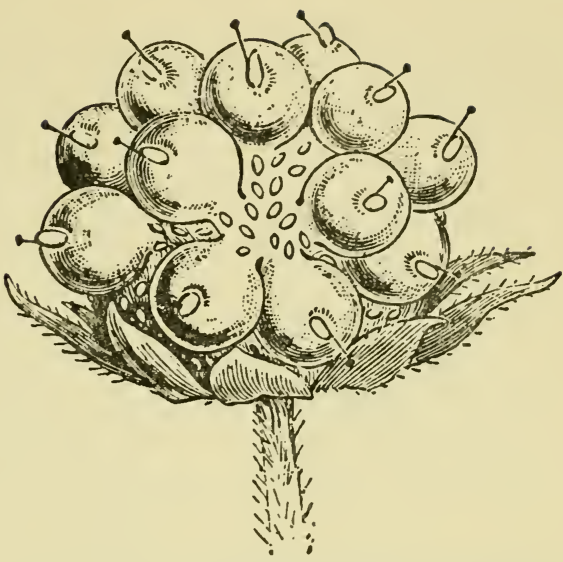

Frg. 22. - A freak strawberry; the exposed seed carpels are covered with pulp, like a blackberry. why a stem may occasionally spring from the berry just as it does from a layer plant.

\section{Breeding Methods}

There has been much indefinite and futile effort in strawberry breeding. Some enthusiastic amateurs have entertained the notion that superior new varieties can be produced simply by growing the seeds of exceptionally large and attractive berries. There is a chance that among thousands of seedlings produced in this haphazard fashion one may be of merit, but usually the result is wholly disappointing.

Methods of the early breeders. - The only way to be absolutely sure of the parentage of seedlings is to pollinate the blossoms by hand. It is possible that berries not

${ }^{1}$ Estac. Cent. Agron. (Cuba), Rept. 2 (1905-9), pt. 2, p. 142. 
produced by hand-crossing may be self-pollinated if there is no other variety blossoming at the same time within about 500 feet; but this cannot be certain. Some of

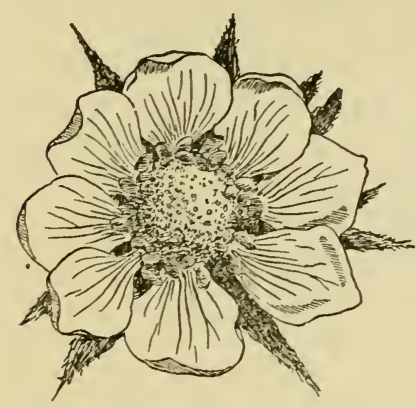

FIg. 23. - A staminate blossom, showing the numerous yellow anthers, containing the pollen, surrounding the cone of green pistils. A pistillate blossom lacks well-developed stamens. the early strawberry breeders took a middle course; they planted two varieties close together at some distance from other varieties, in the expectation that they would cross-pollinate naturally and that the seedlings would combine the qualities of both parents. When one of the varieties was a pistillate and the other staminate, this method was fairly satisfactory; but there was a large element of uncertainty, because of the possibility of pollination from other sources.

The method used by Seth Boyden, originator of many noted sorts, was to set four plants of the staminate variety in a square, with one plant of a pistillate variety in the center. These were given high culture and covered with a small frame and sash before they bloomed. F. W. Louden, originator of the Jessie, made his crosses on plants in eight inch pots. These were kept in the cellar through the winter and placed close together in hot beds about the middle of March. The object was to bring the plants into bloom two or three weeks before strawberries in the field, so that it would not be necessary to cover the beds with sash to exclude insect visitors. Many other methods of securing cross-pollination, without the necessity of hand-crossing, have been tried. The Hovey, 
the first variety of fruit originated in North America, was produced by hand-crossing. Nearly all the numerous varieties produced by E. W. Durand, of Irvington, New Jersey, between 1865 and 1880 were the result of handcrossing. At present, most strawberry breeders practice hand-pollination; it is the only way to be sure of results.

Hand-crossing. - The work may be done in the field or in the greenhouse. Most of those who breed strawberries extensively find it best to work with potted plants in the greenhouse or in cold frames, because conditions can be controlled more perfectly than in the field and the crossing can be done when other work is not pressing. Strong plants in six inch pots are brought into bloom, and the number of blossoms on a fruit stalk reduced to five or six. ${ }^{1}$ Before these have expanded fully the anthers are cut off while still unopened, using a sharp scalpel or small scissors. Some prefer to pull off the anthers with tweezers. It is best not to mutilate the blossoms, except to cut off the anthers; the petals and sepals should not be cut. Be careful that none of the anthers lodge in the blossoms. If the seed-bearing parent is a pistillate variety, it is important to cut out all the rudimentary stamens; frequently these are half hidden and inconspicuous, but produce enough pollen to vitiate the results. Many pistillate varieties, as the Crescent, produce enough pollen to use for crossing. If there are staminate varieties near, other than the one to be used as a pollinizer, it is necessary either to isolate all emasculated plants or to cover each fruit stalk with a paper sack, after it has been prepared for pollination. These are preferably of tough, oiled, tissue paper, but ordinary manila sacks

${ }^{1}$ The methods of forcing strawberries are detailed in "Strawberry-Growing," Chapter XIII. 


\section{THE STRAWBERRY IN NORTH AMERICA}

may be used. They should be tied closely at the bottom. Pollen-carrying insects are not present in the greenhouse, yet currents of air may distribute the pollen to some extent. If care is used in watering and ventilating, practical isolation is secured by separating the male and female plants several feet.

If only a few crosses are to be made, pollen may be secured from the fully opened blossoms of the male plant and transferred directly to the pistils, provided both mature at the same time. When many crosses are to be made, and the blossoms of the male parent mature
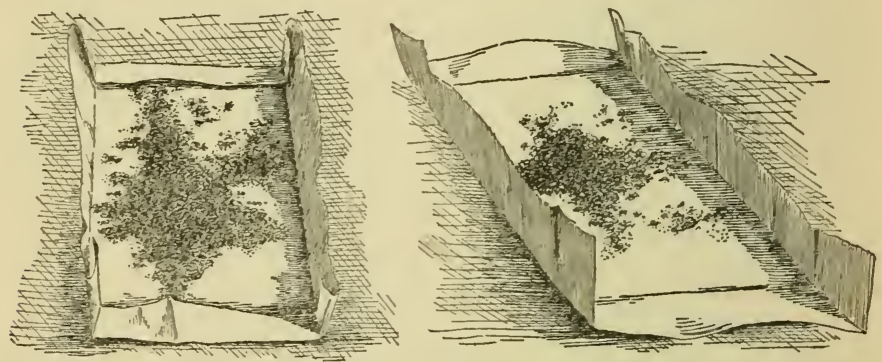

FIG. 24. - Anthers clipped off and exposed to the sun, to secure pollen.

a few days earlier than those of the female, the pollen should be secured beforehand. A large number of fully developed anthers are clipped off closely and exposed to the sun upon sheets of paper (Fig. 24). The anthers soon burst; then most of them may be winnowed off, leaving the dry pollen. This is preserved until needed in small paper envelopes or vials ; if kept in bottles, these should not be corked, as pollen ferments easily. C. S. Crandall finds that the maximum period that strawberry pollen will retain its viability is fifteen days. ${ }^{1}$

${ }^{1}$ Proc. Soc. Hort. Sci., 9 (1912), pp. 121-30. 
Pollination is done when the pistils are receptive. This is when the stigmas are covered with a glistening, sticky fluid, which can be seen in the sunshine without the aid of a hand lens. The stigmas often remain receptive several days, but pollen should be applied as soon as possible after they are ready. When the stigmas begin to

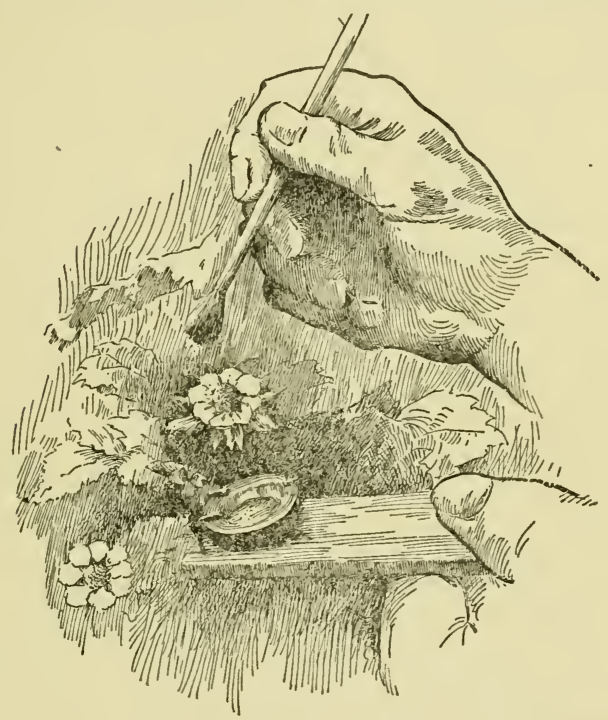

FIG. 25. - Pollinating with a camel's-hair brush.

turn brown they have passed the receptive period. A sunny day is favorable for hand-pollination. The pollen is commonly transferred to the pistils with a small camel'shair brush but some merely touch the pollen, then the pistils, with the end of a finger. It is important to place pollen upon each of the numerous pistils; those that are missed will not produce seeds. Pollen should be applied very freely. If paper sacks are used to protect the pistils 
from foreign pollen, these should be kept on for two or three days after pollination. Crosses should be labeled at the time of pollination. Hand-crossing in the field is done in the same way, but it is necessary to use greater care to protect the blossoms from foreign pollination, and the results are much more uncertain; the weather may be unfavorable when pollination is done, the sacks may be torn, and the crossed fruit cannot be protected so readily from the depredations of birds and boys.

Albert F. Etter, of Ettersburg, California, describes his method of crossing as follows: ${ }^{1}$ "You may need a penknife, but not necessarily. You will need a piece of tissue paper two or three inches square, which is used as a hood to hold the male blossom in place over the newly opened female blossom. The stem of the plucked male blossom is inserted in a hole through the center of the tissue paper, and the blossom is placed over the female blossom. Now fold the paper back and tie with a small piece of cord. As the male blossom withers the pollen sacks burst and the dust is brought into contact with the pistils. By using a pistillate female parent, all that is necessary is to plant it side by side with the prospective male parent, and insects will do the rest. This, of course, is not scientific, but it is practical."

The methods of Louis Hubach, a prominent breeder of Judsonia, Arkansas, are interesting. He uses only pistillate varieties as mother plants. "His experience has been that when he has crossed perfect-flowered with perfect-flowered varieties, the progeny lost in productiveness. In an experiment in which he tested this, he found that the decrease in yield continued for several generations. Because of this experience he has developed sev-

${ }_{1}$ Pacific Rural Press, Feb., 1916. 
eral varieties having imperfect flowers which are used in breeding only. He grows, in a separate plot, four plants of each pistillate variety which he wishes to use. At the beginning of the flowering period, he encloses the four plants in a wooden frame covered with a white cloth of fine weave - preferably silk cloth. When a cross is to be made, a flower is picked early in the morning and is placed in an inverted position on one of the flowers under the cloth frame. Pollen falls on the pistils and fertilization takes place." 1

Sowing the seed. - Strawberries are grown from seed more easily than most other fruits. The berries are picked when dead ripe. The seeds may be separated from the pulp by crushing the berries and rubbing the pulp in fine, dry sand or loam until the soil and seeds are well mixed. Years ago it was advised that the berries be crushed between folds of blotting paper or absorbent cloth; when dry, the whole material was sown. This method may have been satisfactory for small berries, but it is not suitable for large-fruited sorts, which have so much pulp that the seeds do not separate from it readily. These are best handled by paring off the surface of each berry with a thin, sharp knife, removing a small amount of pulp with the seeds. The parings are placed in a stout cloth, which is held under water and kneaded to work out the pulp. Some breeders prefer to crush and wash the whole berry; the seeds will settle, but the pulp will float and can be drained off.

Formerly it was thought necessary to keep the seeds several months, or until the following spring, before sowing them. The seeds were placed in paper bags or mixed with sand and kept in a cool, dry place. There was much

${ }^{1}$ Jour. Heredity, VII, No. 12 (Dec., 1916), pp. 534-535. 
loss from poor germination; only about five per cent of the dry, imported seed grows. Now, most breeders sow the seed as soon as possible after it is separated from the pulp and do not allow it to dry out. It is not necessary, as some have thought, to pack the clean seeds between cakes of ice in order to "give a touch of winter." After the pulp is separated, mix the seeds thoroughly with a little dry, sifted sand, so as to be able to scatter it thinly and evenly.

The seeds and sand are sown in pots, flats, frames or in the open ground. F. W. Louden kept the seeds from each berry separate and sowed them in an eight-inch pot filled with sharp sand, sunk into a frame shaded with laths. These precautions are not necessary. The seed may be sown in any light, rich soil, in rows about ten inches apart. The soil used in flats or frames is preferably half sand, and it is well to sterilize it. The seed should be covered not over one-eighth of an inch deep with fine, sifted soil. The soil is packed firmly around the seeds by walking on a board placed over it. Cover the surface with coarse burlap so that the seeds will not be washed out by beating rains or with the sprinkler. Watering should be done with a hand sprinkler and a fine rose.

Fruiting the seedlings. - When many seedlings are to be grown, it may be more convenient to sow the seed in low cold frames, covered with lath screens. The screens are made by leaving strips equal to the width of the lath between each two laths, thus providing alternate light and shade. A few seeds may be handled to best advantage in flats, which are small boxes about four inches deep, provided with drainage holes and a layer of cinders or potsherds in the bottom. Place a 
pane of glass over each flat and set it in the shade. The chief advantage of flats is that they can be moved.

If the seed was sown thinly, the seedlings may remain in the bed until August, when the strongest may be transplanted to fruiting rows, where they are set two to three feet apart each way. In hot weather, invert small flower pots over each seedling during the middle of the day for a few days after transplanting, removing them at night and in damp weather. If there are only a few seedlings, they may be potted off in two-inch pots when about two weeks old, carried through the winter in the greenhouse or cold frame, and set in the field the next spring. After that the seedlings are given the same treatment as fallset plants. They will need an abundance of plant food, thorough tillage and the removal of runners. In the North, exceptional care in mulching is necessary.

The following spring the strongest seedlings may bear a little fruit, perhaps enough to indicate something of their value, but this will be at the expense of vigor. In the North, it is best to remove most of the blossoms and to wait until the next season, in which case it is two years from crossing to fruiting. In the South, fairly reliable evidence of the value of seedlings frequently is secured within a year. Seedlings of everbearing varieties have been known to fruit within six months from the cross (page 147).

When the time to judge the seedlings arrives, the grower should fortify himself against disappointment; fully ninety per cent of them are likely to be inferior to either parent. There will be no uniformity in size, color of fruit, season of ripening or any other character. The berries of a large majority of the seedlings will be too soft to be of value. The quality of firmness has been bred 
into the strawberry so recently, as compared with the centuries that this fruit has been in existence, that it is not surprising that a majority of the seedlings revert.

\section{Bud Variation}

Practically all new varieties of the strawberry, if not all, are produced by crossing; there is a commingling of the characters of two parents. Whether new varieties that will persistently retain their distinctive characters are produced by bud variation, without the aid of crossing, long has been in dispute. Permanent varieties of numerous other plants are produced by bud variation. There are many distinct varieties of the pineapple, banana and horse radish, yet these plants never bear seed. A large proportion of the varieties of the carnation, rose, chrysanthemum, violet and other cultivated flowers, originated as bud sports. It cannot be denied that it is impossible for varieties of strawberry to originate by bud variation; all that can be said is that this is not common and that more emphasis has been placed upon it by certain propagators than the facts warrant.

The influence of environment. - The test of a new variety is ability to retain its distinctive character, as compared with other varieties, when grown under diverse conditions of soil and climate. When a variety becomes popular, various "improved" forms of it are offered. These are claimed to be distinct from the original variety and superior to it. Thus, we have had Felton's Improved, Wilson's Albany, Improved Bisel, Improved Bubach, Improved Parker Earle and many others. These are not seedlings, but merely plants of the original variety which, because of some favoring circumstance in culture and 
perhaps, also, because of more care in propagation, have shown decided superiority; they may be more productive, or the fruit larger or firmer than the type of that variety. When these plants or their progeny are taken out of this favorable environment, however, and grown elsewhere side by side with other plants of this variety, little or no difference can be observed between the two. This shows that there has been no mutation, or marked and transmissible variation from type, which is necessary before the propagator is justified in designating it as a new variety. Differences between individual plants of the same variety are due almost entirely to differences in their environment. F. W. Card says: "The environment, though apparently the same, may, in fact, differ greatly even in the same row. Perhaps, in distributing fertilizer, a larger amount may have fallen near one plant. Soil moisture is variable. Perhaps one plant may have suffered from an insect attack or from some mechanical accident which no longer shows. Even under the best conditions of field culture such possibilities always exist." Doubtless, the propagator was sincere in believing that he had produced a new variety by selection, but the fact is he simply had some excellent plants of the old sort, and he should have advertised them as such.

Reported instances of bud variation. - Two supposed bud variations of the strawberry have been noted. The PanAmerican, which is the progenitor of North American everbearing sorts, is said to have originated as a sport. The originator, Samuel Cooper, of Delevan, New York, says : "The Pan-American was found by me in the fall of 1898 growing in a row of Bismarck plants set the previous spring. The Pan-American is evidently a sport, by bud variation, of the Bismarck." This conjecture may be true, but it 


\section{THE STRAWBERRY IN NORTH AMERICA}

is equally possible that the plant was a seedling that had become mixed with the plants of Bismarck. Another supposed bud variation was reported by W. Van Fleet in 1904 as "a sport from the William Belt, originated on the grounds of T. N. White, Little Silver, New Jersey. It showed decided superiority over its parent when propagated and grown in quantity, being larger and more shapely." 1 The circumstances surrounding these supposed instances of bud variation are obscure and the facts not fully authenticated. It is difficult to escape the conviction that if distinct varieties of the strawberry do originate by sporting, this is decidedly uncommon.

"Pedigree" strawberry plants. - In 1845 A. J. Downing advocated a method of propagating or breeding strawberries that has since caused much discussion. He said : ${ }^{2}$ "When the parent plants have become degenerated or partially or wholly barren, we should avoid taking the runners from such and choose only those which grow from the most fruitful ones. In order to make sure of the latter point, it is only necessary to mark the bearing plants by small sticks pushed into the bed by the side of each when the fruit is in perfection." Not much attention was paid to this advice for over fifty years. In 1896 O. W. Blacknall, of North Carolina, asserted: "Only a few exceedingly virile varieties, such as the Wilson, have sufficient vigor to last over a quarter of a century. Many excellent varieties run out in less time. This can be checked by selection. As the berries begin to ripen, go over the fields and select the most vigorous and most fruitful plants. Take them up, remove the berries and blossoms, and set them in a propagating bed." He contended that all

${ }^{1}$ Rural New Yorker, 1904, p. 542.

2 "Fruits and Fruit Trees of America," p. 521. 
varieties could be greatly improved in this way. If this were true, it would remove the method from the field of propagation to that of breeding.

R. N. Kellogg, of Three Rivers, Michigan, became the leading exponent of this method; he called plants propagated in this way "pedigree plants." In 1902 he described his method thus: "I have, for years, grown all my plants from ideal, or perfect, specimens, found here and there in the field, beginning the search for them in the growing season. Those most promising - showing large fruit crowns and healthy foliage - were staked and numbered and the following spring restricted by removing half the blossom buds, to prevent pollen exhaustion. After the fruit is set, only two berries on each fruit stem are allowed to ripen, so that the form, texture, flavor and color of the berries may be determined. Each plant is scaled on the basis of one to ten, and the one showing the greatest number of points of excellence is given the blue ribbon and becomes the mother of the future plants of that variety on the farm."

"Pedigree". strawberry plants have not proved to be permanent departures from the type of the variety. As grown at the South Dakota and Ohio Experiment Stations, the Central Experiment Farm of Canada, and elsewhere, they have proved to be practically identical with the variety of which they were supposed to be an improved form. At the Missouri Experiment Station, continuous bud selection for high yield over a period of fifteen years gave no consistent gain in the productiveness of the plants propagated from heavy-yielding plants over those propagated from low-yielding plants. ${ }^{2}$ It is evident that few,

1 Mem. Hort. Soc. of N. Y., 1902, p. 171.

2 Bul. 131, Mo. Exp. Sta. 


\section{THE STRAWBERRY IN NORTH AMERICA}

if any, permanent varieties may be expected from this source. This is not saying that it is not worth while to select the best mother plants in propagating a variety. That has been proved desirable with other kinds of plants propagated asexually, as well as those propagated by seeds; - why not with the strawberry? If practiced for several generations, this should give a stronger and more desirable stock of plants. It is conceivable that, if the plants are selected rigidly for many years, this might even modify the character of the variety to an appreciable extent; but this result could hardly be expected in a few years, and most of the so-called "pedigree" plants have been selected but a short time.

The term "pedigree" is, of course, wrongly applied here, since it implies an accurate record of many generations. No variety of strawberry has been selected long enough, and sufficiently full records kept, to justify the use of this term. Moreover, since the strawberry is propagated by dividing the old plant, there is really but one generation. The runners, from one generation to another, are merely a part of the original seedling. There can be no pedigree in plants that are propagated asexually. In so far as the term is used by nurserymen simply to designate well-grown nursery stock of the variety, propagated from desirable mother plants, the practice is to be commended, although the term is unfortunate. In so far as it is used to create the impression that the plants are markedly superior to ordinary nursery stock, it is a deception. Most of the "pedigree" plants sold today are simply well-grown plants of the variety, and nothing more. It would be better if they were sold for what they really are - selected, not "pedigree," plants. 


\section{STRAWBerRy BreEders}

The achievements of C. M. Hovey and James Wilson are recorded on pages 22 and 35 . Between 1834 and 1854 a large number of strawberry growers made crosses and raised seedlings, hoping to duplicate the success of Hovey. One of the most fortunate of these early breeders was Zera Burr, of Columbus, Ohio, who introduced nine varieties. His Burr's New Pine, introduced in 1848, was widely grown in home gardens for many years because of its exquisite quality. The Longworth, which originated in 1848 with Mr. Schneike, a tenant of Nicholas Longworth of Cincinnati, Ohio, is still grown commercially in California and is the oldest North American variety in cultivation.

Achievements of Boyden, Downer and Durand. - Soon after the introduction of the Wilson, there appeared a trio of strawberry breeders who contributed largely to the list of improved varieties, - Seth Boyden, of Newark, New Jersey; J. S. Downer, of Fairview, Kentucky, and E. W. Durand, of Irvington, New Jersey. Seth Boyden raised many thousands of seedlings, but not from hand-crosses. His most notable contributions were the Agriculturist, Green Prolific and the Seth Boyden, which were introduced in 1863, 1864 and 1868, respectively. Green Prolific was grown in New Jersey as late as 1897. It was a seedling of the Hovey, and from it have descended a number of varieties that are prominent today (page 189).

J. S. Downer contributed three great commercial varieties, - Downer's Prolific (1858), Charles Downing (1867) and Kentucky (1869). All three, especially the Charles Downing, were widely grown. Downer's Prolific, 
which was said to have been produced from seed of the native Iowa strawberry, and its seedling, Charles Downing, were strong rivals of the Wilson between 1865 and 1890. Kentucky was a standard late sort before the introduction of the Gandy. No man contributed more to North American strawberry culture, as measured by commercial results, than J. S. Downer, with the exception of James Wilson.

List of breeders, 1854-1900. - These three were the outstanding names in strawberry breeding between 1854 and 1900, but many other men contributed valuable varieties during that period. The following list includes some of these, together with the names and dates of the introduction of the varieties by which they will be remembered.

P. M. Augur \& Sons, Middlefield, Connecticut, Jewell (1885).

James Stayman, Leavenworth, Kansas, Clyde (1890).

J. C. Bauer, Judsonia, Arkansas, Bismarck (1895).

Charles Arnold, Paris, Ontario, Maggie (1881), Alpha (1890).

E. W. Cruse, Leavenworth, Kansas, Aroma (1892), Cyclone (1894).

J. F. Beaver, Dayton, Ohio, Margaret (1896), Kitty Rice (1896), Nich Ohmer (1898).

Mark T. Thompson, Lakewood, Ohio (later of Rio Vista, Virginia), Carrie (1894), Mark Hanna (1898).

William Parry, Parry, New Jersey, Parry (1885).

H. H. Alley, Hilton, New Jersey, Mary (1894).

M. H. Ridgeway, Wabash, Indiana, Ridgeway (1897).

J. K. Sharpless, Catawissa, Pennsylvania, Sharpless (1877).

W. S. Gandy, Newport, New Jersey, Gandy (1888).

James Ninon, Denison, Texas, Parker Earle (1889).

R. L. Cloud, Independence, Louisiana, Klondike (1900).

J. R. Reasoner, Urbana, Illinois, Dunlap (1900).

John Little, Granton, Ontario, Woolverton (1891).

Henry Young, Ada, Ohio, Enhance (1887).

B. O. Curtis, Paris, Illinois, Enormous (1895).

George Townsend, Gordon, Ohio, Frances Cleveland (1885).

F. W. Loudon, Janesville, Wisconsin, Jessie (1886). 
B. Hathaway, Little Prairie Ronde, Michigan, Michigan (1858), Bidwell (1877).

M. Crawford, Cuyahoga Falls, Ohio, Mrs. Garfield (1883).

B. H. Haverland, Cincinnati, Ohio, Haverland (1888).

Fred E. Clark, Mt. Tabor, Oregon, Clark (1880).

Breeders since 1900. - The list of strawberry breeders has been greatly enlarged since 1900 . It is possible to mention here only a few of those who have contributed valuable varieties.

C. C. Stone, Moline, Illinois, Buster (1902).

Central Experiment Farm, Canada. Several varieties named for Shakespeare's heroines.

Walter Van Fleet, Little Silver, New Jersey, Late Jersey (1912), Early Jersey (1912).

H. J. Schild, Ionia, Michigan, July (1907), Grand Marie (1910). Samuel Cooper, Delevan, New York, Pan-American (1902), Superb (1911).

Louis Hubach, Judsonia, Arkansas, Early Hathaway (1902), Annie Hubach (1904), Hubach and Hathaway (1906).

J. A. Bauer, Judsonia, Arkansas, St. Louis (1907).

J. H. Black, Son \& Co., Hightstown, New Jersey, Joe (1899), Nettie (1899), Fisher (1904).

E. H. Riehl, North Alton, Illinois, Ruby (1895), Luxury (1901). Harlow Rockhill, Conrad, Iowa, Americus (1910), Francis (1910), Progressive (1912).

New York State Experiment Station, Geneva, New York, Quality (1908), Magnus (1908), Prolific (1908).

Albert F. Etter, Ettersburg, California, Rose Ettersburg (1903). S. H. Warren, Weston, Massachusetts, Latest (1900), Golden Gate (1906).

E. W. Wooster, Hancock Point, Maine, Wooster (1908).

G. W. Howard, Stevensville, Michigan, Satisfaction (1896), Ninety-six (1904), Howard (1904).

A. B. Howard, Belchertown, Massachusetts, Dighton (1908), Howard (1909).

The above lists do not include those who found promising chance seedlings and were shrewd enough to recognize their value and to propagate them. Among these are : 


\section{THE STRAWBERRY IN NORTH AMERICA}

William Parmalee, New Haven, Connecticut, Crescent (1876). Oscar F. Felton, Mechanicsburg, New Jersey, Dollar (1894).

E. T. Ingram, Westchester, Pennsylvania, Brandywine (1895).

J. A. Ingram, E. Bradford, Pennsylvania, Glen Mary (1896).

D. A. Thompson, Mt. Olive, North Carolina, Thompson (1895).

Marshall Ewell, Marshfield Hills, Massachusetts, Marshall (1893).

J. G. Bubach, Princeton, Illinois, Bubach (1890).

George Michel, Judsonia, Arkansas, Michel (1889).

The rewards of strawberry breeding. - It is easy to raise seedlings, but only very few of them are worth keeping. Hardly one seedling in ten thousand proves superior; most of them revert and are distinctly inferior to the parents. Successful strawberry breeding requires an infinite amount of patience, as well as skill. In recent years the laws of heredity have become better known and the results are somewhat more predictable. Some men raise hundreds of thousands of seedlings without producing one that they consider worthy of introduction; others pick up valuable sorts by the roadside. Those noted authorities on strawberry culture, A. S. Fuller and E. P. Roe, did not produce a single variety that stood the test, although they labored faithfully.

The pecuniary reward in strawberry breeding is not large. Fifty years ago a valuable new variety could be sold for a good price. C. M. Hovey realized a large sum from the sale of plants of his seedling, but he enjoyed the advantages of exclusive propagation and exceptional facilities for advertising. Nicholas Longworth paid three hundred dollars for McAvoy's Superior, which was considered a big price at that time. The "Tribune Strawberries," three varieties originated by A. S. Fuller, none of which became prominent, captured a prize of three thousand dollars offered by the New York Tribune Company in 1872. George J. Streator, originator of the 
Cardinal, was paid one thousand dollars for it by the Templin Company in 1905; yet this variety has not gained a foothold. It was reported that Jesse K. Sharpless made about two thousand dollars on his seedling, although he lost control of the stock before its merits were fully known.

Probably the largest price paid for a new variety in recent years was to Louis Hubach, of Judsonia, Arkansas, for the Hubach and Hathaway, more commonly called the "H. and H." It was sold in 1906 for fifteen hundred dollars; this price, however, included 150,000 plants. These are exceptional rewards. Ordinarily, a promising seedling, perhaps the sole survivor of many thousands of seedlings and years of effort, sells for one hundred dollars or less. The chance that it will become a standard sort among the numerous candidates for favor is so remote that nurserymen are not justified in paying more. In 1894 Matthew Crawford purchased from the originator that sterling variety, the William Belt, for one hundred dollars. Occasionally a strawberry breeder tries to collect a royalty from all nurserymen who propagate his variety. This cannot be done; an originator can trade-mark a certain name, but he cannot copyright, trade-mark or patent anything that is not manufactured by man, but is produced by nature, as in the propagation of a variety.

Methods of introducing varieties. - The originator should be careful to whom he sends seedlings for preliminary tests; many breeders have been defrauded by careless or unscrupulous dealers. Beder Wood, of Moline, Illinois, gave a few plants of his famous seedling to George Ashford, of Davenport, Iowa, for trial. This man propagated it and a neighbor of his, John Racster, introduced it as the Racster a year before Beder Wood introduced it himself. 
Plants of Michel were stolen from the originator, J. G. Michel, of Judsonia, Arkansas, and it was introduced the same year by different firms as Michel and Osceola.

Usually, it is best to send a seedling to a number of

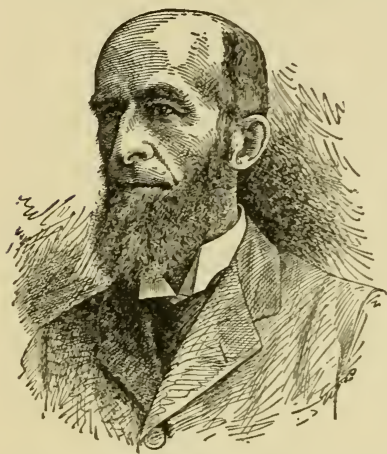

Fig. 26. - Matthew Crawford, for nearly fifty years the foremost North American propagator of the strawberry. strawberry specialists and experiment stations for preliminary trial before it is introduced to the public. If the reports from these tests are encouraging, there are several ways of bringing the new variety to the attention of the public. The most common method, and usually the most satisfactory, is to sell it outright to a nurseryman. Some breeders prefer to let the nurseryman handle it on commission, in which case the originator gets twenty or twenty-five per cent of the gross sales of plants. Occasionally the originator introduces it himself, but this is rarely satisfactory unless he is an experienced propagator.

\section{Naming and Testing New Varieties}

No other fruit has a larger number of inappropriate and freak names. In $1882 \mathrm{~T}$. T. Lyon indignantly branded the name of a recently introduced sort, Big Bob, as "rowdyish and an outrage upon propriety." Nothing daunted, the originator of this euphonious variety proceeded to inflict upon the public a seedling of it, which he named Big Bob's Baby. For many years the Code of 
Nomenclature of the American Pomological Society has exerted a strong influence for simplicity and clearness in naming varieties. In brief, the Code recommends that the name consist of a single word, whenever possible, and never more than two words; it should not include superfluous and grandiose terms such as Seedling, Beauty, Mammoth or Wonder, nor any titles, as General, Senator or Lady ; the use of the possessive, as in Boyden's Mammoth, is not advisable; the name should be distinctive, easy to pronounce and spell and preferably indicate something of the origin or parentage of the variety.

Usually it is best to name a variety for the originator, introducer, place of origin or for some distinctive feature of its appearance or behavior. When named for a certain person, it is permissible to use both family and given names; as Frances Cleveland, but not Mrs. Cleveland. Varieties should not be named for persons without their consent. It is an embarrassing fact that practically all of the varieties named for horticultural celebrities have not achieved distinction; consider, for example, the E. P. Roe, Peter Henderson, T. T. Lyon and Marshall P. Wilder. The Hovey and Charles Downing are notable exceptions.

Some years ago it was suggested that varieties be named so as to indicate their sex, but this has not been done to any extent. It does not seem appropriate, however, for Lady Thompson, Eleanor, Jessie, Margaret, Louise, Belle, Annie Laurie, Brunette, Gertrude and Mrs. Mark Hanna to be male or staminate varieties, while Mark Hanna, Col. Cheney and Big Bob are female or pistillate varieties. Since the pistillate sorts are being gradually eliminated, there is no need to consider this matter further. 
Synonyms. - In 1824 James Barnet, Under Gardener in the garden of the Horticultural Society of London, at Chiswick, grew all the varieties known at that time except the French sorts. There were 226 supposed varieties, but on comparing them he found but fifty-four distinct sorts. If all of the 1879 North American varieties could be brought together for comparison, undoubtedly many synonyms would be detected, but certainly not as large a proportion as Barnet found. Most varieties are so fleeting that it would not be worth while to do this, even if it were possible.

Synonyms arise chiefly from the re-introduction of old varieties under new names. In most cases this is the result of honest error rather than of intent to defraud. It is easy to mix plants in the nursery and exceedingly difficult to recognize them when mixed. In 1867 A. F. Fuller decided, "Twembly's Union is Trollope's Victoria renamed, although it was awarded a premium as a new variety at a strawberry show in New York." Similar conditions exist today. Undoubtedly several of the New York group of varieties, which includes the Morgan, Oswego, Ryckman, Hummer, New York and several others, are really the same sort renamed. In 1898 Henry Jerolamen of Hilton, New Jersey, introduced what he really supposed was a distinct novelty, but which turned out to be the Marshall. There were marked points of difference between the Marshall as grown by the originator and the Henry as grown by Jerolamen, but when both were grown side by side these differences disappeared. This honest re-introduction of a variety, arising from failure to recognize it, is quite common; intentional re-naming, fortunately, is rare.

What is a distinct variety? - Part of the confusion in 
strawberry nomenclature is due to differences of opinion as to what constitutes a distinct variety. Most horticulturists agree that if it can be proved to have had a distinct origin, it is entitled to recognition, even though it is practically identical in appearance and behavior with an older sort. The controversy about the Champion and Windsor is a conspicuous example. Windsor was originated in 1875 by C. A. Gardner, Dimondale, Michigan, and was said by him to be Champion (of Neff) $\times$ Charles Downing. After general trial it was found to be practically indistinguishable from Champion. Many were inclined to accuse Mr. Gardner of intentional deception, but it is more reasonable to suppose that the history of the variety is as he stated it and that Windsor is really a distinct seedling, but practically identical with one of its parents. There have been a number of similar cases. Soon after a variety has become established, various "improved" strains of it are offered. Most of these are merely selected stock, not seedlings, and do not differ materially from the type. They soon pass out of cultivation.

About 1879 there was a movement to establish a "Board of Fruit Patents" which would pass upon the distinctiveness of new varieties. Nothing came of this, nor of similar efforts in later years. It would be impracticable for three or four men to attempt to decide whether a proposed variety is distinct and whether or not it is worthy of being named and introduced. That authority should reside, not in a Board, but in horticulturists everywhere. However, it would be a distinct advantage to have all proposed varieties registered and descriptions filed at one point. This would tend to make the introduction of a variety a matter for more careful consideration than has 
been accorded to it hitherto, and would aid in detecting synonyms. ${ }^{1}$

Value of variety tests. - The public is liable to take snap judgment upon a new variety ; if it is reported unfavorably by some authority, this condemns it in the minds of many growers. "There is not a variety of strawberry in cultivation," said Thomas Meehan, "that has not, at some time or other, been pronounced utterly worthless by some competent authority." In 1860 the Wilson was voted "unfit for cultivation" by the Massachusetts Horticultural Society. For years the American Pomological Society was the recognized authority on the value of varieties. A group of men from different parts of the United States and Canada met every other year and voted upon varieties. Some were "recommended for general cultivation," others put "on trial " and others "rejected." For the most part, these men voiced merely experience with varieties in their own localities, yet their recommendations covered great districts, perhaps including several States. This broadside method of determining the value of varieties was serviceable in the formative years of North American horticulture; now it is superseded by the more local reports from State experiment stations, State horticultural societies and numerous other agencies.

Many have supposed that the judgments of the experiment stations should be considered final and varieties accepted or rejected according to their behavior on the station test plots. The fallacy of this view has been set forth by L. H. Bailey: "What the farmer wants to know is the

${ }^{1}$ All of the over 1800 varieties of North American origin are described in Technical Bulletin 11, Virginia Agricultural Experiment Station, Blacksburg, Virginia: "North American Varieties of the Strawberry," by S. W. Fletcher. 
value of the variety upon his place, not upon the experiment station farm, and he is the only person who can find it out. To thoroughly test a variety is to introduce it. When it is once introduced the general consensus of opinion of men who actually grow it for the purpose for which it is desired forms the best and the only criterion of its value."

After making variety tests of strawberries for a series of years, with a discrimination and minuteness of record almost unknown in America, the Woburn Fruit Experiment Farm, of England, reached this conclusion in 1900: "The experiments have entirely failed in proving accurately the respective merits of different varieties of strawberries. The crops of any particular variety vary enormously from year to year. The comparative merits of different varieties of the same age, when under precisely similar conditions, are almost entirely different in one year from what they are in the next. ... The average difference in the position of the heaviest cropping variety and the lightest cropping variety from one year to another was twelve places out of sixty-four varieties tested. . . . Our results are of little value when applied to the country at large, where the variations in soil are infinitely greater than those on our own farm. Without impugning our ground or manure, there would seem to be ample explanation for the variations noticed in dealing with such a short-lived, low growing and somewhat delicate plant. The crop must depend largely, if not chiefly, on the progress of events during the short period from blossoming to fruitage. We do not hesitate to say that a large proportion of the energy of many horticultural stations is entirely thrown away in making large collections of different varieties with the sole object of recording their behavior at the station in question." 
Why varieties run out. - Varieties that have been in cultivation a long time and, apparently, have become less vigorous and productive than when introduced, are said to have "run out." Strawberries run out more quickly than other fruits because of the shorter interval between generations. Fifty years ago, when most growers were beginning to find the Wilson less responsive than it had been, it was thought that no variety of strawberry could be expected to last longer than twenty-five years, even under the most favorable care. It was argued that it is natural and inevitable for a variety to gradually decline and that the only solution is to have a succession of new sorts coming forward to replace the exhausted old varieties. This theory has been effectually disproved. J. M. Smith, of Green Bay, Wisconsin, grew the Wilson profitably long after it had run out elsewhere. The Longworth still is a profitable commercial variety in California, although seventy-five years old. Several varieties over one hundred years old are grown in England and are, apparently, just as valuable today as when introduced. There is no limit to the life of a variety if it has good care.

The chief cause of running out is neglect. At the time when growers were mourning the decline of the Wilson, they were fruiting their beds for six to twelve years, without annual renewal. Not only was the vigor of the plants seriously impaired, but, also, the beds became full of seedlings. "At this time we have but few beds of pure Wilsons in this State," declared J. L. Budd of Iowa in 1876. "If some known variety be not mixed with it, its own seedlings are annually produced." Some prominent varieties have declined and eventually disappeared because of their susceptibility to disease; the Hunn was ruined by leaf blight. Most varieties are lost because nurserymen 
cease to propagate them, either because there is not enough demand for the plants or because they do not multiply readily.

The foregoing paragraphs indicate that no one need be tempted to undertake the breeding of strawberries by the hope of financial reward. Scarcely a dozen men, out of the many hundreds who have engaged in this fascinating occupation, have received even a fair recompense for their effort. Those who see greater possibilities in the strawberry than appear in the varieties of today will continue to give themselves to the task of perfecting it, mainly as a labor of love. 



\section{INDEX}

Abergust, the secret of, 98 .

Abnormal structural forms, 200.

Acreage, about 1854, 33.

large individual, at Norfolk, 1871, 69.

Alabama, history of culture in, 73.

Alpine, culture as an everbearer, 138.

botany of, 153 .

American Pomological Society, code of nomenclature of, 220.

Analyses of berries, 182 .

Bailey, L. H., quoted on variety tests, 224.

Barnet, James, on the pollination of the Chili, 96.

"Barren" plants, 19, 98.

Beecher, Henry Ward, quoted on the Wilson, 39.

Beginning of garden culture, 6 .

Berries, character of flesh, 171.

desirable color, 169.

desirable shape of, 167 .

desirable type of calyx, 158 .

flavor of, 172.

food value of, 181 .

"Mammoth," 18, 164.

medicinal value of, 184 . quality in, 173.

Blossom, desirable type of, 161 .

Boom days, 1858-1870, 42.

Boston, culture near, 1812, 13. prejudiced against the Wilson, 38 . "wonderful yield" near, 1869, 48.

Botanical relationships of the strawberry, 196.

Botany of the strawberry, 147 .
Box, evolution of, 81 .

first gift, 84 .

return, introduction of, 82 .

Breeders, list of, 215.

Breeding, 188.

changing ideals in, 192.

for a specific purpose, 192.

for one thing at a time, 193.

methods, early, 201.

rewards of, 218.

species and varieties used in, 195.

Broadcast training, era of, 88 .

Bud variation, occurrence of, 210.

reported instances of, 211.

Bunyard, E. A., quoted, on origin of the Pine, 122.

Burbank, Luther, strawberry-raspberry hybrid, 195.

California, history of culture in, $\mathbf{7 4}$.

Calyx, desirable type of, 168 .

Canada, history of culture in, 75 .

Chili strawberry, commercial culture in U.S. about 1771, 6. culture of, in France, 115.

introduction into Europe, 114.

Cincinnati, culture near, about 1845 , 27.

culture near, 1855,31 .

field culture near, 1865, 44 .

Horticultural Society, Report of, on pollination, 104.

stand of drawers, 78 .

Cist, Charles, quoted, 27.

Color of berries, describing, 170 . desirable, 169.

Commercial culture, beginning of, near Baltimore, 17. 
Commercial culture - continued. condition of, in 1854, 33. extension of, 1838-1854, 27. near Boston, 13. near New York City, 15.

Competition from the South, 52.

Cooper, Samuel, origin of the PanAmerican, 144.

Crate, evolution of, 81 . first gift, 84 . return, introduction of, 82 .

Crawford, Matthew, referred to, 220.

Crossing, hand, 203.

Cultural methods, special, 1820$1870,49$.

Culture, commercial, beginning of, 12.

about $1800,10$.

early, in Europe, 109.

market garden, near Pittsburgh, $1867,45$.

methods of, about 1790,7 .

near Cincinnati, 1865, 44.

of strawberries in Mexico, 140.

Dean, Samuel, "New England Farmer," quoted, 7.

Delaware-Maryland peninsula, history of culture on, 63 .

Describing varieties, 175 .

Diet, value of strawberries in, 185 .

Disease resistance of varieties, 158.

Downing, A. J., quoted on pollination, 102.

Drawers, Cincinnati stand of, 78 .

Duchesne, pollination experiments of, 94 .

Dwight, Timothy, "Travels in New England," quoted, 13.

Earle, Parker, experiments with the refrigerator car, 55 .

our obligation to, 60 .

England, early culture in, 110.

Etter, A. F., quoted on methods of crossing, 206.
Everbearers, early failures with, 142.

European varieties of, 141 .

origin of, American type, 138.

Exhibitions, strawberry, origin of, 43.

Express, fruit-growers', introduction of, 54 .

Fall-bearers, 147.

Festival, strawberry, origin of, 42 .

"Fever, Strawberry," 1858-1870, 42.

Flavor of berries, 172 .

Flesh of berry, desirable character in, $171,172$.

Florida, history of culture in, 70 .

Foliage, good characters in, 159.

Food value, 181.

Forcing in hot-beds and coldframes, 49.

Fragaria americana, botanical description of, 153.

ananassa, origin of, 116.

chiloensis, as parent of the Pine, $117,122$.

botanical description of, 150 .

commercial culture of, in France, 115.

early importations pistillate, 96 . hardiness of, 135.

introduction into England, 115. introduction into Europe, 114. variation under cultivation, 136. variations in, 152 .

chinensis, as a possible parent of the Pine, 122.

elatior, botanical description of, 154.

grandiflora, origin of, 116 .

mexicana, occurrence of, in Mexico, 140.

vesca, as a possible parent of the Pine, 121.

botanical description of, 153 . early culture in Europe, 113. virginiana, a probable parent of Downer's Prolific and Charles Downing, 131. 
Fragaria virginiana - continued. botanical description of, 149 . free-running habit of, 135 .

hardiness of, 136.

in the evolution of the garden strawberry of North America, 125.

introduction into Europe, 113.

Freak strawberries, 201.

Frezier, Captain, introduction of the Chili, 115.

Fruit, desirable characters in, 162. buds, when formed, 198. stalks, desirable type of, 161.

Fuller, A. S., quoted, on training, 88.

Gardiner, John, "The American Gardener," quoted, 10.

Georgeson, C. C., quoted on breeding, 194.

Gift packages, introduction, 84 .

Goff, E. S., quoted on fruit bud formation, 198.

Goldsborough, A. T., "mammoth" berries of, 166 .

Gulf States, history of culture in, 73.

Hallocks, origin of, 82 .

Hansen, N. E., quoted on breeding, 194.

Hardiness, as evidence of botanical origin, 135.

breeding for, 194.

comparative, of varieties, 158 .

of $F$. chiloensis, 135.

of $F$. virginiana, 136.

Hautbois, botanical description of, 154.

culture in United States about $1771,6$.

pollination of, 95 .

Hedge-row, evolution of, 91.

Hill training previous to 1840,87 .

History, early, in Europe, 109.

in North America, 1.

of important districts, 60 .

Hot-beds and cold-frames, forcing in, 49 .
Hovey, C. M., originator of the Hovey, 21.

quoted, on pollination, 100, 101 .

quoted, on Wilson strawberry, 38.

strawberry, sex of, 100.

Hubach, Louis, quoted on method of crossing, 206.

Hybrid of strawberry and raspberry, 195.

Hyde, James F. C., quoted, 13.

Illinois, history of culture in, 64 .

Jamestown, Virginia, strawberries at, 2 .

Keens, Michael, on pollination of the Hautbois, 95.

originator of Keens' Seedling, 123.

Kellogg, R. M., quoted on "pedigree" plants, 213.

"King," strawberry, 27, 30.

Knight, Thomas Andrew, on strawberry breeding, 124 .

Knox, John, gift box of, 84 .

methods of culture, 1867, 46 .

yields and prices, 47 .

Longworth, Nicholas, quoted on pollination, 98, 100 .

"Longworth's Theory," final vindication of, 107.

Louisiana, history of culture in, 73 .

McMahon, Bernard, "American Gardeners' Calendar," quoted, 11.

quoted on pollination, 97.

Male plants, 100, 105, 106.

"Mammoth" berries, 18, 164.

Market, cars arriving late on, 55 .

Maryland, acreage in, 1850, 29.

field culture in, 1850, 44.

Massachusetts Horticultural Society, influence of, 22.

Matted row, evolution of, 90.

Medicinal value, 184. 
Meehan, Thomas, quoted on pollination, 103.

Mexico, culture in, 140.

Michigan, history of culture in, 64 . Mississippi, history of culture in, 73.

Missouri, history of culture in, 74.

Morphology of the strawberry, 196.

Naming varieties, 220.

Neck, long, as evidence of botanical origin, 134.

New England, wild strawberries of, 2.

New Jersey, culture in, about 1820 , 15.

history of culture in, 62 .

yields and prices in, 1865-1870, 49.

New York City, culture near, about $1820,15$.

strawberries marketed in, 1847, 28.

stra wberry market, 1861, 61.

New, York, Oswego County, history of culture in, 63 .

Norfolk, first berries shipped from, 52.

North Carolina, history of culture in, 72 .

Novelty, the first, 23.

Ohio Pomological Society, Report of, 1865,44 .

Oregon, history of culture in, 75 .

Origin of everbearers, 138.

the four-stem varieties, 128.

the garden strawberry, botanical evidence, 132 .

the garden strawberry, historical evidence, 128.

the garden strawberry of Europe, 113.

the garden strawberry of North America, 125.

the English name, 111.

the Pine, 116.
Packages, early, 76.

evolution of box and crate, 81 . gift, slow adoption in East, 84. return, disadvantages of, 85 . the first gift, 84 .

"Paradisus Terrestris," quoted, $111,114$.

Parker Earle, quoted, on refrigerator cars, 33.

Parkinson, John, quoted on medicinal value, 184

"Pedigree" plants, origin of, 212. experiments with, 213.

Pennsylvania, wild strawberries of, 4.

Pine, first record of culture in North America, 10. origin of, 116.

Pistillate variety, definition of, 104 .

Plant breeding, stimulated by introduction of the Hovey, 26.

Plant, desirable characters in the, 157.

Plant-making habits of varieties, 160.

Pollen, collecting for crossing, 204. vitality of, 204.

Pollination discussion, 100.

early troubles with, in America, 96.

in crossing, 205.

of the Chili, 96.

of the Hautbois, 95.

question, early history of, 94 .

secret of Abergust, 99.

stimulating effect of, 32 .

troubles, 1823, 19.

Pottle, use near Boston, 1820, 76.

Prices, about 1835, 18.

about 1840,30 .

at Cincinnati, 1847, 28.

at Norfolk, 1871, 68 .

high, 1858-1870, 42,48 .

in New Jersey, 1865-1870, 49.

of John Knox, Pittsburgh, 1860, 47.

Prince, William, nursery of, 6 .

Productiveness, standards of, 158.

Profits, large, in Florida, 1886, 71. 
Punnet, use near New York City, 1815-1850, 77.

Purdy, A. M., quoted, 79.

Quality in berries, 173. shipping, 171.

Railroads, extension of, after 1854, 51.

Refrigerator cars, early experiments with, 55 . successful results with, 59 .

Renewing the bed, early methods of, 92 .

Return packages, disadvantages of, 85.

introduction, 82.

Reversion of seedlings to primitive types, 123.

Richardson, C. W., quoted on origin of the Pine, 121.

Rockhill, Harlow, originator of everbearing varieties, 146 .

Runners, abundance of, as evidence of botanical origin, 134 .

number desirable in a variety, 160.

Scarlet, introduction into Europe, 113.

Score card for varieties, 178.

Season of ripening, 162.

Seed, sowing, 207.

Seedlings, fruiting the, 208.

reversion to primitive types, 123.

Seeds, as affecting value of berry, 171.

position of, as evidence of botanical origin, 134.

Sex in the strawberry, 96.

influence of culture on, 102.

naming varieties to indicate, 221.

Shape of berries, desirable, 167 .

Shipping quality, 171.

Size of berries, abnormal, 164 . about $1833,18$.

most desirable, 163.

Slaymaker, A. W., quoted, 55, 62.
Smith, B. F., quoted, 65.

Solms-Laubach, Count of, quoted, on the origin of the Pine, 122.

South Carolina, history of culture in, 69.

South, increasing competition from, after 1860,52 .

Staminate variety, definition of, 104.

Stand of drawers, 78.

"Strawberry King," 27, 30.

Strawberry mound, in 1859, 50.

Strawberry, origin of the name, 111.

"Strawberry War," 99.

Sturtevant, E. Lewis, quoted, on origin of the garden form, 133.

Synonyms, origin of, 222 .

Taylor, W. A., quoted, on refrigerator cars, 58.

Tennessee, history of culture in, 74 .

Thivolet, Abbé, originator of everbearers, 141 .

Thomas, F. A., development of refrigerator car system, 58.

Thorburn, Grant, "Gentleman's and Gardener's Kalender," quoted, 12.

Training, broadcast, era of, 88 .

early methods of, 87 .

evolution of hedge-row, 91 .

of matted row, 90.

Transportation, by boat, Norfolk to New York, 1850, 67.

facilities, improvement in, after $1854,50$.

Tubs, used for marketing strawberries, 78 .

Varieties, Bidwell, origin of, 132.

Charles Downing, 40.

descendants of, 132.

origin of, 131.

Crescent, competitor of the Wilson, 40.

descendants of, 131, 191.

origin of, 131.

pollination of, 96 . 
Varieties - continued.

Crimson Cone, culture of, 16 . describing, 175.

Downer's Prolific, origin of, 131.

Early Hudson, introduction of, 7.

European, sweeter than American, 183.

everbearing, early failures with, 144.

fall bearing, 147 .

Fressant, first cultivated variety, 113.

grown, 1800-1838, 19.

1838-1854, 31.

Hovey, descendants of, 129, 189. introduction of, 23.

"mammoth" berries of, 165 .

origin of, 21.

parentage of, 128 .

unsatisfactory results with, 25 .

Jucunda, as grown at Pittsburgh, $1860,47$.

Keens' Seedling, origin and description of, 123.

Large Early Scarlet, 5 . commercial culture of, $1800-$ $1875,126$.

methods of introducing, 219.

naming and testing new, 220.

of known parentage, 189.

of $F$. virginiana grown commercially, 126.

Old Pine, origin of, 116.

description of, 119.

Pan-American, origin of, 144 .

prices paid for new, 218.

Red Wood, culture near Boston, about 1820, 14.

running out of, 226.

score card for, 178.

Sharpless, competitor of the Wilson, 41 .
Varieties - continued.

Sharpless - continued. descendants of, 130 . parentage of, 130 .

the four-stem, 189.

Wilson, competitors of, 40 . descendants of, 130, 190 . good points of, 39 . long popularity of, 36 . objections to, 38 . origin of, 35 . parentage of, 130.

Variety, desirable characters in a, 157.

tests, value of, 224 .

what is a distinct, 222 .

Ventilator cars, introduction of, 54 .

Vilmorin, P. de, quoted, on origin of the Pine, 118.

Virginia, history of culture in, 67 . wild strawberries in, 2.

Virginian strawberry, commercial culture of, 125 .

Warder, J. A., quoted, on pollination, 99.

White-fruited form of $F$. vesca, 153. varieties, 170 .

Wild strawberries, not sweeter than cultivated, 183.

distribution of, 147.

of New England, 2.

of Virginia, 2.

Wilson, James, originator of the Wilson, 35.

Woburn Fruit Experiment Farm, quoted, on variety tests, 225 .

Yields, about 1823, 17.

$1840,30$.

heavy, about 1867,48 .

in New Jersey, 1865-1870, 49.

John Knox, Pittsburgh, 1860, 47. 


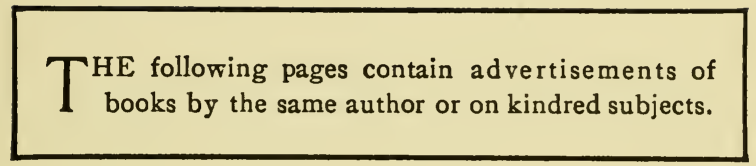





\section{THE RURAL SCIENCE SERIES}

\section{Strawberry Growing}

Edited by L. H. BAILEX

By S. W. FLETCHER

Professor of Horticulture at the Pennsylvania State College

24 full-page plates and 22 figures in the text, $\$ 1.75$

The strawberry occupies a position among North American fruits second only to the apple in commercial importance. Professor Fletcher here gives a clear outline of present commercial practice, taking up all the important points in considerable detail - location of beds, most desirable soils, planting, rotation of crops, treatment with fertilizers, tillage and irrigation, the training of the plant, mulching, pollination, picking, packing, marketing, varieties of berries, insects, diseases, and statistics on acreage, production, and value.

CBAPTER

\section{TABLE OF CONTENTS}

I. Locations, sites, and soils.

II. Planting.

III. Rotations, manuring, and fertilizing.

IV. Tillage and irrigation.

V. Training the plant.

VI. Mulching.

VII. Pollination.

VIII. Packages.

IX. Picking and packing.

$\mathrm{X}$. Marketing.

XI. Cost of production, yields, profits.

XII. Propagation and renewal.

XIII. Everbearing varieties, forcing and other special methods of culture.

XIV. Insects, diseases, and frost.

$\mathrm{XV}$. Varieties.

ApPendix. Statistics on Acreage, Production, and Value.

THE MACMILLAN COMPANY

Publishers 64-66 Fifth Avenue Now York 


\section{The Potato}

By ARTHUR W. GILBERT, Ph.D.

Professor of Plant Breeding, Cornell University, assisted by

MORTIMER F. BARRUS, Ph.D.

Professor of Plant Pathology, Cornell University, and

DANIEL DEAN

Formerly President of the New York State Potato Association

With illustrations, $\$ 1.50$

The authors of this book are especially fitted to write upon the potato. Professor Gilbert, as professor of plant breeding at Cornell, has made a careful study of potato breeding and varieties for several years. Formerly teacher of farm crops and director of agricultural extension work at the University of Maine, he has become thoroughly familiar with potato growing in the East, particularly in the famous Aroostook County region. Dr. Barrus is considered one of the best authorities on potato diseases in the country. The chapters he has contributed to the work deal with disease and its control. Mr. Dean wrote the chapters on field practice. $\mathrm{He}$ is a successful commercial grower, and has given much attention to the different systems of potato growing throughout the United States.

\section{THE MACMILLAN COMPANY}

Pablishers

64-66 Fifth $\Delta$ venue

New York 


\title{
The Standard Cyclopedia of Horticulture
}

\author{
Edited By L. H. BAILEY
}

WITH THE ASSISTANCE OF OVER 500 COLLABORATORS

New edition, entirely rewritten and enlarged, with many new features; with 24 plates in color, 96 full-page half tones, and over 4,000 text illustrations. Complete in six volumes. Sold only in sets.

"The Standard Cyclopedia of Horticulture," pronounced by experts to be an absolute necessity for every horticulturist and of tremendous value to every type of gardener, professional and amateur, is completed. "An indispensable work of reference to every one interested in the land and its products, whether commercially or professionally, as a student or an amateur," is the Boston Transcript's characterization of it, while Horticulture adds that "it is very live literature for any one engaged in any department of the horticultural field."

"This really monumental performance will take rank as a standard in its class. Illustrations and text are admirable. . . . Our own conviction is that while the future may bring forth amplified editions of the work, it will probably never be superseded. Recognizing its importance, the publishers have given it faultless form. The typography leaves nothing to be desired, the paper is calculated to stand wear and tear, and the work is at once handsomely and attractively bound." - New York Daily Tribune.

\section{THE MACMILLAN COMPANY \\ Publishers \\ 64-66 Fifth Avenue \\ New York}




\section{A Manual of Fruit Diseases}

\section{BY $\{$ LEX! $\mid R$. HESLER}

Assistant Professor of Plant Pathology in the New York State College of Agriculture at Cornell University, and

\section{HERBERT H. WHETZEL}

Professor of Plant Pathology in the New York State College of Agriculture at Cornell University

With illustrations; cloth, I2mo, $\$ 2.00$

This manual contains a presentation of the known facts and data with respect to the common diseases of fruits. It has been prepared primarily for the modern agriculturist, the farmer, the thinking fruit grower, but it should also be of service to anyone who has an interest in plant diseases. The fruits are taken up in alphabetical order. The discussion of the diseases proceeds in order of their importance and prominence in the United States. Particular attention is paid to the description and illustration of the symptoms, to the cause and to the generally accepted measures of control. Technical details are omitted as far as possible though the effort has been made to present the matter in as popular a fashion as possible.

\section{THE MACMILLAN COMPANY \\ Publishers \\ 64-66 Fifth Avenue \\ New York}





\section{QL 145 . F7 F545 \\ Fletcher Stevenson/The strawberry in No || || || || || || || || || | || || || || || || | || 3 5185000718898}


